DÉBORA VIEIRA PARRINE SANT'ANA

\title{
ANÁLISE DE FLUXOS METABÓlICOS APLICADA À BIOSSÍNTESE DO POLÍMERO BIODEGRADÁVEL POLI-3-HIDROXI-BUTIRATO \\ P(3HB) POR Burkholderia sacchari
}

Dissertação apresentada ao Programa de PósGraduação Interunidades em Biotecnologia USP/Instituto Butantan/IPT, para obtenção do Título de Mestre em Ciências. 


\title{
DÉBORA VIEIRA PARRINE SANT’ANA
}

\author{
Análise de fluxos metabólicos aplicada à biossíntese \\ do polímero biodegradável poli-3-hidroxi-butirato
}

P(3 HB) por Burkholderia sacchari

Dissertação apresentada ao Programa de PósGraduação Interunidades em Biotecnologia USP/Instituto Butantan/IPT, para obtenção do Título de Mestre em Ciências.

Área de Concentração: Biotecnologia

Orientadora: Profa. Dra. Luiziana Ferreira da Silva

Versão corrigida A versão original encontra-se disponível tanto na Biblioteca do ICB quanto na Biblioteca Digital de Teses e Dissertações da USP (BDTD) 
DADOS DE CATALOGAÇÃO NA PUBLICAÇÃO (CIP)

Serviço de Biblioteca e Informaçăo Biomédica do

Instituto de Ciências Biomédicas da Universidade de São Paulo

(c) reproduçăo total

Sant'Ana, Débora Vieira Parrine.

Análise de fluxos metabólicos aplicada à biossíntese do polímero biodegradável poli-3-hidroxibutirato $\mathrm{P}(3 \mathrm{HB})$ por Burkholderia sacchari I Débora Vieira Parrine Sant'Ana. -- São Paulo, 2013.

Orientador: Profa. Dra. Luiziana Ferreira da Silva.

Dissertaçăo (Mestrado) - Universidade de São Paulo. Instituto de Ciéncias Biomédicas. Programa de Pós-Graduaçăo Interunidades em Biotecnologia USP/IPT/Instituto Butantan. Área de concentração: Biotecnologia. Linha de pesquisa: Plásticos biodegradáveis (PHA).

Versão do título para o inglês: Metabolic flux analysis applied to the biosynthesis of the biodegradable polymer poly-3-hydroxybutyrate (P3HB) produced by Burkholderia sacchari.

1. Análise de fluxos metabólicos 2. Polihidroxibutirato 3. Rastreamento de carbonos 4. Burkholderia sacchari 5. Plástico biodegradável I. Silva, Profa. Dra. Luiziana Ferreira da II. Universidade de São Paulo. Instituto de Ciências Biomédicas. Programa de Pós-Graduação Interunidades em Biotecnologia USP/IPT/Instituto Butantan III. Título. 
UNIVERSIDADE DE SÃO PAULO

Programa de Pós-Graduação Interunidades em Biotecnologia

Universidade de São Paulo, Instituto Butantan, Instituto de Pesquisas Tecnológicas

Candidato(a): Débora Vieira Parrine Sant'Ana.

Título da Análise de fluxos metabólicos aplicada à biossíntese do polímero biodegradável poli-3-hidroxibutirato $\mathrm{P}(3 \mathrm{HB})$ por Burkholderia sacchari.

Orientador(a): $\quad$ Profa. Dra. Luiziana Ferreira da Silva.

A Comissão Julgadora dos trabalhos de Defesa da Dissertação de Mestrado,
em sessão pública realizada a ................................................, considerou
$\begin{array}{ll}\text { ( ) Aprovado(a) } & (\text { ) Reprovado(a) }\end{array}$

Examinador(a): Assinatura:

Nome:

Instituição:

Examinador(a): Assinatura:

Nome:

Instituição:

Presidente: Assinatura:

Nome:

Instituição: 


\section{CERTIFICADO DE ISENÇÃO}

Certificamos que o Protocolo CEP-ICB No 618/13 referente ao projeto intitulado: "Análise de fluxos metabólicos aplicada à biossintese do polímero biodegradável poli-3-hidroxi-butirato P(3HB) por B.sacchari” sob a responsabilidade de Débora Vieira Parrine Sant'Ana, foi analisado na presente data pela CEUA - COMISSÃO DE ÉTICA NO USO DE ANIMAIS e pela CEPSH- COMISSÃO DE ÉtICA EM PESQUiSA COM SERES humanOS, tendo sido deliberado que o referido projeto não utilizará animais que estejam sob a égide da lei 11.794 de 8 de outubro de 2008, nem envolverá procedimentos regulados pela Resolução CONEP nº196 de 1996.

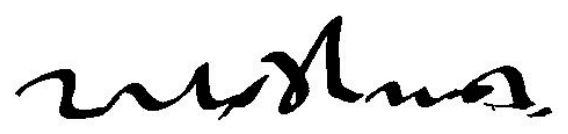

PROF. DR. WOTHAN TAVARES DE LIMA Coordenador da CEUA - ICB/USP
São Paulo, 24 de setembro de 2013.

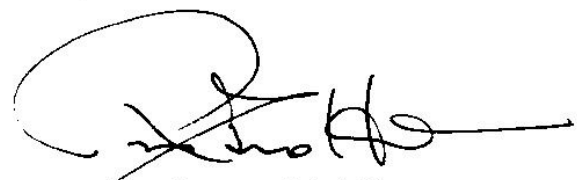

PRoF. DR. PAOLO M.A Z.ANOTTO

Coordenador da CEPsh - ICB/USP 
Às mulheres que dedicaram suas vidas à ciência, à minha família. 


\section{AGRADECIMENTOS}

À minha orientadora, professora Luiziana Ferreira da Silva pela orientação, motivação, atenção e apoio durante as minhas decisões tomadas durante este período.

Ao professor Gregório pela disponibilidade para discussões e revisões que foram de inestimável importância para este trabalho.

Ao professor Patrick Hallenbeck por possibilitar o estágio realizado em seu laboratório e pela confiança em meu desempenho acadêmico.

À minha família e amigos pela compreensão em momentos de ausência. Aos meus pais que traçaram seus caminhos permitindo que eu pudesse realizar esta etapa, à minha mãe pela coragem, ao meu pai pela tranquilidade, ao meu padrasto pelo carinho. À minha irmã pelo exemplo de dedicação. Ao Fabio Andres Castillo por seu apoio, companheirismo, amizade e carinho que me transformam em uma pessoa melhor.

Aos colegas de laboratório em especial a Thatiane, Carlos, Kelli, Johana, Liege e César pela ajuda na realização de experimentos e análises e também pela amizade. Ao Aelson pelas análises de cromatografia. À Marilda Taciro pela orientação nas análises de experimentos e valiosos conselhos profissionais. Aos técnicos e funcionários do Instituto de Ciências Biomédicas II.

Aos meus amigos que estiveram comigo em todos os lugares que estive: Rafael Facundo, Maurício Lucchesi e Lucas Lucchesi. A Pierre-Ludovic qui m’a motivé à faire le master à São Paulo.

À Fapesp pelo financiamento do meu projeto de mestrado e estágio internacional. 
How many years can a mountain exist Before it's washed to the sea?

How many years can some people exist Before they're allowed to be free? How many times can a man turn his head Pretending he just doesn't see? The answer my friend is blowin' in the wind 


\section{RESUMO}

SANT'ANA, D. V. P. Análise de fluxos metabólicos aplicada à biossíntese do polímero biodegradável poli-3-hidroxi-butirato $\mathrm{P}(3 \mathrm{HB})$ por Burkholderia sacchari. 2013. 112 f. Dissertação (Mestrado em Biotecnologia) - Instituto de Ciências Biomédicas, Universidade de São Paulo, São Paulo, 2013.

No contexto da problemática mundial do excesso de consumo de plásticos sintéticos nasce como alternativa os polihidroxialcanoatos, polímeros completamente biodegradáveis acumulados dentro da célula, produzidos por diversos micro-organismos. Apesar de sua produção já ocorrer em nível industrial, a comercialização deste produto não ocorre em grande escala devido ao seu alto custo, majoritariamente provindo do valor do substrato do qual ele é originado. O presente trabalho tem como objetivos a determinação de fluxos metabólicos de Burkholderia sacchari envolvidos na produção de $\mathrm{P}(3 \mathrm{HB})$ e propostas de aumento da sua eficiência na produção deste composto. Utilizou-se a Análise de Fluxos Metabólicos (AFM) como ferramenta para determinar os fluxos metabólicos da eficiência máxima da linhagem Burkholderia sacchari na produção de PHA a partir de açúcares. Foram reavaliadas as eficiências de conversão de carboidratos em PHA de B. sacchari e Cupriavidus necator, que resultaram em 80 e aproximadamente $100 \%$ dos seus máximos teóricos, respectivamente. B. sacchari também foi cultivada em experimentos em batelada alimentada, apresentando o máximo teórico em fase de crescimento e acúmulo simultâneos sob oferta de glicose. Estes dados, submetidos ao software Metatool, resultaram em mapa metabólico contendo os fluxos das reações centrais e de síntese de PHA ocorridos no experimento. Ainda, através do cultivo de $B$. sacchari e Cupriavidus necator em agitador rotativo sob oferta de glicose marcada com ${ }^{13} \mathrm{C}$, determinou-se que as duas espécies utilizam as mesmas vias metabólicas para produção do polímero biodegradável, o que indica que a menor eficiência da primeira linhagem comparativamente à segunda é devido apenas a uma diferença de fluxos nestas vias. Concluiu-se que cultivos que mantenham crescimento e acúmulo simultâneos podem favorecer e manter a eficiência máxima teórica de produção de PHB na linhagem estudada e que $C$. necator utiliza as mesmas vias metabólicas que $B$. sacchari na produção deste polímero. Ademais do tema de redução do custo de produção do plástico biodegradável, estudou-se a eficiência da produção do biopolímero, a partir de resíduos (melaço de cana e glicerol cru) e acetato, em linhagens produtoras de hidrogênio e PHA, onde verificou-se não apenas o aumento da produção de PHA em mutantes nifh de $R$. capsulatus mas a interação dos parâmetros luz e concentração de nitrogênio a partir das metodologias Design of Experiment e Response Surface Methodology.

Palavras-chave: Análise de fluxos metabólicos. Polihidroxibutirato. Sacarose.

Rastreamento de carbonos. Burkholderia sacchari. Plástico biodegradável. Fluxometria 


\begin{abstract}
SANT'ANA, D. V. P. Metabolic flux analysis applied to the biosynthesis of the biodegradable polymer poly-3-hydroxybutyrate $\mathrm{P}(3 \mathrm{HB})$ produced by Burkholderia sacchari. 2013. 112 p. Masters thesis (Biotechnology) - Instituto de Ciências Biomédicas, Universidade de São Paulo, São Paulo, 2013.
\end{abstract}

In the context of the worldwide problem of excessive consumption of synthetic plastics, full biodegradable polymers as polyhydroxyalkanoates are studied as an environmentally friendly alternative. PHA are biopolymers accumulated inside the cell, produced by various microorganisms. Although its production already occurs at the industrial level, the marketing of this product does not occur on a large scale due to its high cost, mostly coming from the value of the needed substrate. This study aims to determine metabolic fluxes of Burkholderia sacchari involved in the production of $\mathrm{P}(3 \mathrm{HB})$ and to proposals for increasing efficiency in the production of this compound .This work applied Metabolic Flux Analysis (MFA) as a tool to determine the metabolic fluxes of Burkholderia sacchari in PHA production from sugars. Conversion yields of B. sacchari and Cupriavidus necator from carbohydrates to PHA were reassessed, resulting in, respectively, around 80 and $100 \%$ of the theoretical maximum eficiency. The model strain was also grown in reactor fed-batch cultivations, and presented the theoretical maximum when growth and accumulation occurred simultaneously while cultivated on glucose. These data were submitted to the Metatool software and resulted in a metabolic network containing the experimental fluxes of central and PHA biosynthesis reactions when maximum conversion efficiency was obtained. Still, the cultivation of $B$. sacchari and $C$. necator on a shaker under 13C-labeled glucose, showed that both species use the same metabolic pathways for the biodegradable polymer, which indicates that the low efficiency of the first strain compared to the second is due to a difference of these pathways fluxes. Finally, it was found in this work that maximum efficiency of PHB production on $B$. sacchari can be obtained while growth and accumulation occur, still, this strain and C. necator uses the same metabolic pathways to produce PHB .Furthermore still on the theme of reducing the cost of biodegradable plastic production, the efficiency of biopolymer production from waste (molasses and raw glycerol) and acetate in strains producing hydrogen and PHA was tested. Results showed that there was not only an increase in PHA production by $R$. capsulatus nifH mutants but also the interaction of light and nitrogen effects were studied by Design of Experiments and Response Surface Methodology.

Keywords: Metabolic Flux Analysis. Polyhydroxybutyrate. Sucrose. Tracer experiments. Burkholderia sacchari. Plástico biodegradável. Fluxometry. 


\section{LISTA DE ILUSTRAÇÕES}

Figura 1 - Estrutura geral dos monômeros de poli-hidroxialcanoatos. Onde "n" é igual a 1, 2, 3 ou 4 para 3, 4, 5 ou 6-hidroxialcanoatos, respectivamente.

Figura 2 - Micrografia de transmissão de elétrons de seção ultra-fina da cepa A-04 de $C$. necator (a) bastonetes típicos medindo de 0,6 a 1,0 $\mu \mathrm{m}$. Barra, $1 \mu \mathrm{m}$. (b) cepa A-04 de $C$. necator contendo grânulos de PHB (círculos brancos). Barra $200 \mathrm{~nm}$. (Fonte: CHANPRATEEP, 2008).

Figura 3 - Vias metabólicas principais responsáveis pela produção de $\mathrm{P}(3 \mathrm{HB})$ a partir de sacarose. As enzimas codificadas pelos genes $p h a A$, phaB e phaC são, respectivamente: 3cetiolase, acetoacetil-CoA redutase (NADPH dependente) e PHA sintase

Figura 4 - Esquema apresentando a metodologia de cultivo de B. sacchari e $C$. necator sob condições com limitação única de nitrogênio utilizando glicose $(\mathrm{G})$, ou frutose $(\mathrm{F})$, ou sacarose $(\mathrm{S})$, ou mistura de glicose e frutose $(\mathrm{G}+\mathrm{F})$..

Figura 5 - Esquema representando metodologia empregada no cultivo de $B$. sacchari e $C$. necator em condições de limitação de nitrogênio ou fósforo distintas utilizando glicose $(\mathrm{G})$, ou frutose (F). MMN1, MMN2, MMN3, contém, respectivamente, as seguintes concentrações de nitrogênio, 0,5 g/1, 1,0 g/1, 1,5 g/l. MMP1, MMP2, MMP3 contém, respectivamente: 0,06 $\mathrm{g} / 1,0,12 \mathrm{~g} / 1,0,18 \mathrm{~g} / 1$ de fósforo.

Figura 6 - Variação da produção de PHB por B. sacchari em porcentagem de MSC durante 24, 48 e 72 horas de cultivo. Médias de triplicatas com desvio padrão representado.

Figura 7 - Variação da produção de PHB por C. necator em porcentagem de MSC durante 24, 48 e 72 horas de cultivo. Médias de triplicatas com desvio padrão representado.

Figura 8 - Variação de consumo de sacarose, formação de biomassa e produção de PHB durante $32 \mathrm{~h}$ do cultivo em biorreator.

Figura 9 - Gráfico relacionando velocidades de formação de $\mathrm{O}_{2}(\mathrm{OUR}$ - oxygen uptake rate) e consumo de $\mathrm{CO}_{2}$ (CER - carbono evolution rate) de cultivo a partir de sacarose

Figura 10 - Curvas de concentração de hexoses consumidas, PHB e XR (g/l) características do estado pseudo-estacionário analisado.

Figura 11 - Variação de consumo de glicose, formação de biomassa e produção de PHB durante o cultivo em biorreator.

Figura 12 - Gráfico relacionando velocidades de formação de $\mathrm{O}_{2}(\mathrm{OUR}$ - oxygen uptake rate) e consumo de $\mathrm{CO}_{2}$ (CER - carbon evolution rate) de cultivo a partir de glicose. 
Figura 13 - Curvas de concentração de glicose, PHB e XR para cálculo de balanço de carbonos. Curva de LnXr utilizada para cálculo de velocidade específica de crescimento.

Figura 14 - Quadro contendo valores dos fluxos metabólicos gerados pelo programa Metatool, relativos ao fluxo de entrada da sacarose ou glicose (reações SAC e EMP1, respectivamente). Destacados em cinza: valores correspondentes ao modo elementar representando o acúmulo de $80 \%$ de PHB em relação à biomassa, condição em que ocorreu o máximo teórico. Em fundo branco, modo elementar contendo fluxos da condição de $68 \%$ de acúmulo de PHB.

Figura 15 - Diagrama do mapa metabólico de $B$. sacchari contendo valores relativos aos fluxos de vias metabólicas obtidos através do software Metatool na condição de acúmulo de $80 \%$ de PHB em que obteve-se eficiência máxima téorica de conversão de carboidratos em PHB. Fluxos são normalizados de acordo com o fluxo de entrada do substrato na célula $($ GLIEXT $\rightarrow$ G6P).

Figura 16 - Variação de consumo de sacarose, formação de biomassa e produção de PHB durante o cultivo em biorreator (EB3).

Figura 17 - Variação de consumo de glicose, formação de biomassa e produção de PHB durante o cultivo em biorreator (EB4).....

Figura 18 - Padrões de embaralhamentos de carbonos da molécula de acetil-CoA originada a partir de frutose-6-fosfato contendo carbonos marcados (coloridos) e não marcados (pretos) fornecidos pela mistura de glicose marcada e não marcada com ${ }^{13} \mathrm{C}$. A molécula de acetilCoA formada terá embaralhamento de carbonos apenas se for originada através da frutose-6fosfato que for metabolizada pela Via das Pentoses (VP) e pela Enter-Doudoroff (ED), caso ela seja metabolizada apenas pela VP ou pela VP e pela Embden-Meyerhof-Parnas (EMP), os acetil-CoA formados não terão carbonos marcados e não marcados na mesma molécula (não sofrerão embaralhamento). Circulo azul envolvendo moléculas de acetil-CoA destacam a situação em que o embaralhamento de carbonos ocorre.

Figura 19 - Fragmentos m/z: 87, 89 e 131 resultantes da quebra do propil-éster do monômero $3 \mathrm{HB}$ contendo carbonos provenientes de acetil-CoA

Figura 20 - Cromatograma de CG-MS da amostra BS1A correspondente a análise dos propil-ésteres produzidos por $B$. sacchari. Setas indicam os fragmentos m/z: 87, 89 (em cinza) e 131. TR: tempo de retenção.

Figura 21 - Visão geral da produção de hidrogênio por bactérias fotossintéticas nãosulfúricas através da enzima nitrogenase.

Figura 22 - Organização do cluster que contém os genes da enzima nitrogenasemolibdênio.

Figura 23 - Fotografia do modelo de experimento realizado neste estudo, cultivos foram feitos em triplicata. 
Figura 24 - Gráfico da curva padrão de concentração de PHB. OD obtida em 235 $\mathrm{nm}$

Figura 25 - Superfície de resposta dos dados coletados no experimento de SB1003 com melaço de cana-de-açúcar.

Figura 26 - Gráfico de Pareto relativo ao experimento com SB1003 e melaço de cana-deaçúcar mostrando a padronização do efeito de cada parâmetro. (L): linear, (Q): quadrático.

Figura 27 - Superfície de resposta dos dados coletados no experimento de SB363II com melaço de cana-de-açúcar.

Figura 28 - Gráfico de Pareto relativo ao experimento com SB636II e melaço de cana-deaçúcar mostrando a padronização do efeito de cada parâmetro. (L): linear, (Q): quadrático

Figura 29 - Superfície de resposta dos dados coletados no experimento de SB1003 com acetato

Figura 30 - Gráfico de barras contendo dados de porcentagem de $\mathrm{PHB}$ em relação à biomassa coletados em cultivo com $R$. eutropha (C. necator) e $B$. sacchari em meio contendo limitação de nitrogênio ou fósforo e frutose como fonte de carbono.

Figura 31 - Gráfico de Pareto relativo ao experimento com SB1003 e acetato mostrando a padronização do efeito de cada parâmetro. (L): efeito linear, (Q): efeito quadrático.

Figura 32 - Superfície de resposta dos dados coletados no experimento de SB363II com acetato

Figura 33 - Gráfico de Pareto relativo ao experimento com SB363II e acetato mostrando a padronização do efeito de cada parâmetro. (L): efeito linear, (Q): efeito quadrático

Figura 34 - Superfície de resposta dos dados coletados no experimento de CGA009 com glicerol.....

Figura 35 - Gráfico de Pareto relativo ao experimento com CGA009 e glicerol mostrando a padronização do efeito de cada parâmetro. (L): efeito linear, (Q): efeito quadrático.

Figura 36 - Superfície de resposta dos dados coletados no experimento de CGA750 com glicerol.

Figura 37 - Gráfico de Pareto relativo ao experimento com CGA009 e glicerol mostrando a padronização do efeito de cada parâmetro. (L): efeito linear, (Q): efeito quadrático. 


\section{LISTA DE TABELAS}

Tabela 1 - Dados da comercialização de PHB e copolímeros produzidos por diferentes empresas.

Tabela 2 - Formulação dos meios minerais utilizado nos experimentos em agitador rotativo contendo variações nas limitações de nitrogênio e fósforo.

Tabela 3 - Composição da solução de elementos traços utilizada. 32

Tabela 4 - Meio mineral utilizado para cultivo do inóculo. .33

Tabela 5 - Meio mineral utilizado em cultivo de biorreator. 33

Tabela 6 - Valores de conversão de carboidratos em PHB (Y $\left.\mathrm{Y}_{\mathrm{PHB} / \mathrm{C}}\right)$ obtidos por B. sacchari (LFM101) neste estudo comparados aos obtidos no artigo Gomez et al. (1996).....

Tabela 7 - Valores de conversão de carboidratos em PHB (Y $\mathrm{Y}_{\mathrm{PHB} / \mathrm{C}}$ ) por C. necator (DSM545) obtidos neste estudo comparados aos obtidos no artigo Gomez et al., 1996.

Tabela 8 - Dados de velocidades de consumo de sacarose, formação de biomassa residual (Xr), PHB e $\mathrm{CO}_{2}$ utilizados para balanço de carbonos do primeiro intervalo (8 a 12 horas) 48

Tabela 9 - Comparação entre resultados de experimentos em biorreator realizados neste estudo e da literatura.

Tabela 10 - Dados de síntese de PHB de cultivo de $B$. sacchari e $C$. necator a partir de glicose......

Tabela 11 - Dados de síntese de PHB de cultivo de B. sacchari e C. necator a partir de glicose.

Tabela 12 - Resultados de experimento utilizando substrato marcado $c{ }^{13} \mathrm{C}$ e não marcado (20:80).

Tabela 13 Cálculo da frequência de ocorrências dos diferentes isotopômeros do fragmento $\mathrm{m} / \mathrm{z}=131$ e $\mathrm{m} / \mathrm{z}=89$ considerando o metabolismo de glicose marcada (20\%) e não marcada $(80 \%)$ pela via das pentoses e ED. Cores indicam a procedência dos carbonos do fragmento segundo a molécula de acetil-CoA que o compõe (Acetil-CoA 1 ou Acetil-CoA 2).

Tabela 14 - Cálculo da frequência de ocorrências dos diferentes isotopômeros do fragmento $\mathrm{m} / \mathrm{z}=87$ considerando o metabolismo de glicose marcada $(20 \%)$ e não marcada $(80 \%)$ pela via das pentoses e ED.

Tabela 15 - Cálculo da frequência de distribuição dos diferentes isotopômeros dos fragmentos $\mathrm{m} / \mathrm{z}=87,89$ e 131 experimental comparada à estimada para o fluxo via VP e ED para as linhagens $B$. sacchari e $C$. necator. 
Tabela 16 - Solução de super sais do meio RCV.

Tabela 17 - Solução de elementos traços do meio RCV

Tabela 18 - Comparação entre os resultados das médias das triplicatas da produção de PHB por SB1003 (selvagem) e SB363II (mutante) em melaço de cana-de-açúcar em porcentagem da relação da quantidade em gramas de PHB na biomassa total (PHB (g)/ biomassa $(\mathrm{g}))$. 78

Tabela 19 - Comparação entre os resultados das médias das triplicatas de produção de PHB por SB1003 (selvagem) e SB363II (mutante) com acetato em porcentagem da relação da quantidade em gramas de PHB na biomassa total (PHB (g)/ biomassa $(\mathrm{g}))$

Tabela 20 - Produção média de hidrogênio (em nmol) por SB1003 (selvagem) com acetato.

Tabela 21 - Comparação entre os resultados das médias das triplicatas de produção de PHB por CGA009 (selvagem) e CGA750 (mutante) com glicerol em porcentagem da relação da quantidade em gramas de PHB na biomassa total (PHB (g)/ biomassa $(\mathrm{g})$ ).

Tabela 22 - Comparação entre os experimentos de produção de $\mathrm{PHB}$ e $\mathrm{H}_{2}$ realizados com SB1003, SB 363II, CGA009 e CGA750. 


\section{LISTA DE ABREVIATURAS E SIGLAS}

PHA - polihidroxialcanoatos

$\mathrm{P}(3 \mathrm{HB})$ - poli-3-hidroxibutirato

3HB - 3-hidroxi-butirato

PHB - polihidroxibutirato

AFM - Análise de Fluxos Metabólicos

$\mathrm{Xr}$ - biomassa residual (biomassa sem polímero) (g/l ou g)

$\mathrm{Xt}$ - biomassa total (biomassa contendo polímero) (g/l ou g)

$\mathrm{Y}_{\mathrm{PHB} / \mathrm{C}}$ - fator de conversão de carboidrato em polihidroxibutirato (g de $\mathrm{PHB} / \mathrm{g}$ de Xt)

MSC - Massa Seca Celular (g ou g/l)

RMN - Ressonância Nuclear Magnética

GC-MS - Cromatografia Gasosa - Espectrometria de Massa

DoE - Design of Experiments

RSM - Response Surface Methodology

G6P - glicose-6-fosfato

F6P - frutose-6-fosfato

F16P - frutose-1,6-bisfostato

PG6 - 6-fosfogliconato

KDPG2 - 2-ceto-desoxi-6-fosfogliconato

G3P - gliceraldeído-3-fosfato

E4P - eritrose-4-fosfato

S7P - sedo-7-heptulose 
Rbl5P - ribulose-6-fosfato

Rb5P - ribose-5-fosfato

X5P - xilulose-5-fosfato

DHP - dihidroxiacetona

BPG13 - 1,3-bisfosfoglicerato

PG3 - 3-fosfoglicerato

PG2 - 2-fosfoglicerato

PEP - fosfoenolpiruvato

PIR - piruvato

AcCoA - acetil-CoA

Cit - citrato

IsoCit - isocitrato

KG2 - $\alpha$-cetoglutarato

SucCoA - succinil-CoA

Suc - succinato

Fum - fumarato

OAA - oxaloacetato 


\section{SUMÁRIO}

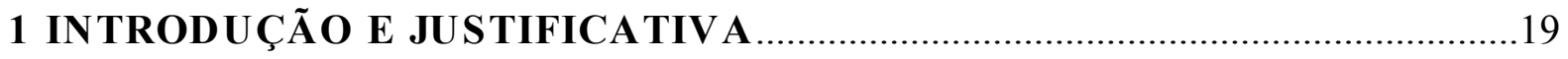

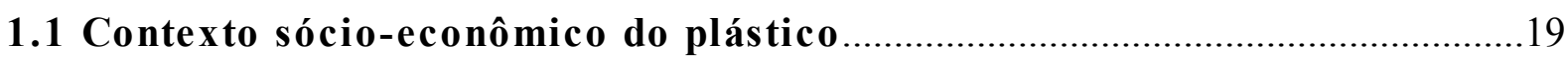

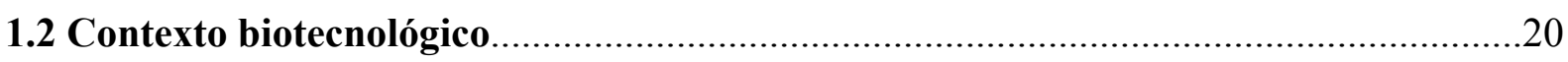

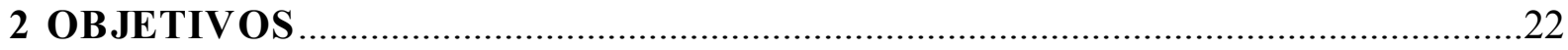

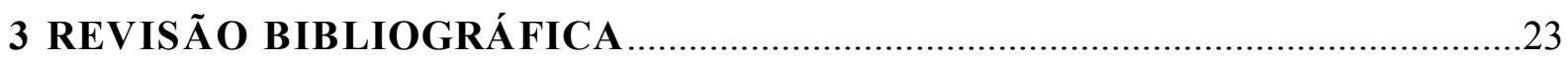

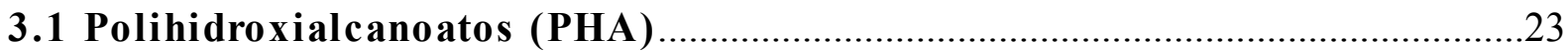

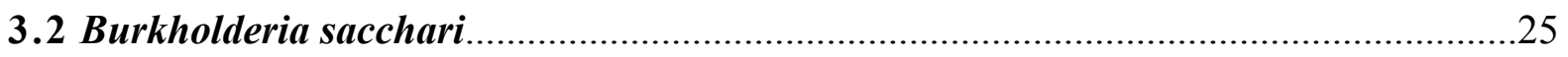

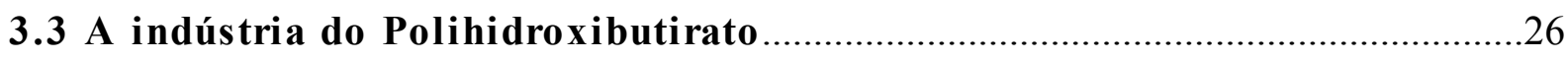

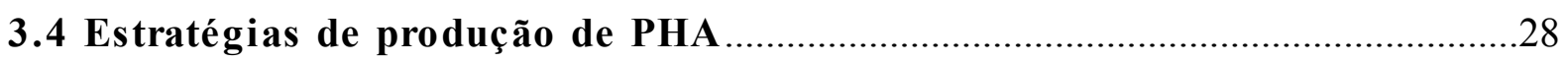

3.5 Aplicação da Análise de Fluxos Metabólicos - AFM.....................................29

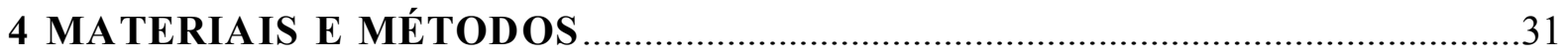

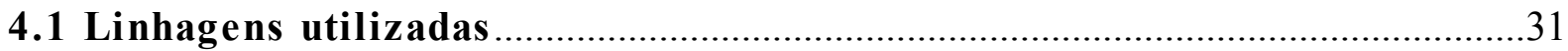

4.2 Meios de cultura e condições de cultivo

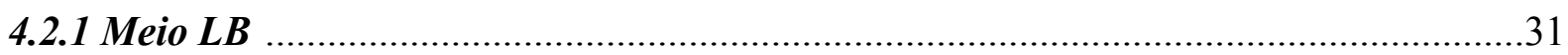

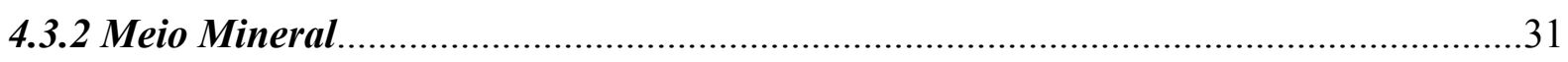

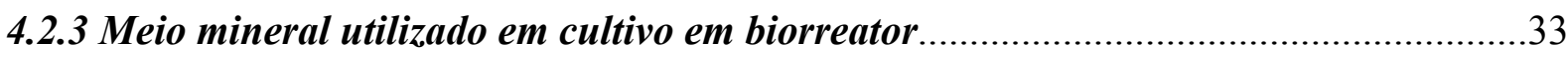

4.3 Estudo das eficiências de produção de polímero de $B$. sacchari e $C$. necator.

4.4 Cultivos de $B$. sacchari e $C$. necator para produção de PHB sob diferentes

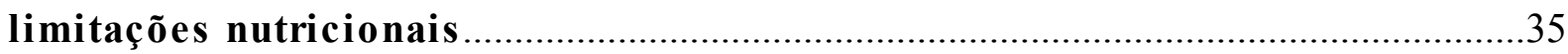

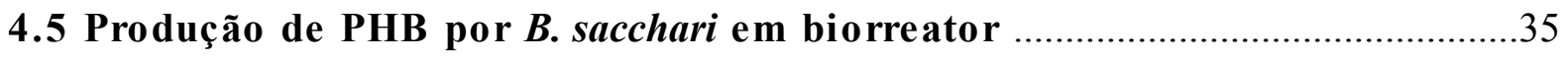

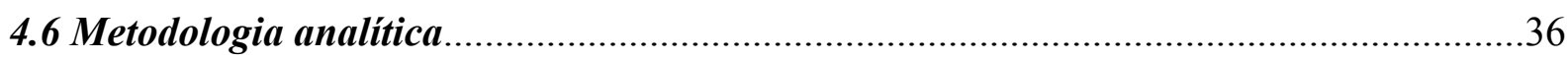

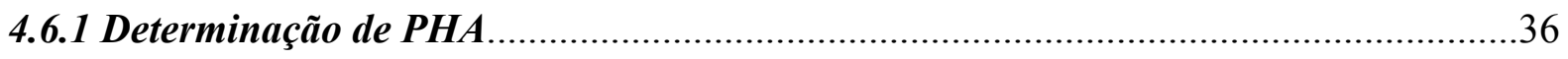

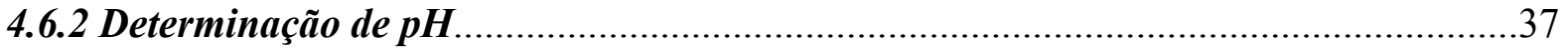

4.6.3 Determinação de Biomassa (Massa Seca Celular - MSC)........................................37

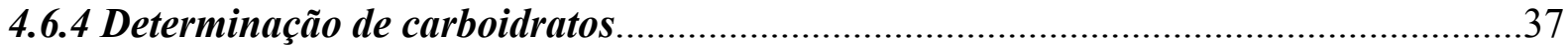

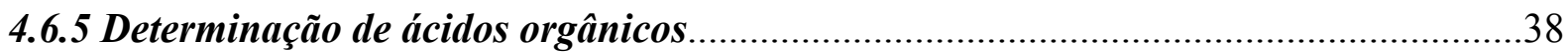

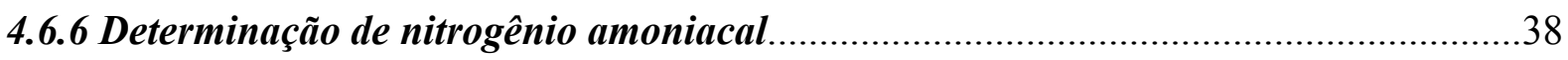

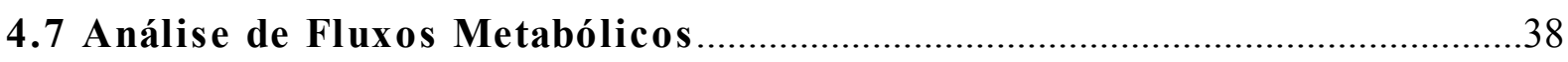

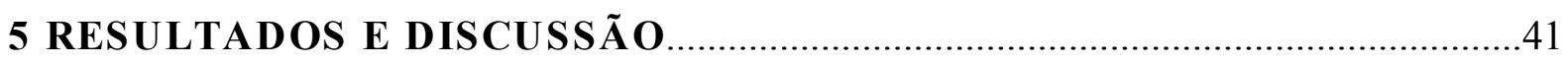

5.1 Determinação de eficiência de conversão de diferentes substratos em PHB 
por Burkholderia sacchari e Cupriavidus necator.

5.1.1 Burkholderia sacchari.

5.1.2 Cupriavidus necator.

5.2 Produção de PHB em biorreator a partir de sacarose utilizando meio MB1

- EB1

5.3 Produção de PHB em biorreator a partir de glicose utilizando meio MB1 -

EB2

5.4 Análise de modos elementares de cultivo de B. sacchari a partir de glicose

5.5 Cultivos em biorreator com meio mineral balanceado (MB2) - EB3 e

EB4

5.6 Cultivo de $B$. sacchari e $C$. necator com limitação variáveis de nitrogênio ou

fósforo a partir de diferentes fontes de carbono.

5.7 Cultivos com glicose contendo carbonos marcados $\left({ }^{13} \mathrm{C}\right)$.

5.8 Projeto: Influência da produção de hidrogênio na síntese de PHB

5.8.1 Introdução do projeto "Influência da produção de hidrogênio na síntese de PHB”

5.8.2 Metodologia do projeto "Influência da produção de hidrogênio na síntese de

PHB”. .73

5.8.2.1 Linhagens

5.8.2.2 Meios de cultura para micro-organismos fotossintéticos.......

5.8.2.3 Experimentos.

5.8.2.4 Desenho Experimental (Design of Experiments - DoE e Response Surface

Methodology - RSM).

5.8.3 Resultados do projeto "Influência da produção de hidrogênio na síntese de

PHB” .77

5.8.3.1 Rhodobacter capsulatus

5.8.3.2 Rhodopseudomonas palustris.

5.8.4 Conclusões do projeto "Influência da produção de hidrogênio na síntese de PHB”

6 CONCLUSÃO E PERSPECIVAS FUTURAS ...................................................92

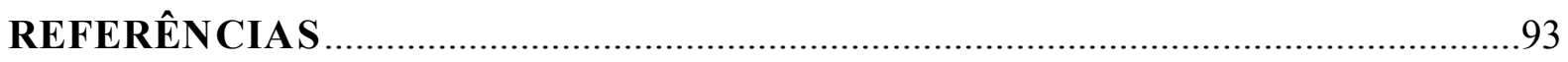

APÊNDICES 
APÊNDICE A - Arquivo de entrada contendo vias metabólicas centrais e de síntese de PHB de B. sacchari a partir de sacarose.

APÊNDICE B - Tabela contendo dados obtidos no experimento com Burkholderia sacchari de estudos da eficiência de conversão de carboidratos em PHB

APÊNDICE C - Tabela contendo dados obtidos no experimento com Curpiavidus necator de estudos da eficiência de conversão de carboidratos em PHB 101

APÊNDICE D - Tabela contendo dados do cultivo de B. sacchari realizado em biorreator com sacarose como fonte de carbono e gráfico com curva de $\mathrm{LnXr}$ - EB1

APÊNDICE E - Tabela contendo dados do cultivo de $B$. sacchari realizado em biorreator com glicose como fonte de carbono e curva de $\mathrm{LnXr}$.

APÊNDICE F - Resumo do arquivo de saída contendo vias metabólicas centrais e de síntese de PHB de B. sacchari a partir de glicose

APÊNDICE G - Tabela de dados do cultivo de B. sacchari realizado em biorreator com glicose como fontede carbono. Gráfico contendo curva de $\operatorname{LnXr}$ (biomassa residual) EB3

APÊNDICE H - Tabela contendo dados do cultivo de $B$. sacchari realizado em biorreator com sacarose. Gráfico contendo LnXr.- EB4. 


\section{INTRODUÇÃO E JUSTIFICATIVA}

\subsection{Contexto sócio-econômico do plástico}

As propriedades mecânicas e características como durabilidade, processabilidade e baixo custo do plástico, fizeram com que seu uso se espalhasse em diversas aplicações (GÓMEZ; MICHEL, 2013). Entre os diversos polímeros de uso na sociedade atual, os plásticos sintéticos têm sido os mais utilizados.

Segundo a Associação Brasileira da Indústria do Plástico (Abiplast), em 2012, a indústria de transformação de plástico totalizou 6,66 mil toneladas de plástico transformado, esta demanda está dividida entre: a construção civil (que consome 16\%), o setor de alimentos e bebidas (que também consome 16\%) e o setor de automóveis e autopeças (com 15\% do consumo de produtos plásticos). Em 2012, o faturamento da indústria brasileira de transformação de plástico cresceu 7\% em relação ao ano anterior, correspondendo a $\mathrm{R} \$ 56,49$ bilhões, o que demonstra a importância do plástico no mercado brasileiro.

Atualmente, tenta-se reduzir o impacto do acúmulo de embalagens plásticas no meio ambiente causado pelo excesso de consumo deste material através da redução do seu uso, incineração, reciclagem e bio ou foto-degradação Estas, porém são soluções que acarretam em si outros problemas.

A incineração pode produzir cianeto de hidrogênio e ácido clorídrico (JOHNSTONE, 1990) e pode ainda ter alto custo (KHANNA; SRIVASTAVA, 2005). Outra solução é a reciclagem destes materiais, contudo, além desta estratégia exigir coleta seletiva, o processo de reciclagem também não é completamente livre de produzir contaminantes do meio ambiente e, ainda, não é aplicável a todos os tipos de plástico: existem materiais com tratamentos de pigmentos e outras características que podem tornar o processo de reciclagem limitado.

Nos últimos anos, a situação sócio-econômica trouxe novamente a importância de pesquisas voltadas para a produção de polímeros naturais visando a substituição dos polímeros sintéticos.

A substituição de plásticos não-degradáveis por degradáveis é um grande interesse não só dos que tomam decisões como também das indústrias de plástico (SONG; HEIN; STEINBÜCHEL, 1999). Alguns dos fatores responsáveis pelo retorno da importância destes materiais são: 
- Econômicos: embargos petrolíferos, preço oscilante do petróleo, preocupação com sua disponibilidade a longo prazo.

- Ambientais: diversos tipos de poluição causadas pelo seu uso, tempo de degradação demasiado longo, acúmulo de embalagens plásticas.

Existem diferentes classificações para os plásticos biodegradáveis, uma delas é a separação ente plásticos fotodegradáveis, semi-degradáveis e completamente degradáveis. $\mathrm{O}$ grupo dos fotodegradáveis é caracterizado por polímeros que podem ser desintegrados por exposição prolongada (de semanas a meses) a radiação ultravioleta (KALIA; RAIZADA; SONAKYA, 2000a) e então podem ser degradados por bactérias. Os semi-degradáveis contém ligações de amido que mantem ligados os polietilenos. As bactérias atacam o amido, porém não conseguem degradar os fragmentos de polietileno liberados (JOHNSTONE, 1990). Já o último grupo, os completamente degradáveis são polímeros sintetizados por bactérias. Este inclui: poliésteres alifáticos, ácido poliláctico (PLA), polissacarídeos, polihidroxialcanoatos (figura 1), copolímeros ou misturas dos citados (REDDY et al., 2003).

Figura 1 - Estrutura geral dos monômeros de poli-hidroxialcanoatos. Onde "n" é igual a 1, 2, 3 ou 4 para 3, 4, 5 ou 6-hidroxialcanoatos, respectivamente.

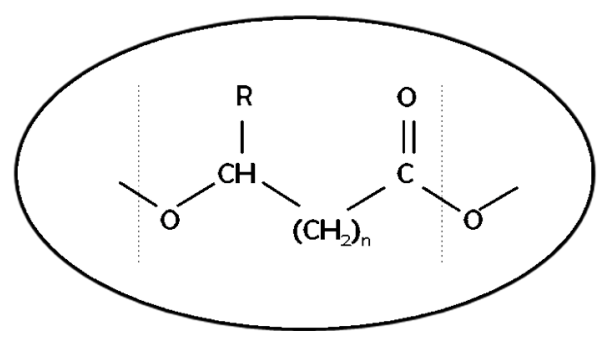

\subsection{Contexto biotecnológico}

A linhagem escolhida para a realização deste projeto, Burkholderia sacchari, produtora de $\mathrm{P}(3 \mathrm{HB})$ - um representante dos polihidroxialcanoatos - exibe diferentes vantagens em relação a produção destes plásticos biodegradáveis: demonstrou a capacidade de conversão de carboidratos em $\mathrm{P}(3 \mathrm{HB})$ de $80 \%$ do máximo teórico (GOMEZ et al., 1996), e é apta a 
consumir sacarose (MENDONÇA et al., 2013) um açúcar menos custoso economicamente que os mais comumentes utilizados para estes processos como glicose e frutose.

Neste âmbito, a tentativa de aumentar a eficiência da síntese dos polímeros biodegradáveis por Burkholderia sacchari se mostra uma estratégia valiosa para a diminuição do custo de comercialização deste produto. Para tanto, a Análise de Fluxos Metabólicos (AFM) é uma escolha interessante, já que consegue prever os possíveis fluxos metabólicos celulares dos cultivos realizados e também a distribuição dos mesmos em situações de maior eficiência. Também, a análise de rastreamento de carbonos, feita através da observação do embaralhamento de carbonos em produtos sintetizados a partir de substratos marcados com ${ }^{13} \mathrm{C}$ consegue complementar esta análise, evidenciando as vias metabólicas utilizadas e as parcelas de carbono que são direcionadas à síntese de $\mathrm{P}(3 \mathrm{HB})$. Com estas ferramentas, podem-se visualizar de forma abrangente soluções para aumentar a eficiência já reportada de $80 \%$ do valor do máximo teórico para a produção do polímero biodegradável por $B$. sacchari. 


\section{OBJETIVOS}

Este projeto tem como objetivo geral:

Determinar a eficiência de $B$. sacchari na conversão de açúcares em PHB e sua distribuição de fluxos metabólicos.

Os objetivos específicos são:

- Quantificar a parcela do carbono, proveniente dos carboidratos incorporados pelas células que é destinada às vias das Pentoses-Fosfato, Entner-Doudoroff ou EmbdenMeyerhof-Parnas;

- Determinar estratégia visando o melhoramento da eficiência da produção de PHB por $B$. sacchari a partir dos resultados obtidos. 


\section{REVISÃO BIBLIOGRÁFICA}

\subsection{Polihidroxialcanoatos (PHA)}

Os polihidroxialcanoatos constituem uma família de poliésteres acumulados intracelularmente por diversos organismos eucarióticos e procarióticos na forma de grânulos (figura 2). Pelo menos 75 gêneros de bactérias são produtoras de PHA (REDDY et al., 2003). Dentre os todos os tipos de PHA, o mais estudado atualmente e alvo deste trabalho - o poli-3hidroxibutirato $[\mathrm{P}(3 \mathrm{HB})]$ - é formado em inclusões na célula que medem, aproximadamente, de 0,2 a 0,5 $\mu \mathrm{m}$ de diâmetro (POIRIER; NAWRATH; SOMMEVILLE, 1995). Cada inclusão contêm, em torno de 1.000 cadeias de polímeros, elas possuem, de 97 a 98\% de P(3HB), 2\% de proteínas e $0,5 \%$ de lipídeos. Estes lipídeos constituem uma mistura de ácido fosfatídico, triacetina, tributirina, tripropionina e outros polímeros indefinidos (KAWAGUCHI; DOI, 1990). Os grânulos encontram-se na forma não cristalina in vivo, porém, quando isolados, são de 60 a 70\% cristalinos, o que sugere a influência de interação com água na parede celular (MÜLLER; SEEBACH, 1993).

Figura 2 - Micrografia de transmissão de elétrons de seção ultra-fina da cepa A-04 de $C$. necator. bastonetes típicos medindo de 0,6 a 1,0 $\mu \mathrm{m}$. Barra, $1 \mu \mathrm{m}$. (b) cepa A-04 de C. necator contendo grânulos de PHB (círculos brancos). Barra 200 nm. Fonte: Chanprateep, 2008.

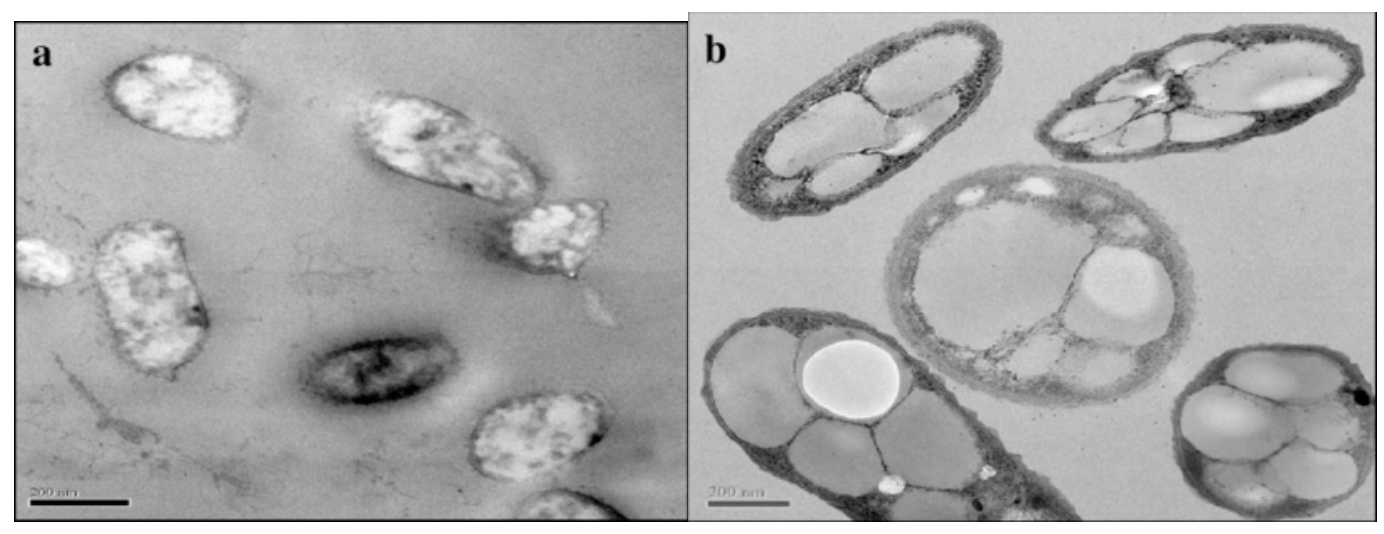

A síntese de PHA ocorre de maneira mais expressiva quando há excesso de fonte de carbono disponível e condições de limitação de pelo menos um nutriente essencial ao crescimento das celular, como nitrogênio, fósforo, magnésio, ferro, etc. Quando há limitação de carbono ou de energia, mas não de outros nutrientes, os polihidroxialcanoatos podem ser 
reutilizados para suprir essa necessidade (ANDERSON, DAWES, 1990; LEE, 1996). A formação dos biopolímeros pode ser realizada de duas maneiras: em uma única etapa, em que ocorre a síntese de PHA juntamente ao crescimento celular, ou em duas etapas, em que, primeiramente, apenas a multiplicação celular está presente, na posterior, há somente o acúmulo de PHA.

Estes polímeros são degradados eficientemente por micro-organismos de solo que são capazes de secretar polihidroxibutirato despolimerases, enzimas que hidrolisam as ligações éster do polímero tornando-os monômeros ou oligômeros solúveis em água (CHANPRATEEP, 2010). Os micro-organismos metabolizam estes produtos da degradação formando água e dióxido de carbono (JENDROSSEK; HANDRICK, 2002; SRIDEWI; BHUBALAN; SUDESH, 2006).

A importância biotecnológica destes materiais está no fato de poderem ser aplicados na produção de plásticos e elastômeros biodegradáveis sendo, além disso, biocompatíveis. Suas aplicações encontram-se em diversas áreas, como: agroindustrial (braçadeiras), biomédica (indicados para engenharia de tecido duro ou material de substituição de ossos) e indústria de embalagens de uma maneira geral.

Embora um grande número de monômeros constituintes do PHA já tenha sido detectado, convém destacar que a síntese e incorporação destes monômeros depende do fornecimento de um substrato adequado que possa ser convertido no hidroxiacil-CoA desejado, como o 3-hidroxibutiril-CoA, através das vias metabólicas existentes na célula bacteriana (figura 3). A PHA sintase é a enzima chave para a biossíntese de PHA, pois é responsável pela catálise da polimerização das moléculas de $R$-hidroxiacil-CoA formando o biopolímero (GOMEZ, 2000). 
Figura 3 - Vias metabólicas principais responsáveis pela produção de $\mathrm{P}(3 \mathrm{HB})$ a partir de sacarose. As enzimas codificadas pelos genes phaA, phaB e phaC são, respectivamente: 3cetiolase, acetoacetil-CoA redutase (NADPH dependente) e PHA sintase.

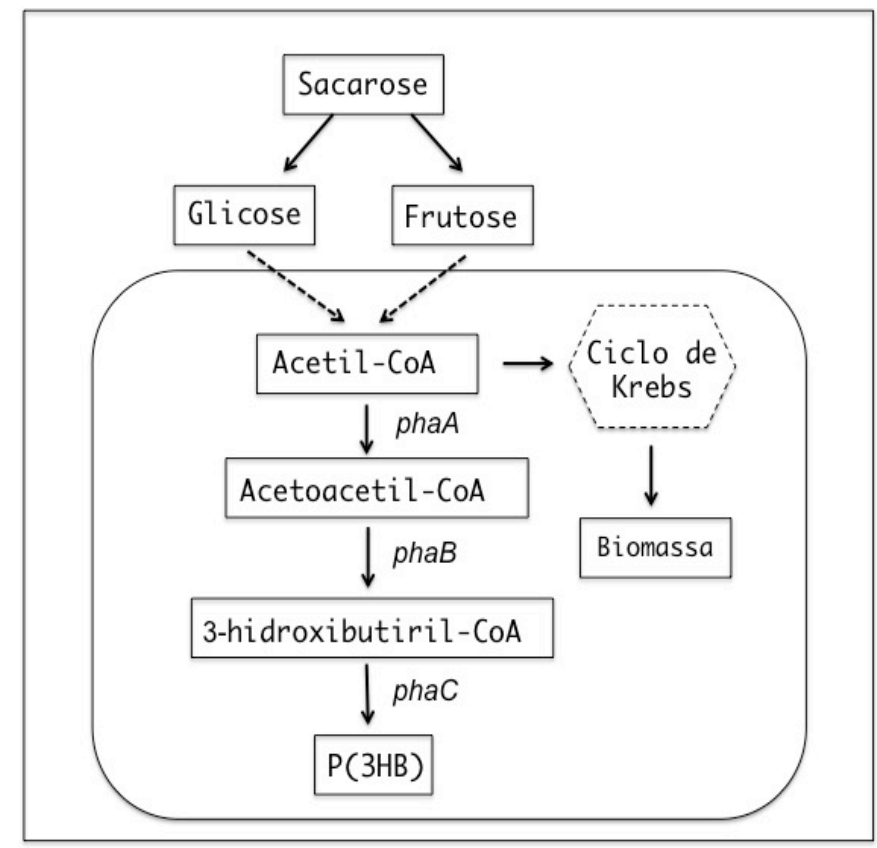

A seleção de bactérias produtoras de $\mathrm{P}(3 \mathrm{HB})$ a partir de sacarose foi realizada no início dos anos 90 (GOMEZ et al., 1996). Após o isolamento inicial, cerca de 300 isolados produtores de PHA foram obtidos a partir de amostras de solo de canavial. Estudos mais detalhados revelaram uma linhagem bacteriana promissora para a produção industrial destes polímeros que se tratava de uma espécie nova ainda não descrita, denominada então Burkholderia sacchari (BRÄMER et al., 2001).

\subsection{Burkholderia sacchari}

O preço do plástico biodegradável formado por $\mathrm{P}(3 \mathrm{HB})$ depende principalmente do valor do substrato, da eficiência de conversão em PHA e do rendimento da formulação do produto no seu processamento (LEE, 1996b). Diferentes substratos tem sido utilizados junto a diferentes estratégias para solucionar o problema do alto custo de produção do biopolímero, já que o custo da matéria-prima corresponde a $29 \%$ do valor final do produto (NONATO; MANTELATO; ROSSEL, 2001). A sacarose, substrato utilizado neste projeto, possui custo 
reduzido comparativamente à glicose e o etanol, por exemplo, e tem alto rendimento de conversão em $\mathrm{P}(3 \mathrm{HB})$.

A linhagem Burkholderia sacchari LFM101 (também identificada como IPT101, LMG19450 e CCT 6771) foi isolada de solo de canavial brasileiro (Saccharum officinarum), é uma bactéria gram-negativa, possui muitos flagelos polares, sua forma é de bastonete, medindo 0,5 a $0,8 \mu \mathrm{m}$ de comprimento. Sua temperatura ideal de crescimento está entre o intervalo 28 a $30{ }^{\circ} \mathrm{C}$ e pode acumular mais de $68 \%$ de sua massa seca celular na forma de grânulos de poli-3-hidroxibutirato P(3HB) a partir de sacarose (BRÄMER et al., 2001).

B. sacchari atinge eficiência de conversão de glicose em $\mathrm{P}(3 \mathrm{HB})$ de aproximadamente $80 \%$ da eficiência máxima teórica, entretanto, um pouco inferior da linhagem mais amplamente estudada para produção de $\mathrm{P}(3 \mathrm{HB})$, denominada Cupriavidus necator (GOMEZ et al., 1996). Uma das vantagens de LFM101 sobre C. necator é sua capacidade de hidrolisar a sacarose, permitindo a produção de $\mathrm{P}(3 \mathrm{HB})$ sem a necessidade de operação industrial adicional para promover a hidrólise prévia desse dissacarídeo (GOMEZ et al., 1996) e tornando o custo de produção do polímero mais atrativo.

\subsection{A indústria do Polihidroxibutirato}

Políticas que visam a diminuição do uso de materiais constituídos de compostos de origem petrolífera estabelecidas por diferentes países, têm impulsionado as empresas ligadas ao ramo de produção de plásticos biodegradáveis. Dentre estas políticas, podemos citar a ecotaxa, adotada pela União Européia que cobra $€ 3 \mathrm{~kg}^{-1}$ por embalagens, como sacolas plásticas, incentivando o uso de embalagens compostáveis.

$\mathrm{O}$ poli-3-hidroxibutirato $(\mathrm{P}(3 \mathrm{HB})$ ) tem sido o mais estudado dentre os polihidroxialcanoatos e empreendimentos para sua produção em nível industrial foram realizados em diferentes países (tabela 1). No Brasil, um dos países que mais exporta cana-deaçúcar, existe sua produção a partir de derivados de cana-de-açúcar em escala piloto pela empresa PHB Industrial. O polímero produzido pela empresa recebe o nome de Biocycle $^{\mathrm{TM}} \mathrm{e}$ começou a ser produzido em 1992, após a junção de duas empresas: Irmãos Biagi, produtora de açúcar, e Grupo Balbo, produtora de álcool.

A maior empresa de produção do polímero é a americana Metabolix Inc, localizada em Cambridge, Massachusetts, junto com a Archer Daniels Midland Company (ADM) fornecem o Mirel ${ }^{\mathrm{TM}}$, uma resina de PHA produzida a partir de xarope de milho. 
Tabela 1 - Dados da comercialização de PHB e copolímeros produzidos por diferentes empresas.

\begin{tabular}{|c|c|c|c|c|}
\hline Polímero & Nome comercial & Produtor & $\begin{array}{c}\text { Capacidade } \\
\text { (toneladas) }\end{array}$ & $\begin{array}{l}\operatorname{Preço~}\left(\mathrm{kg}^{-1}\right) \\
\text { (em 2010) }\end{array}$ \\
\hline PHB & Biogreen ${ }^{\circledR}$ & $\begin{array}{c}\text { Mitsubishi Gas } \\
\text { Chemical Company Inc. } \\
\text { (Japão) }\end{array}$ & 10.000 & $€ 2,5-3,0$ \\
\hline PHB & Mirel'TM & Telles (US) & 50.000 & $€ 1,50^{\mathrm{a}}$ \\
\hline PHB & Biocycle ${ }^{\circledR}$ & $\begin{array}{l}\text { PHB Industrial } \\
\text { Company (Brasil) }\end{array}$ & 50 & $\mathrm{n} / \mathrm{d}$ \\
\hline $\begin{array}{l}\text { PHB e } \\
\text { PHBV }\end{array}$ & Biomer ${ }^{\circledR}$ & Biomer Inc. (Alemanha) & 50 & $€ 3,0-4,0$ \\
\hline $\begin{array}{l}\text { PHBV, } \\
\text { PHBV + } \\
\text { mistura } \\
\text { Ecoflex }\end{array}$ & Enmat ${ }^{\circledR}$ & $\begin{array}{c}\text { Tianan Biologic, Ningbo } \\
\text { (China) }\end{array}$ & 10.000 & $€ 3,26$ \\
\hline PHBH & Nodax ${ }^{\mathrm{TM}}$ & $\mathrm{P} \& \mathrm{G}$ (EUA) & $20.000-50.000$ & $€ 2,50$ \\
\hline PHBH & Nodax ${ }^{\mathrm{TM}}$ & Lianyi Biotech (China) & 2.000 & $€ 3,70$ \\
\hline PHBH & Kaneka PHBH & $\begin{array}{c}\text { Kaneka Corporation } \\
\text { (Japan) }\end{array}$ & 1.000 & $\mathrm{n} / \mathrm{d}^{\mathrm{b}}$ \\
\hline $\begin{array}{c}\text { P(3HB-co- } \\
4 \mathrm{HB})\end{array}$ & Green Bio & $\begin{array}{l}\text { Tianjin Gree Bio- } \\
\text { Science Co/DSM }\end{array}$ & 10.000 & $\mathrm{n} / \mathrm{d}$ \\
\hline $\begin{array}{l}\text { Polihidroxi- } \\
\text { alcanoatos da } \\
\text { P\&G }\end{array}$ & Meredian & Meredian (EUA) & $272.000(2013)$ & $\mathrm{n} / \mathrm{d}$ \\
\hline
\end{tabular}

Notas: a Bacteria to produce biplastics, BIOPRO Baden-Württemberg GmbH, 24 de setembro, 2009. Disponível em: http://www.bio-pro.de/magazin/thema/04308/ index.html? lang=en\&artikelid=/ artikel/04310/index.html, acessado em junho de 2012. ${ }^{\text {b }}$ Full-scale development of the world's first completely bio-based polymer with soft and heat resistant proprieties, Kaneka Corporation, 10 de março de 2009. Disponível em: www.kaneka.co.jp/kaneka-e/news/pdf/090310.pdf, acessado em junho de 2012.

Fonte: Chanprateep (2010) - traduzida. 


\subsection{Estratégias de produção de PHA}

Segundo as características já citadas do PHA que o tornam uma boa alternativa para a substituição dos plásticos sintéticos, muitas pesquisas são realizadas atualmente visando reduzir o preço do PHA e torná-lo mais atrativo comercialmente. As mais conhecidas buscam o uso de substratos mais baratos e/ou aumento da eficiência da produção de uma determinada linhagem. Juntamente a estes, existem estudos que pretendem sintetizar copolímeros e, desta forma, alterar as propriedades do material, tornando-o mais flexível, por exemplo, e aumentando a abrangência da sua aplicabilidade. Estes copolímeros podem ser obtidos pelo fornecimento de substratos distintos como ácidos orgânicos.

Dentre as estratégias de síntese de polihidroxialcanoatos podemos citar o uso de culturas mistas a partir de resíduos (industriais ou agroindustriais, por exemplo) que apresentam baixo custo, porém não atingem melhor rendimento que as culturas puras. Outra estratégia é reduzir o tempo de geração de recombinantes. A título de exemplo, um mutante de $E$. coli, que sua célula possui a habilidade natural de ser facilmente lisada, foi engenheirada para acumular polihidroxialcanoatos sob alta taxa de crescimento, o que diminui o custo de produção do polímero, já que exclui a fase de purificação dos grânulos (MADISON; HUISMAN, 1999; STEINBÜCHEL; SCHLEGEL, 1991; WANG; BAKKEN, 1998). Recombinantes com modificações em vias metabólicas relacionadas à síntese de PHA são uma alternativas para melhorar o rendimento da produção do bioplástico. Uma das estratégias é o uso de E. coli contendo muitas cópias dos genes de Cupriavidus necator para biossíntese de PHA em plasmídeos estáveis (LEE; YIM; CHANG, 1994; ZHANG et al., 1994). Também existem trabalhos com recombinantes atualmente estudados, mutantes de Pseudomonas oleovorans com expressão heteróloga do genes da biossíntese de PHA de Cupriavidus necator para a produção de copolímeros de misturas de $\mathrm{P}(3 \mathrm{HB})$ com msc-PHA (medium-side-chain PHA) (PREUSTING; NIJENHUIS; WITHOLT, 1990).

Em resumo, pode-se dizer que existem duas metodologias principais para a produção de polihidroxialcanoatos a partir de fontes de carbono de menor custo. Uma delas é consiste na inserção de genes responsáveis pelo uso destes substratos em micro-organismos produtores de PHA. A segunda, é o oposto: genes de síntese de PHA são introduzidos em microorganismos que naturalmente não produzem PHA, mas que possuem a capacidade de metabolizar substratos mais baratos. 
Existe, ainda, a produção de PHB por plantas geneticamente modificadas está se tornando estável e pode ser uma rota preferencial para produzir PHA, porém esta não produz a variedade de tipos de PHA possivelmente obtidos em fermentações (GUMEL; ANNUAR; CHISTI, 2013). Em uma pesquisa, genes das enzimas $p h b \mathrm{~B}$ e phbC de C. necator foram inseridos em Arabidopsis thaliana e geraram o acúmulo de PHB no citoplasma, vacúolo e núcleo, mas resultaram em alterações no crescimento da planta. Mais tarde, conseguiu-se expressar os genes no plastídeo, onde ocorre um alto fluxo de carbono pelo acetil-CoA, o que incrementou o sistema de produção. Apesar disso, o rendimento máximo obtido, até 2012, foi de $0,36 \%$ da massa seca da semente (SCHNELL et al., 2012), muito inferior ao obtido por micro-organismos como Cupriavidus necator que acumula mais de 70\% de PHB em relação à massa seca celular.

\subsection{Aplicação da Análise de Fluxos Metabólicos - AFM}

Uma das melhores formas de se caracterizar a fisiologia celular é por meio da avaliação das velocidades de reação de suas vias metabólicas, método conhecido como Análise de Fluxos Metabólicos (AFM). Este reflete a integração das regulações genéticas e metabólicas. A compreensão detalhada e quantitativa das vias de reações bioquímicas requer não somente o conhecimento sobre seus componentes individuais, mas também informação sobre o comportamento da rede metabólica em sua totalidade (FONSECA, 2007).

Através da AFM, pode-se calcular os fluxos reais ocorrendo nas reações de uma dada rede metabólica. Também é possível propor soluções de arranjo de fluxos metabólicos que permitem incrementar a produção de um metabólito de interesse. Estas alternativas nem sempre são óbvias pela análise apenas dos genes diretamente envolvidos em um dado processo, portanto, o uso da AFM possibilita propor modificações genéticas e de bioprocessos através de uma visão mais detalhada.

Dentro deste contexto da AFM, ferramentas computacionais que analisam o metabolismo celular tem sido desenvolvidas por mais de duas décadas. Estas ferramentas calculam o fluxo de metabólitos através das taxas das reações catalisadas por enzimas que participam no metabolismo celular. A análise de modos elementares faz parte destas ferramentas. Ela introduz um método sistemático de extrair vias biológicas importantes de um metabolismo complexo (TRINH; WLASCHIN; SRIENC, 2010). Para tanto, ela gera modos elementares, desenvolvidos por softwares, que representam um conjunto de reações escritas como 
equações baseadas no princípio de conservação de massa. Cada modo elementar é um conjunto único mínimo de enzimas que sustentam um estado estacionário de uma rede metabólica com reações irreversíveis que seguem direções apropriadas (PFEIFFER et al., 1999; SCHUSTER, HILGETAG, 1994). Ainda, um modo elementar é um vetor capaz de solucionar uma matriz constituída de fluxos metabólicos.

Uma outra estratégia elegante que faz parte da Análise de Fluxos Metabólicos é a utilização de experimentos de rastreamento. Detalhes da distribuição de fluxos podem ser obtidos pela combinação de experimentos com rastreadores e balanço estequiométrico (WITTMANN; HANS; HEINZLE, 2002). Neste projeto, o substrato rastreador utilizado foi o isótopo estável, não radioativo, ${ }^{13} \mathrm{C}$ incluído em moléculas de glicose e o composto final analisado foi o PHB. Esta análise é facilitada no caso da produção de PHA pois em diversas situações o fluxo de metabólitos desviados para o crescimento celular é nulo, todo o carbono é então direcionado para a síntese de PHA (BRÄMER et al., 2002).

Nesta técnica, substratos ${ }^{13} \mathrm{C}$-marcados são utilizados e os produtos do metabolismo são analisados por métodos que distinguem diferentes padrões isotópicos de marcação, como a Ressonância Nuclear Magnética (RMN) e/ou a Cromatografia Gasosa - Espectrometria de Massa (GC-MS). Esta interpretação global dos dados permite uma consideração integrada e quantitativa de todos dados fisiológicos e de ${ }^{13} \mathrm{C}$ marcados. Com os modelos e softwares atualmente disponíveis, estes métodos de balanço isotopomérico têm atingido um nível elevado de precisão e aplicabilidade, apesar de serem intensamente trabalhosos (SAUER et al., 1999; SZYPERSKI, 1995). 


\section{MATERIAIS E MÉTODOS}

\subsection{Linhagens utilizadas}

Foi utilizada a linhagem Burkholderia sacchari LFM101 obtida de solo de canavial brasileiro (GOMEZ et al., 1996). Com o objetivo de comparar a produção de polímeros desta linhagem, foi utilizada como controle a linhagem Cupriavidus necator (também chamada de Alcaligenes eutrophus, Ralstonia eutropha, LFM026, DSM545). Ambas estão disponíveis na coleção do laboratório de fisiologia de micro-organismos, mantidas em glicerol $10 \%$ à - $80^{\circ} \mathrm{C}$ ou liofilizadas.

\subsection{Meios de cultura e condições de cultivo}

Neste trabalho foram realizados cultivos com os seguintes meios de cultura: LBÁgar, LB líquido, meio mineral - MR (ROCHA et al., 2008). Para cultivos em biorreator utilizou-se diferentes formulações deste meio mineral descritas abaixo. Os meios de cultivo e soluções estéreis utilizadas nos experimentos deste projeto foram esterilizadas por meio de autoclave, à temperatura de $121^{\circ} \mathrm{C}$ durante o tempo mínimo de $15 \mathrm{~min}$.

\subsubsection{Meio LB}

Este meio de cultura complexo foi utilizado neste estudo para a obtenção de crescimento e manutenção celular. Sua composição corresponde a $10 \mathrm{~g} / 1$ de triptona, $5 \mathrm{~g} / 1 \mathrm{de}$ extrato de levedura e $10 \mathrm{~g} / 1 \mathrm{de} \mathrm{NaCl}$. Para a obtenção de LB sólido, adicionou-se $20 \mathrm{~g} / 1 \mathrm{de}$ ágar-ágar.

\subsubsection{Meio Mineral}

Neste projeto, utilizou-se diferentes meios de cultura para o cultivo das linhagens $B$. sacchari e C. necator de acordo com o objetivo pretendido. Para os experimentos que visavam a identificação da condição ideal para os experimentos com substrato contendo carbonos marcados, as linhagens foram cultivadas com os meios Rocha e colaboradores (2008) com modificações apresentadas na tabela 2 . As concentrações de nitrogênio variaram em: 0,$5 ; 1,0$; 
1,5 quando foi testada a limitação deste nutriente e de fósforo foram: 0,$06 ; 0,12$ e 0,18 . Quando as concentrações de nitrogênio foram variadas, a concentração de ferro foi mantida em 3,0 g/l, quando o ferro foi o nutriente testado, a concentração de nitrogênio foi $0,3 \mathrm{~g} / 1$.

Os meios de cultivo utilizados nos experimentos em biorreator foram descritos por Ramsay e colaboradores (1990) estão detalhados na tabela 4 e 5.

Tabela 2 - Formulação dos meios minerais (ROCHA et al., 2008) utilizados nos experimentos em agitador rotativo contendo variações nas limitações de nitrogênio e fósforo.

\begin{tabular}{cc}
\hline Componente & Concentração \\
\hline $\mathrm{KH}_{2} \mathrm{PO}_{4}$ & Variável* \\
$\left(\mathrm{NH}_{4}\right)_{2} \mathrm{SO}_{4}$ & Variável* \\
Tris Amoniacal & $12 \mathrm{~g} / 1$ \\
Sol. de $\mathrm{MgSO}_{4} .7 \mathrm{H}_{2} \mathrm{O}$ & $1 \mathrm{ml} / 1$ \\
a $20 \%$ & \\
Sol. de $\mathrm{CaCl}_{2} .2 \mathrm{H}_{2} \mathrm{O}$ a $1 \%$ & $1 \mathrm{ml} / 1$ \\
Sol. de Citrato de Ferro- $\mathrm{NH}_{4}$ a $6 \%$ & $1 \mathrm{ml} / 1$ \\
Sol. de Elementos traços** & $1 \mathrm{ml} / 1$ \\
Açúcar & $10 \mathrm{~g} / 1$ \\
\hline experimentos realizados, as concentrações & estão descritas nos detalhamentos dos \\
solução de elementos traços está descrita na tabela 3.
\end{tabular}

Tabela 3 - Composição da solução de elementos traços utilizada.

\begin{tabular}{cc}
\hline Componente & Concentração \\
\hline $\mathrm{H}_{3} \mathrm{BO}_{3}$ & $0,3 \mathrm{~g} / 1$ \\
$\mathrm{CoCl}_{2} 6 \mathrm{H}_{2} \mathrm{O}$ & $0,2 \mathrm{~g} / 1$ \\
$\mathrm{ZnSO}_{4} 7 \mathrm{H}_{2} \mathrm{O}$ & $0,1 \mathrm{~g} / 1$ \\
$\mathrm{MnCl}_{2} 4 \mathrm{H}_{2} \mathrm{O}$ & $30 \mathrm{mg} / 1$ \\
$\mathrm{NaMoO}_{4} 2 \mathrm{H}_{2} \mathrm{O}$ & $30 \mathrm{mg} / 1$ \\
$\mathrm{NiCl}_{2} 6 \mathrm{H}_{2} \mathrm{O}$ & $20 \mathrm{mg} / 1$ \\
$\mathrm{CuSO}_{4} 5 \mathrm{H}_{2} \mathrm{O}$ & $10 \mathrm{mg} / 1$ \\
\hline
\end{tabular}




\subsubsection{Meio mineral utilizado em cultivo em biorreator}

O seguinte meio de cultivo descrito por Ramsay e colaboradores (1990) foi utilizado para o inóculo a ser adicionado ao cultivo de B. sacchari em experimento de biorreator, utilizando sacarose como fonte de carbono.

Tabela 4 - Meio mineral utilizado para cultivo do inóculo.

\begin{tabular}{cc}
\hline Componente & Concentração \\
\hline $\mathrm{Na}_{2} \mathrm{HPO}_{4}$ & $1,5 \mathrm{~g} / 1$ \\
$\mathrm{KH}_{2} \mathrm{PO}_{4}$ & $3,5 \mathrm{~g} / 1$ \\
$\left(\mathrm{NH}_{4}\right)_{2} \mathrm{SO}_{4}$ & $1,0 \mathrm{~g} / 1$ \\
Sol. de $\mathrm{MgSO}_{4} \cdot 7 \mathrm{H}_{2} \mathrm{O}$ & $1,0 \mathrm{ml} / 1$ \\
Sol. de $\mathrm{CaCl}_{2} \cdot 2 \mathrm{H}_{2} \mathrm{O}$ & $1,0 \mathrm{ml} / 1$ \\
Sol. de Citrato de Ferro- $\mathrm{NH}_{4}$ & $1,0 \mathrm{ml} / 1$ \\
Sol. de elementos traços & $1,0 \mathrm{ml} / 1$ \\
$\mathrm{NaCl}$ & $1 \mathrm{~g} / 1$ \\
$\mathrm{Açúcar}$ & $10 \mathrm{~g} / 1$ \\
\hline
\end{tabular}

Tabela 5 - Meio mineral utilizado em cultivo em biorreator.

\begin{tabular}{ccc}
\hline Componente & MB1 & MB2 \\
\hline$\left(\mathrm{NH}_{4}\right)_{2} \mathrm{SO}_{4}$ & $2,91 \mathrm{~g} / 1$ & $2,91 \mathrm{~g} / 1$ \\
$\mathrm{KH}_{2} \mathrm{PO}_{4}$ & $0,10 \mathrm{~g} / 1$ & $0,38 \mathrm{~g} / 1$ \\
$\mathrm{MgSO}_{4} .7 \mathrm{H}_{2} \mathrm{O}$ & $0,31 \mathrm{~g} / 1$ & $0,31 \mathrm{~g} / 1$ \\
$\mathrm{CaCl}_{2} .2 \mathrm{H}_{2} \mathrm{O}$ & $0,002 \mathrm{~g} / 1$ & $0,02 \mathrm{~g} / 1$ \\
Citrato de Ferro- $\mathrm{NH}_{4}$ & $0,006 \mathrm{~g} / 1$ & $0,06 \mathrm{~g} / 1$ \\
Sol. Elementos traços & $2 \mathrm{ml}$ & $2 \mathrm{ml}$ \\
$\mathrm{NaCl}$ & $1 \mathrm{~g} / 1$ & $1 \mathrm{~g} / 1$ \\
$\mathrm{Açúcar}$ & $15 \mathrm{~g} / 1$ & $15 / 1$ \\
\hline
\end{tabular}




\subsection{Estudo das eficiências de produção de polímero de $B$. sacchari e $C$. necator.}

Com a intenção de estudar as condições de biossíntese de PHB por B. sacchari e $C$. necator em diferentes substratos de forma a confirmar a eficiência de conversão de carboidratos em PHB, foram realizados experimentos com meio mineral (tabela 2). As linhagens LFM101 e LFM026 foram cultivadas inicialmente em meio LB sólido por, respectivamente, 72 e $48 \mathrm{~h}$ em estufa à $30^{\circ} \mathrm{C}$. Culturas isoladas foram inoculadas em LB líquido e mantidas durante 24 horas, à temperatura de $30^{\circ} \mathrm{C}$ e agitação de $150 \mathrm{rpm}$. As células foram lavadas com solução salina $0,85 \%$ através de centrifugação a $8.000 \mathrm{rpm}(\sim 8870$ xg) e 4 ${ }^{\circ} \mathrm{C}$.

Posteriormente, 2,5 $\mathrm{ml}$ destas células ressuspendidas na mesma solução salina foram utilizadas para inocular frascos contendo MR e uma das quatro opções de fontes de carbono: glicose, frutose, sacarose ou mistura de glicose e frutose. Os cultivos, realizados em triplicata, foram mantidos em agitador rotativo, à $30^{\circ} \mathrm{C}$, sob agitação de $150 \mathrm{rpm}$ durante um total de 72 ou 48 horas (figura 4 ).

Figura 4 - Esquema apresentando a metodologia de cultivo de B. sacchari e C. necator sob condições com limitação única de nitrogênio utilizando glicose $(\mathrm{G})$, ou frutose $(\mathrm{F})$, ou sacarose $(\mathrm{S})$, ou mistura de glicose e frutose $(\mathrm{G}+\mathrm{F})$.

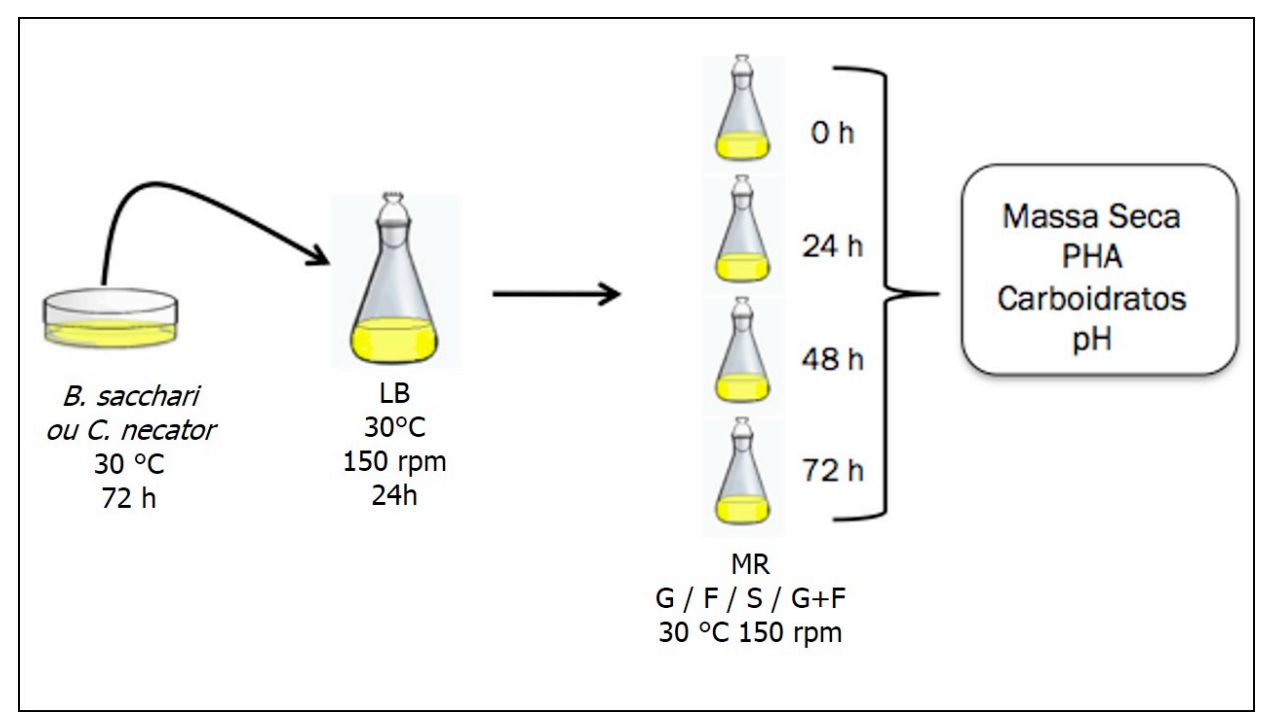




\subsection{Cultivos de $B$. sacchari e $C$. necator para produção de PHB sob diferentes limitações nutricionais}

Primeiramente, as linhagens $B$. sacchari e C. necator foram cultivadas em meio mineral contendo como fontes de carbono glicose ou frutose e segundo as condições de cultivo do item anterior. Visando a seleção de uma condição de cultivo de $B$. sacchari e $C$. necator que gerasse, comparativamente, alta concentração de PHB para reproduzi-la nos experimentos com substrato marcado com ${ }^{13} \mathrm{C}$, os cultivos, em triplicata, foram limitados em nitrogênio ou fósforo, em três níveis para cada um, sendo estes, para o nitrogênio: $0,5 \mathrm{~g} / 1,1,0$ $\mathrm{g} / \mathrm{l}$ ou 1,5 g/l; para o fósforo: $0,06 \mathrm{~g} / 1,0,12 \mathrm{~g} / 1$ ou $0,18 \mathrm{~g} / 1$ (figura 5). A descrição dos meios minerais utilizados consta na metodologia.

Figura 5 - Esquema representando metodologia empregada no cultivo de $B$. sacchari e $C$. necator em condições de limitação de nitrogênio ou fósforo distintas utilizando glicose $(\mathrm{G})$, ou frutose $(\mathrm{F})$.
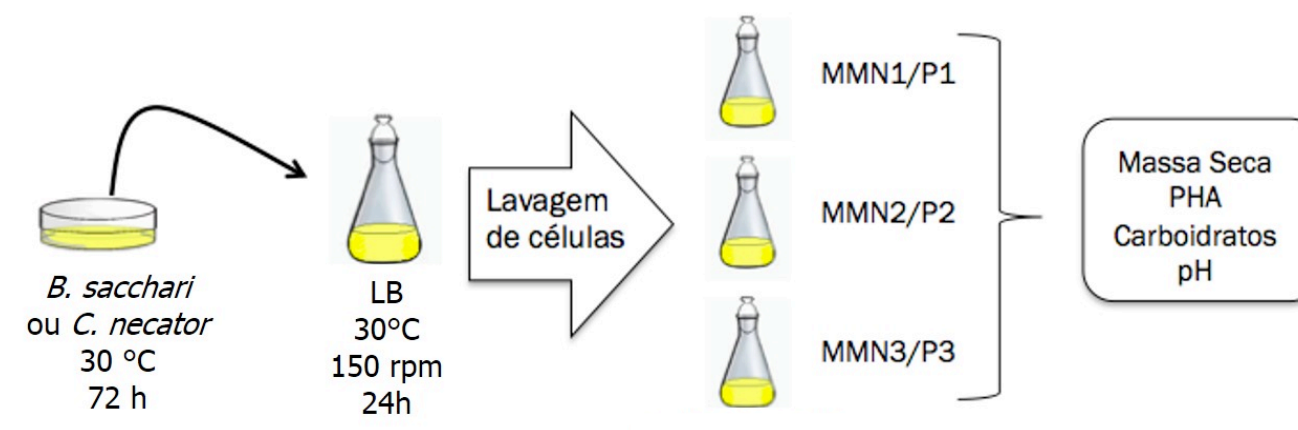

Carboidratos $\mathrm{pH}$

$\mathrm{G} / \mathrm{F}$

$30^{\circ} \mathrm{C} 72 \mathrm{~h}$

Nota: MMN1, MMN2, MMN3, contém, respectivamente, as seguintes concentrações de nitrogênio, 0,5 g/1, 1,0 g/1, 1,5 g/1. MMP1, MMP2, MMP3 contém, respectivamente: 0,06 g/l, 0,12 g/1, 0,18 g/1 de fósforo.

\subsection{Produção de PHB por $B$. sacchari em biorreator}

Culturas de B. sacchari obtidas em LB sólido, crescidas durante $72 \mathrm{~h}$ a $30^{\circ} \mathrm{C}$ foram inoculadas em LB líquido e mantidas a $30{ }^{\circ} \mathrm{C}, 150 \mathrm{rpm}$ em agitador rotativo. Esta, por sua vez, após $24 \mathrm{~h}$ foi inoculada em meio mineral (tabela 4) contendo sacarose ou glicose como fonte de carbono e incubada a $30^{\circ} \mathrm{C}$, sob agitação de $150 \mathrm{rpm}$ durante 24 horas. Este cultivo 
foi centrifugado $(8.000 \mathrm{rpm})$ e teve suas células lavadas com solução salina $0,85 \%$. A suspensão de células obtida foi inoculada em biorreator de capacidade de 4 L contendo o meio mineral descrito anteriormente (MB1 - tabela 6). O pH foi mantido em 7 adicionando-se $\mathrm{NaOH}$ a $0,5 \mathrm{~N}$ e $\mathrm{H}_{2} \mathrm{SO}_{4}$ a $1,0 \mathrm{~N}$.

Procurou-se evitar que a concentração de sacarose se tornasse menor que $5 \mathrm{~g} / \mathrm{l}$ através de adição de solução concentrada $500 \mathrm{~g} / 1$ quando necessário. As condições de temperatura e oxigênio dissolvido foram monitoradas e mantidas a $30^{\circ} \mathrm{C}$ e acima de $70 \%$, respectivamente.

A vazão de ar de entrada no biorreator foi constante e igual a $1 \mathrm{~L} / \mathrm{min}$. A amostragem inicial ocorreu em intervalos de 1 hora, posteriormente as amostras foram retiradas entre maiores intervalos de tempo. A pressão parcial de oxigênio e gás carbônico contidas no ar de saída do biorreator também foram registradas através de analisadores de $\mathrm{CO}_{2}$ e $\mathrm{O}_{2}$ do gás de saída do biorreator, da marca Applikon, para realização do balanço gasoso e um fluxômetro de massa marca Bronkhorst High - Tech B.V serie E-7000.

\subsection{Metodologia analítica}

\subsubsection{Determinação de $\mathrm{PHA}$}

A extração de PHA foi realizada através do método de propanólise descrito por Riis e Mai (1988). Colocou-se até $15 \mathrm{mg}$ de massa seca celular previamente liofilizada em tubos de vidro no qual adicionou-se $2 \mathrm{ml}$ de solução de $\mathrm{HCl}$ e propanol $(1: 4 \mathrm{v} / \mathrm{v})$ e $2 \mathrm{ml}$ de 1,2dicloroetano. Utilizou-se como padrão interno $(100 \mu \mathrm{L})$ uma solução de ácido benzóico (40 $\mathrm{g} / \mathrm{l})$. A mistura foi submetida à agitação vigorosa e incubada a $100{ }^{\circ} \mathrm{C}$ por meia hora, sofrendo agitação novamente e depois, reincubada por 2,5 horas.

Após atingida a temperatura ambiente, adicionou-se $4 \mathrm{ml}$ de água destilada e agitou-se em vórtex. Quando observou-se a separação de fases, a inferior orgânica contendo propilésteres, foi recuperada e cerca de $1 \mu \mathrm{L}$ foi submetido à análise por Cromatografia Gasosa $(\mathrm{CG})$.

A injeção fracionada (1:20) em cromatógrafo Agilent 7890A contendo ou a coluna HP5 ((5\%)phenyl-(95\%)dimethylolysiloxanne), ou HP1 (100\% dimethylolysiloxane) determinou a composição de propil-ésteres através de ionização de chama, sob as temperaturas do injetor e detector, respectivamente, iguais a $250{ }^{\circ} \mathrm{C}$ e $300{ }^{\circ} \mathrm{C}$. Utilizou-se hélio como gás de arraste na vazão $0,8 \mathrm{ml} / \mathrm{min}$ ou nitrogênio em $0,6 \mathrm{ml} / \mathrm{min}$. Visando a 
separação dos propil-ésteres, as temperaturas da coluna foram controladas através de um programa que a manteve a $100{ }^{\circ} \mathrm{C}$ por 1 minuto, e à $210^{\circ} \mathrm{C}$ por 15 minutos, aumentando a uma razão de $8{ }^{\circ} \mathrm{C} / \mathrm{min}$ caso utilizada a primeira coluna citada (HP5) e o gás hélio e tempo inicial de $3 \mathrm{~min}$, com aumento de temperatura na razão de $6{ }^{\circ} \mathrm{C} / \mathrm{min}, 180{ }^{\circ} \mathrm{C}$ por $5 \mathrm{~min}$ e temperatura final de $240{ }^{\circ} \mathrm{C}$ caso utilizada a segunda coluna (HP1).

Como padrões externos, foram utilizados PHA de composição conhecida, permitindo a identificação da constituição dos polímeros. Uma vez já obtidos os picos dos padrões, a comparação entre os tempos de retenção é possível. Portanto, as áreas geradas no cromatograma, que se referem aos picos dos propil-ésteres identificados, correspondem à massa e porcentagem de $3 \mathrm{HB}$, em relação à MSC.

Para a determinação do padrão de marcação dos $\mathrm{PHB}$ contendo carbono ${ }^{13} \mathrm{C}$, as amostras foram enviadas à Central Analítica do Instituto de Química da USP, onde foram analisadas por cromatografia gasosa associada a espectrometria de massa utilizando as seguintes configurações: coluna BPX5 (non polar 5\% phenylpolisylphenylene) de $30 \mathrm{~m}$ de comprimento e $0,25 \mathrm{~mm}$ de diâmetro, volume injetado de $5 \mu$, temperatura do forno $100{ }^{\circ} \mathrm{C}$, temperatura do injetor $280^{\circ} \mathrm{C}$, vazão de $2,1 \mathrm{ml} / \mathrm{min}$.

\subsubsection{Determinação de $\mathrm{pH}$}

Os sobrenadantes resultantes da centrifugação das culturas utilizadas nos experimentos foram analisados quanto ao seus $\mathrm{pH}$ em potenciômetro (Tecnal - TEC-2) calibrado com soluções padrão de pH 4 e 7.

\subsubsection{Determinação de Biomassa (Massa Seca Celular - MSC)}

As alíquotas de cultura foram submetidas à centrifugação $\left(8.000 \mathrm{rpm}, 10 \mathrm{~min}, 4{ }^{\circ} \mathrm{C}\right)$ separadas do respectivo sobrenadante e então liofilizadas e pesadas, determinando a concentração de MSC através de gravimetria.

\subsubsection{Determinação de carboidratos}

As concentrações de glicose, frutose e sacarose foram determinadas por cromatografia em fase líquida de alta pressão (HPLC) segundo método descrito por Pereira (1996). Foi 
utilizada coluna Aminex HPX-87H, água purificada pelo sistema Mili-Q (Waters-Millipore) contendo como fase móvel $\mathrm{H}_{2} \mathrm{SO}_{4}$ numa concentração de $0,005 \mathrm{~N}$. A temperatura do detector de índice de refração (IR) e da coluna na qual ocorreram as análises foram de $40{ }^{\circ} \mathrm{C}$ e $45^{\circ} \mathrm{C}$, respectivamente, a uma vazão de $0,6 \mathrm{ml} / \mathrm{min}$ para as análises de glicose e frutose, e de $40{ }^{\circ} \mathrm{C}$ e $30{ }^{\circ} \mathrm{C}$, na vazão $0,3 \mathrm{ml} / \mathrm{min}$ para sacarose.

Utilizou-se como padrão, soluções dos carboidratos diluídas em concentrações previamente conhecidas e submetidas ao HPLC.

\subsubsection{Determinação de ácidos orgânicos}

A análise de ácidos orgânicos foi realizada através de HPLC, de forma similar à análise de carboidratos, porém a análise é feita por meio de detector de ultravioleta, em vez de IR.

Os padrões utilizados como referência para a análise de ácidos orgânicos foram produzidos igualmente aos padrões utilizados nas análises de carboidratos.

\subsubsection{Determinação de nitrogênio amoniacal}

As quantidades de nitrogênio amoniacal foram medidas através da análise do sobrenadante obtidos nas alíquotas dos cultivos. Utilizou-se eletrodo específico para a detecção de amônia em potenciômetro. Uma curva de calibração foi construída com diferentes soluções de concentrações de $\left(\mathrm{NH}_{4}\right)_{2} \mathrm{SO}_{4}$ entre 10 e 500 ppm de nitrogênio. Em $3 \mathrm{ml}$ de sobrenadante das amostras adicionou-se $30 \mu \mathrm{L}$ de $\mathrm{NaOH}$ a $10 \mathrm{M}$.

\subsection{Análise de Fluxos Metabólicos}

A Análise de Fluxos metabólicos têm como princípio que o conjunto de transformações metabólicas intracelulares e o conjunto de transformações de substâncias possíveis entre a célula e o meio representa matematicamente uma matriz de $\mathrm{n}$ reações e $\mathrm{m}$ metabólitos ( $\mathrm{n} \times \mathrm{m})$. Cada linha desta matriz representa uma reação metabólica e cada coluna representará um metabólito que será consumido, produzido, ou não participará da reação (valores negativos, positivos ou iguais a zero), seu valor representa a quantidade 
estequiométrica que participa da determinada reação. Devido ao tamanho da matriz gerada por uma grande rede metabólica, utiliza-se softwares que geram soluções.

Esta análise só é realizada em estados estacionários ou pseudo-estacionários de sistemas biológicos, que significa que o tamanho do pool intracelular não se altera com o tempo do experimentos, condição que é facilmente observada em culturas contínuas, porém também podem ser observadas na fase exponencial de um cultivo descontínuo ("batch") ou batelada alimentada ("fed-batch") com pequenas variações na alimentação (WIECHERT, 2001). Para esta análise, diversos conceitos e observações são de suma importância:

- Em estados estacionários, a velocidade de produção de um metabólito é a mesma que a reação que o consome, tornando as reações independentes das propriedades cinéticas das enzimas.

- Quanto maior o número de restrições aplicadas ao sistema, mais restringido será o universo de fluxos que satisfazem o modelo (CHEN et al., 2011).

- A determinação de pelo menos uma velocidade de fluxo possibilita o conhecimento dos demais fluxos de uma rede metabólica determinada através das relações estequiométricas.

O conjunto de soluções obtido é posteriormente limitado observando os dados experimentais obtidos de determinado micro-organismo na condição analisada, por exemplo, se são geradas soluções que contém a formação de produtos de fermentação quando estes não são observados no experimento, essas soluções serão desconsideradas.

A análise de fluxos metabólicos deste estudo foi realizada através de um arquivo de entrada contendo as vias metabólicas do metabolismo central e de biossíntese de PHB de Burkholderia sacchari (apêndice A). Neste arquivo, implementou-se uma restrição (reação chamada "BIOTOT") que representou as quantidades de polímero sintetizado e quantidade de carboidrato utilizado segundo o experimento analisado. Também foi considerada a reação de formação de biomassa segundo Neidhardt e colaboradores (1990).

Esta restrição tornou possível a seleção, pelo programa, de soluções que cumpriam a relação de açúcares e polímero proposta, que representava as condições do metabolismo que ocorriam nos experimentos. Este conjunto de soluções geradas pelo Metatool continha soluções com fatores de conversão de carboidratos em biomassa ou PHB que se aproximavam 
do obtido experimentalmente, bem como os fatores máximos para as restrições e reações submetidas. Desta forma, foram analisados os modos elementares que possuíam eficiência de conversão similares às calculadas a partir dos resultados experimentais e as máximas apresentadas pelo programa. 


\section{RESULTADOS DISCUSSÃO}

\subsection{Determinação de eficiência de conversão de diferentes substratos em PHB por Burkholderia sacchari e Cupriavidus necator.}

Estes experimentos foram desenhados com o objetivo de se comprovar a eficiência de B. sacchari e C. necator em converter determinados carboidratos em PHB que já haviam sido calculadas e publicadas anteriormente por Gomez e colaboradores em 1996 utilizando sacarose e mistura de glicose com frutose. Neste artigo, o autor descreve um cálculo para a obtenção do valor máximo teórico que estes micro-organismos poderiam converter carboidratos em polímero segundo seus metabolismos centrais.

$$
Y_{\mathrm{P} / \mathrm{C}}^{\mathrm{O}}=\frac{\mathrm{PHB}}{\operatorname{PHB}\left(\frac{1}{Y_{\mathrm{P} / \mathrm{C}}^{\mathrm{T}}}-\frac{1}{Y_{\mathrm{X} / \mathrm{C}}}\right)+\frac{100}{Y_{\mathrm{X} / \mathrm{C}}}} \quad \text { (equação 1) }
$$

Nota: As siglas correspondem ao fator de conversão global de carboidratos em $\mathrm{PHB}(\mathrm{g} / \mathrm{g}), \mathrm{Y}_{\mathrm{P} / \mathrm{C}}^{\mathrm{O}}$; à porcentagem de PHB em relação à biomassa acumulado (\%), PHB; fator de conversão máximo teórico de carboidratos em PHB $(\mathrm{g} / \mathrm{g}), \mathrm{Y}_{\mathrm{P} / \mathrm{C}}^{\mathrm{T}}$; fator de conversão de carboidratos em biomassa $(\mathrm{g} / \mathrm{g}), \mathrm{Y}_{\mathrm{X} / \mathrm{C}}$. $\mathrm{Y}_{\mathrm{P} / \mathrm{C}}^{\mathrm{T}}, \mathrm{Y}_{\mathrm{X} / \mathrm{C}}$ são calculados segundo as vias centrais de cada micro-organismo como demonstrado por Gomez e colaboradores em 1996.

Este cálculo também foi aplicado aos resultados obtidos neste projeto e o percentual do valor de conversão obtido experimentalmente em relação ao máximo teórico foi calculado.

\subsubsection{Burkholderia sacchari}

A linhagem LFM101 foi cultivada em meio mineral, de acordo com a metodologia descrita. Foram testados os açúcares: glicose, frutose, sacarose e mistura de glicose e frutose. Os resultados obtidos quanto a produção de PHB são mostrados na figura 6. Dados apresentados no apêndice B. 
Figura 6 - Variação da produção de PHB por B. sacchari em porcentagem de MSC durante 24, 48 e 72 horas de cultivo. Médias de triplicatas com desvio padrão representado.

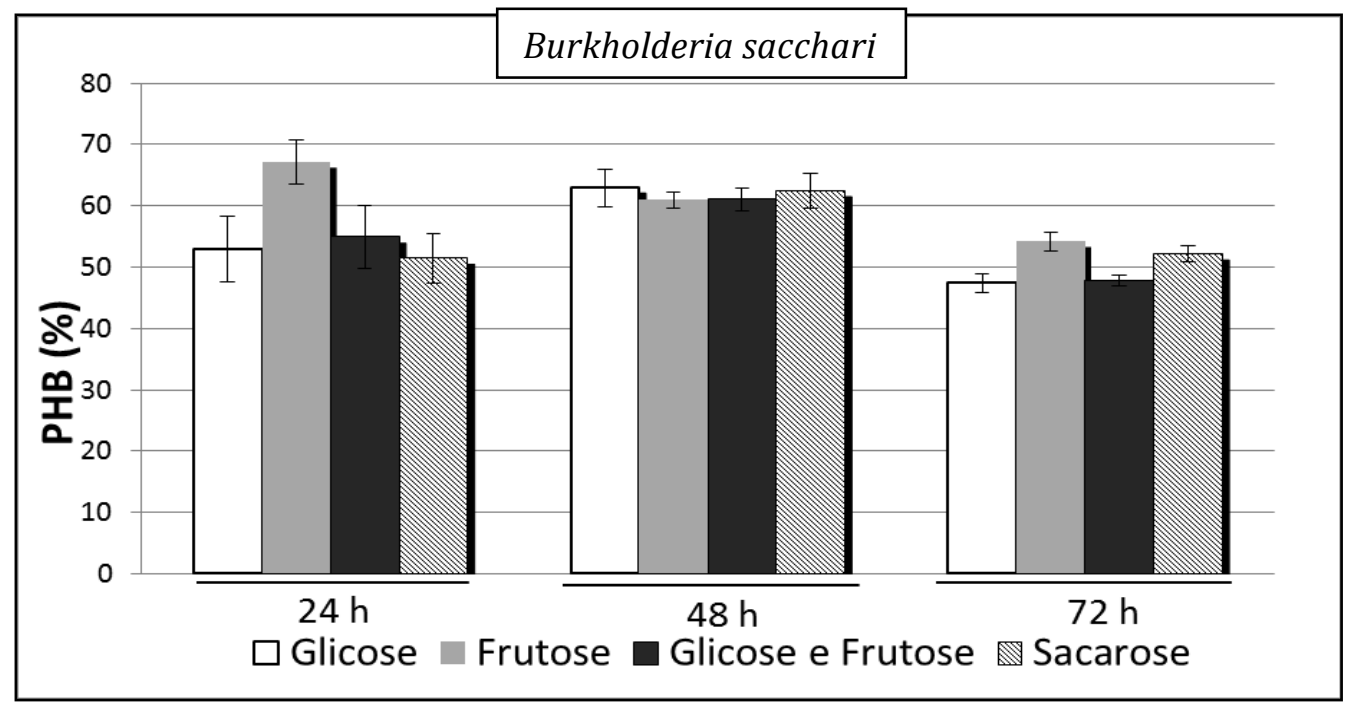

De acordo com os dados apresentados, em 48 h, B. sacchari já havia atingido o valor máximo de acúmulo (aproximadamente $60 \%$ de PHB em relação à massa seca celular (MSC)). Como pode-se observar, em 72 horas de cultivo, já ocorria o consumo de polímero. Esta diminuição do valor de PHB deve-se a limitação de carbono disponível na célula. $\mathrm{O}$ maior valor de acúmulo do polímero foi obtido no cultivo com frutose, em 24 horas, porém, algum erro na medida de PHB pode ter causado este resultado. Nas amostras de 48 horas, a porcentagem de PHB foi semelhante para todos os açúcares utilizados.

Segundo o objetivo do experimento, confirmou-se que a eficiência de B.sacchari na conversão de carboidratos em PHB é de aproximadamente $80 \%$ do máximo teórico calculado (tabela 6), sendo possível então, o estudo de melhoramento desta eficiência metabólica. 
Tabela 6 - Valores de conversão de carboidratos em PHB ( $\left.\mathrm{Y}_{\mathrm{PHB} / \mathrm{C}}\right)$ obtidos por B. sacchari (LFM101) neste estudo comparados aos obtidos no artigo Gomez et al. (1996).

\begin{tabular}{|c|c|c|c|c|c|}
\hline & & $Y_{\mathrm{PHB} / \mathrm{C}}(\mathrm{g} / \mathrm{g})$ & PHB (\%) & $Y_{\text {Máx }}{ }^{2}(g / g)$ & $\% Y_{\mathrm{PHB} / \mathrm{C}} / \mathbf{Y}_{\text {Máx }}{ }^{b}$ \\
\hline \multirow[t]{2}{*}{ Glicose } & Este estudo & 0,26 & 62,86 & 0,31 & 86,19 \\
\hline & $\begin{array}{c}\text { Gomez et al. } \\
\text { (1996) }\end{array}$ & $\mathrm{NA}^{\mathrm{c}}$ & NA & NA & NA \\
\hline \multirow[t]{2}{*}{ Frutose } & Este estudo & 0,24 & 60,98 & 0,30 & 81,11 \\
\hline & Gomez et al. (1996) & NA & NA & NA & NA \\
\hline \multirow[t]{2}{*}{ Gli + Fru } & Este estudo & 0,26 & 61,09 & 0,30 & 87,82 \\
\hline & Gomez et al. (1996) & 0,23 & $\mathrm{ND}^{\mathrm{d}}$ & 0,29 & 80,00 \\
\hline \multirow[t]{2}{*}{ Sacarose } & Este estudo & 0,27 & 62,46 & 0,30 & 88,63 \\
\hline & Gomez et al. (1996) & 0,23 & ND & 0,29 & 80,00 \\
\hline \multicolumn{6}{|c|}{$\begin{array}{l}\text { Notas: }{ }^{\text {a }} \text { Fator de conversão máximo de carboidrato em PHB, para a porcentagem de PHB específica } \\
\text { calculado segundo Gomez et al. (1996). } \\
\text { b Porcentagem do fator de conversão obtido em relação ao máximo calculado. } \\
{ }^{\mathrm{c}} \text { Não avaliado no artigo. } \\
{ }^{\mathrm{d}} \text { Não disponível no artigo }\end{array}$} \\
\hline
\end{tabular}

\subsubsection{Cupriavidus necator}

O cultivo realizado com $C$. necator nas mesmas condições anteriormente citadas, porém não foi utilizada sacarose como fonte de carbono, já que esta linhagem não hidrolisa este carboidrato, também obteve a máxima produção em 48 horas, sendo esta igual a aproximadamente $70 \%$ de PHB da biomassa total, pouco maior que a de B. sacchari $(60 \%)$ (figura 7). Dados detalhados apresentados no apêndice C. 
Figura 7 - variação da produção de PHB por C. necator em porcentagem de MSC durante 24, 48 e 72 horas de cultivo. Médias de triplicatas com desvio padrão representado.

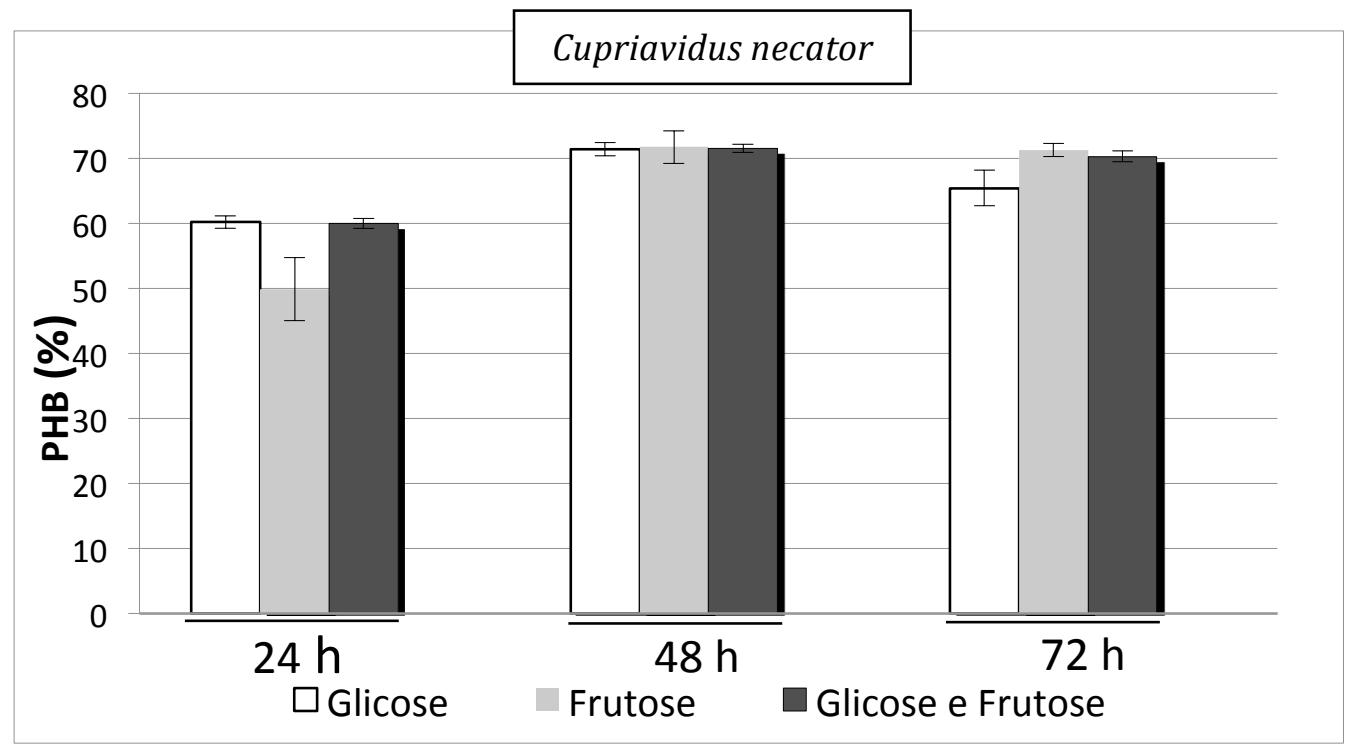

A eficiência de conversão dos carboidratos testados também neste experimento foram similares aos do artigo Gomez e colaboradores (1996) sendo muito próximas ao máximo teórico (cerca de 90\%) (tabela 7).

Tabela 7 - Valores de conversão de carboidratos em PHB (Y $\left.\mathrm{Y}_{\mathrm{PHB} / \mathrm{C}}\right)$ por C. necator (DSM545) obtidos neste estudo comparados aos obtidos no artigo Gomez et al. (1996).

\begin{tabular}{|c|c|c|c|c|c|}
\hline & & $Y_{\mathrm{PHB} / \mathrm{C}}(\mathrm{g} / \mathrm{g})$ & PHB (\%) & $Y_{\text {Máx }}^{a}(g / g)$ & $\% \mathbf{Y}_{\mathrm{PHB} / \mathrm{C}} / \mathbf{Y}_{\mathbf{M a ́ x}} \mathbf{b}$ \\
\hline \multirow[t]{2}{*}{ Glicose } & Este estudo & 0,33 & 71,39 & 0,35 & 94,29 \\
\hline & $\begin{array}{c}\text { Gomez et al. } \\
\text { (1996) }\end{array}$ & $\mathrm{NA}^{\mathrm{c}}$ & NA & NA & NA \\
\hline \multirow[t]{2}{*}{ Frutose } & Este estudo & 0,33 & 71,7 & 0,35 & 94,29 \\
\hline & $\begin{array}{c}\text { Gomez et al. } \\
\text { (1996) }\end{array}$ & $\sim 0,31$ & $\mathrm{ND}^{\mathrm{d}}$ & 0,34 & $\sim 90$ \\
\hline \multirow[t]{2}{*}{ Gli + Fru } & Este estudo & 0,32 & 71,53 & 0,35 & 91,43 \\
\hline & $\begin{array}{c}\text { Gomez et al. } \\
\text { (1996) }\end{array}$ & $\sim 0,32$ & ND & 0,35 & $\sim 90$ \\
\hline
\end{tabular}

Notas: ${ }^{\text {a }}$ Fator de conversão máximo de carboidrato em PHB, para a porcentagem de PHB específica, calculado segundo Gomez et al. (1996).

${ }^{\mathrm{b}}$ Porcentagem do fator de conversão obtido em relação ao máximo calculado.

${ }^{\mathrm{c}}$ Não avaliado no artigo.

${ }^{\mathrm{d}}$ Não disponível no artigo

Estes resultados confirmam os dados apresentados no artigo de referência e ressaltam a importância do estudo da distribuição de fluxos metabólicos em B. sacchari com o objetivo de aumentar a atual eficiência de $80 \%$ como já ocorre em C. necator. 


\subsection{Produção de PHB em biorreator a partir de sacarose utilizando meio MB1 - EB1}

O cultivo de Burkholderia sacchari em biorreator foi realizado como descrito anteriormente na metodologia. Medidas de PHA, açúcares e biomassa (total e residual) foram aferidas. Este experimento teve como objetivo observar as condições de acúmulo de polímero pela linhagem sob oferta de sacarose para submetê-las a Análise de Fluxos Metabólicos (AFM) e à análise de modos elementares.

Além disso, os experimentos em biorreator possuem vantagens em relação aos ensaios em agitador rotativo, já que pode-se, por exemplo, determinar as taxas de consumo de oxigênio e de formação de gás carbônico, importantes para a AFM, pois o gás carbônico faz parte do cálculo de balanço de carbonos. Também permitem determinar os diferentes estados pseudo-estacionários (definidos na metodologia) em que ocorre acúmulo de PHB juntamente, ou não, ao crescimento celular.

Foram realizadas quatro adições de sacarose durante as 45 horas totais de cultivo (figura 8). De uma solução de sacarose a $500 \mathrm{~g} / \mathrm{l}$, aproximadamente, adicionou-se nos tempos de cultivo: $5,75 \mathrm{~h} ; 12,50 \mathrm{~h} ; 15,91 \mathrm{~h}$ e $29 \mathrm{~h}$, respectivamente, $31,23 \mathrm{ml} ; 45,43 \mathrm{ml} ; 30,25 \mathrm{ml}$ e $24,07 \mathrm{ml}$.

O acúmulo máximo de PHB obtido neste experimento equivaleu a, aproximadamente, $80 \%$ da massa seca e foi obtido após 16 h de cultivo, após a concentração de nitrogênio ser menor que $0,40 \mathrm{~g} / 1$ (apêndice D). A concentração inicial de biomassa foi de aproximadamente $0,6 \mathrm{~g} / 1$. 
Figura 8 - Variação de consumo de sacarose, formação de biomassa e produção de PHB durante $32 \mathrm{~h}$ do cultivo em biorreator.

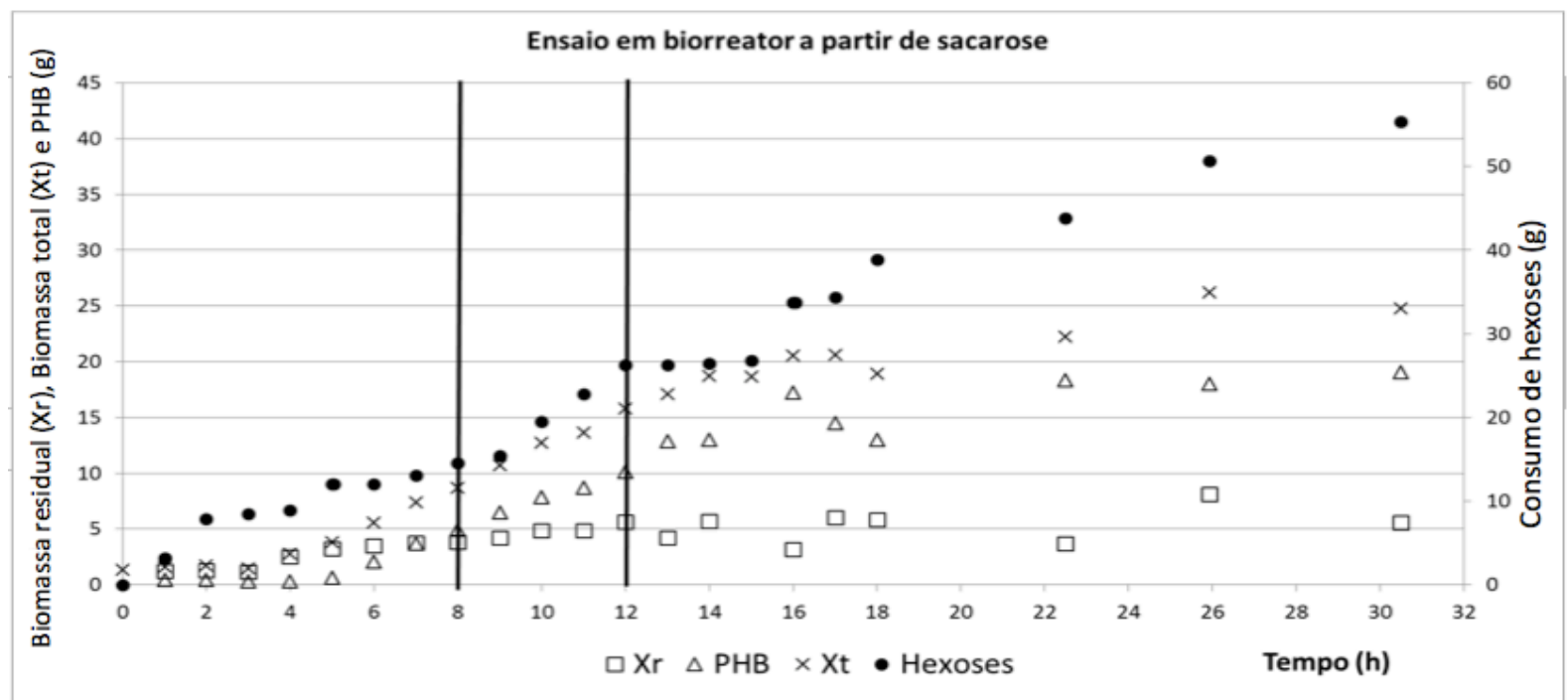

Nota: As barras verticais destacam o intervalo correspondente a um estado pseudo-estacionário (8 a 12 horas).

Pode-se verificar o estabelecimento aparente de duas fases pseudo-estacionárias, que foram definidas em dois intervalos de tempo: de 8 a 12 horas e de 18 a 30,5 horas de cultivo. No primeiro estado pseudo-estacionário observa-se o máximo crescimento celular, juntamente com o máximo de acúmulo do polímero.

Além disso, pode-se observar, no primeiro intervalo proposto, as velocidades de CER (carbon evolution rate) e OUR (oxygen uptake rate) determinadas através de analisadores de gases acoplados ao reator, e que representam, respectivamente, as taxas de formação de $\mathrm{CO}_{2} \mathrm{e}$ consumo de $\mathrm{O}_{2}$ (figura 9). Estas velocidades calculadas para este período ( 8 a 12 horas) foram consideradas constantes, caracterizando um estado pseudo-estacionário. 
Figura 9 - Gráfico relacionando velocidades de consumo de $\mathrm{O}_{2}$ (OUR - oxygen uptake rate) e formação de $\mathrm{CO}_{2}$ (CER - carbono evolution rate) de cultivo a partir de sacarose.

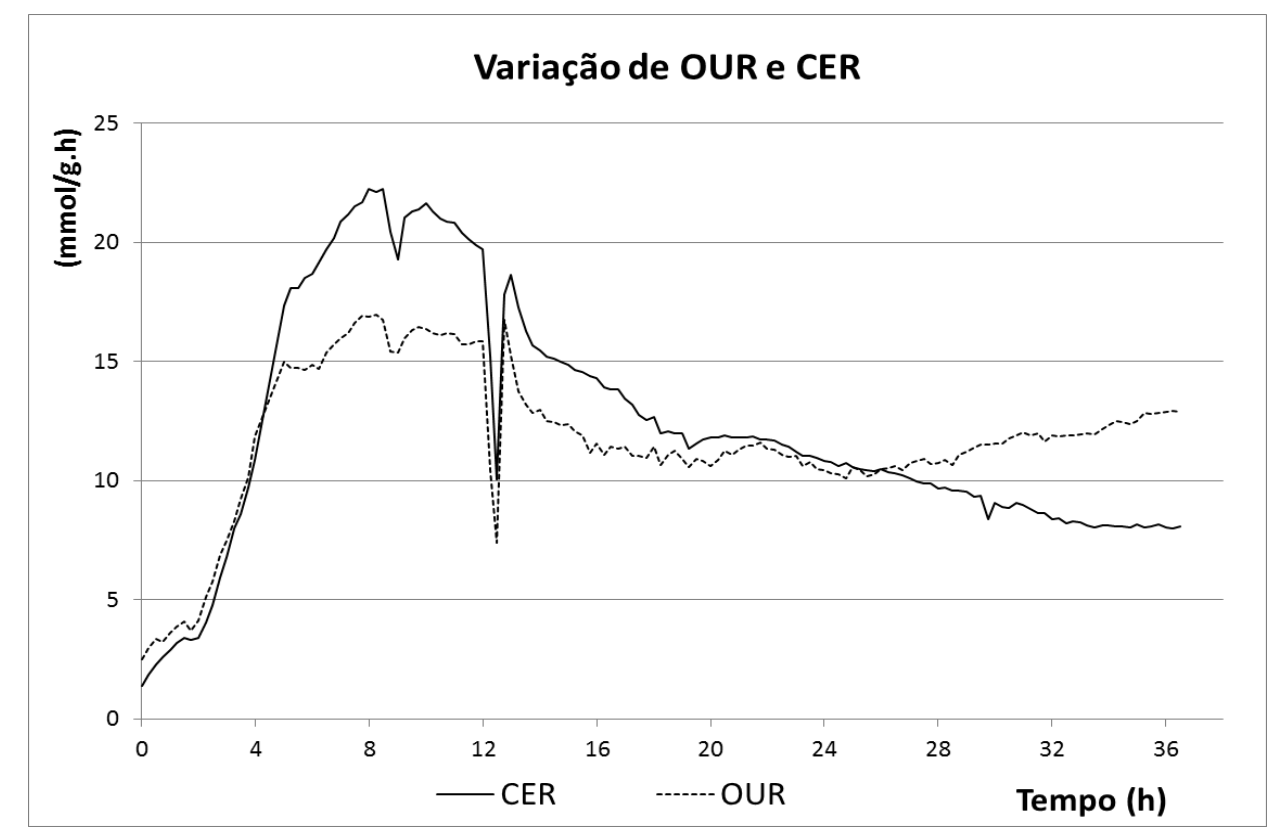

No primeiro intervalo (8 a 12 horas) (figura 10), onde ocorreu a fase exponencial de crescimento, foi possível determinar como $0,09 \mathrm{~h}^{-1}\left(\mathrm{R}^{2}: 0,95\right)$ (apêndice D) a velocidade específica máxima de crescimento celular $\left(\mu_{\text {máx }}\right)$, muito reduzida comparada aos outros experimentos discutidos a seguir. A linhagem teve os fatores de conversão de açúcar em biomassa e PHB iguais a $0,16 \mathrm{~g} / \mathrm{g}$ e $0,40 \mathrm{~g} / \mathrm{g}$, sendo o último similar ao máximo teórico $(0,39$ $\mathrm{g} / \mathrm{g}$ ) obtido através do cálculo publicado por Gomez e colaboradores (1996), em que são considerados os valores máximos de conversão teórica de sacarose em biomassa igual a 0,52 $\mathrm{g} / \mathrm{g}$ e em PHB de $0,50 \mathrm{~g} / \mathrm{g}$. 
Figura 10 - Curvas de concentração de hexoses consumidas, PHB e XR (g/l) características do estado pseudo-estacionário analisado.

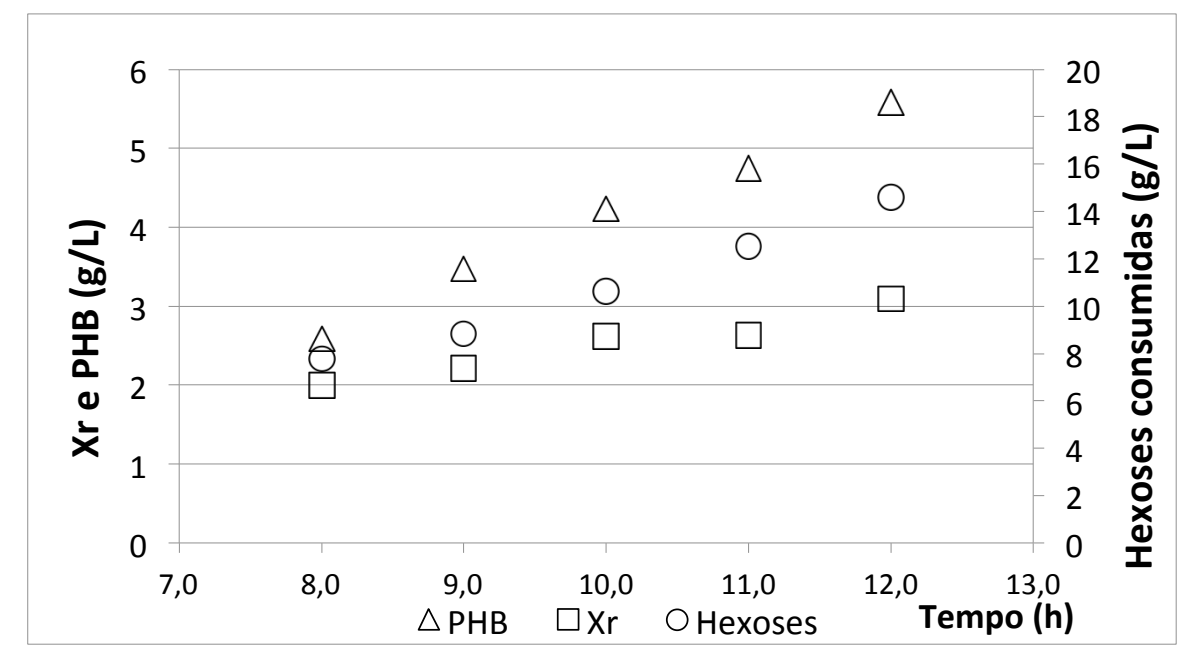

Para avaliar o destino dos carbonos provenientes do carboidrato disponibilizado (sacarose convertida em hexoses), fez-se um balanço de carbonos, em que se observa carbonos desviados para a formação de $\mathrm{PHB}, \mathrm{CO}_{2}$ e biomassa $(\mathrm{Xr})$. O balanço de carbonos (tabela 8), ou recuperação de carbonos, calculado para o primeiro estado pseudo-estacionário foi igual a $111,12 \%$. Considerando um desvio experimental de aproximadamente $10 \%$, este dado comprova que os carbonos da sacarose estão sendo desviados, em sua totalidade, para a formação de $\mathrm{PHB}, \mathrm{CO}_{2}$ e Xr.

Tabela 8 - Dados de velocidades de consumo de sacarose, formação de biomassa residual (Xr), PHB e $\mathrm{CO}_{2}$ utilizados para balanço de carbonos do primeiro intervalo (8 a 12 horas).

\begin{tabular}{cccccc}
\hline & Hexoses & $\mathbf{X r}$ & $\mathbf{P H B}$ & $\mathbf{C O}_{\mathbf{2}}$ & \\
\hline Massa Molar & & & & & \\
g/L.h & 180 & 0,5 & 86 & 28,01 & \\
mmol/L.h & 1,74 & 0,26 & 0,73 & & \\
Carbono mmol/l.h & 9,66 & & 8,48 & 19,59 & \\
Total (\%) & 57,93 & 10,85 & 33,93 & 19,59 & \\
\hline
\end{tabular}

O balanço de carbonos correspondente ao segundo estado pseudo-estacionário, quando só ocorre acúmulo de $\mathrm{PHB}$, foi inferior a 100\% (aproximadamente 88,26\%), o que impediu a análise detalhada deste intervalo, já que, possivelmente, outros produtos contendo carbonos estão sendo formados, porém não foi possível detectá-los e identificá-los. 


\subsection{Produção de PHB em biorreator a partir de glicose utilizando meio MB1 - EB2}

Com o objetivo de comparar o crescimento e acúmulo de PHB por LFM101 em sacarose e glicose, este experimento foi conduzido de forma similar ao experimento anterior, modificando, apenas, a fonte de carbono.

O cultivo durou aproximadamente 50 horas, realizou-se três alimentações de glicose, feitas nos tempos: 13 h, 23,17 h e 35 h. Os volumes da solução de alimentação a $500 \mathrm{~g} / 1$ foram, respectivamente: $40 \mathrm{ml}, 41,67 \mathrm{ml}, 37,92 \mathrm{ml}$. As adições foram feitas quando as concentrações de glicose atingiam valores próximos a $5 \mathrm{~g} / \mathrm{l}$, e tinham o intuito de evitar a modificação do crescimento ou acúmulo pela diminuição da oferta de carboidratos. Dados detalhados apresentados no apêndice E.

O máximo de acúmulo do polímero foi obtido em, aproximadamente, 17 horas de cultivo (figura 11), após atingir a concentração de $0,23 \mathrm{~g} / 1$ de nitrogênio (apêndice E). Este valor foi próximo a 70\% em relação à MSC e foi menor, comparativamente ao experimento anterior, em que houve a produção de $80 \%$ de PHB em relação à MSC. A concentração inicial de biomassa foi próxima a $0,47 \mathrm{~g} / 1$, também menor que no cultivo contendo sacarose.

Figura 11 - Variação de consumo de glicose, formação de biomassa e produção de PHB durante o cultivo em biorreator.

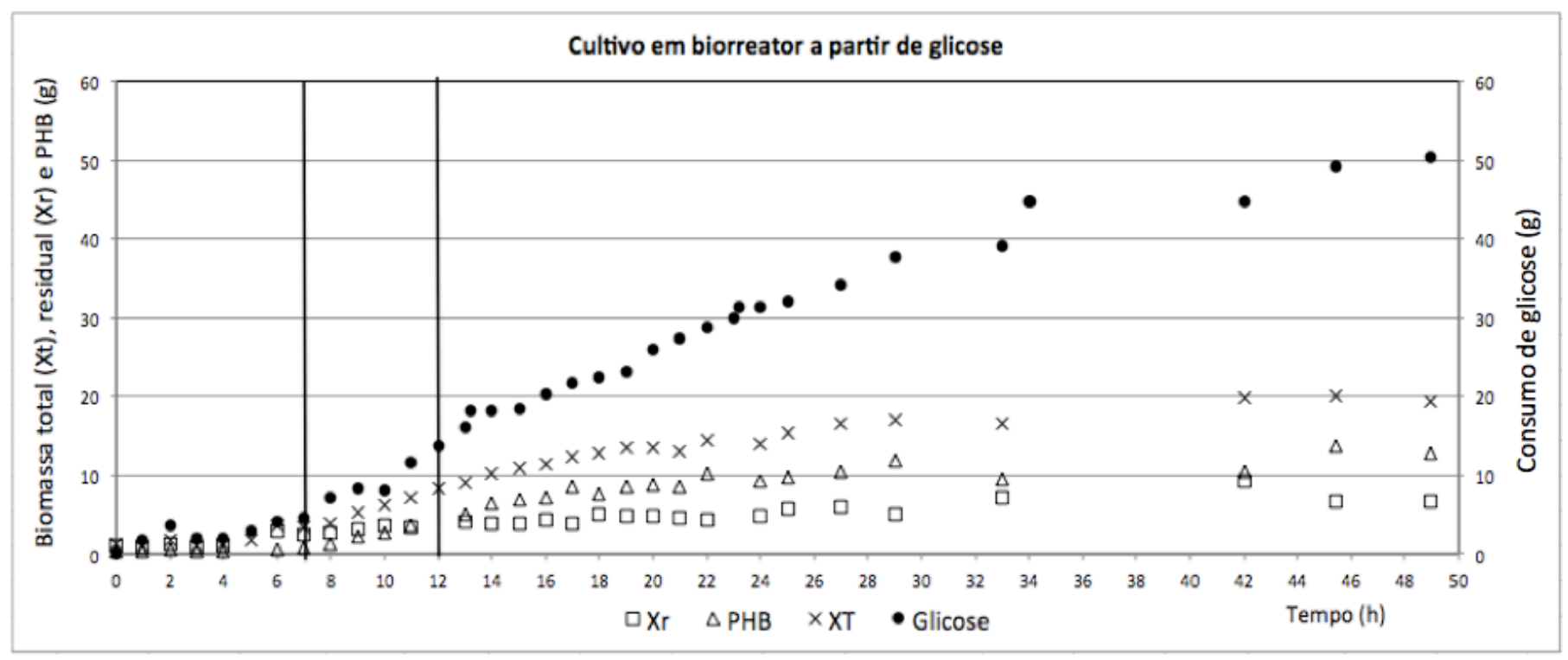

Nota: Barras verticais indicam o intervalo analisado (7 a 12 horas).

Neste experimento, os estados pseudo-estacionários não se mostraram tão claros como no cultivo contendo sacarose. Porém, pela observação da variação das concentrações de PHB 
e Xr, supôs-se uma fase exponencial de 7 a 12 horas de experimento, apesar de as velocidades de consumo de $\mathrm{O}_{2}$ e $\mathrm{CO}_{2}$ não serem constantes neste intervalo (figura 12).

Figura 12 - Gráfico relacionando velocidades de formação de $\mathrm{O}_{2}$ (OUR - oxygen uptake rate) e consumo de $\mathrm{CO}_{2}$ (CER - carbon evolution rate) de cultivo a partir de glicose.

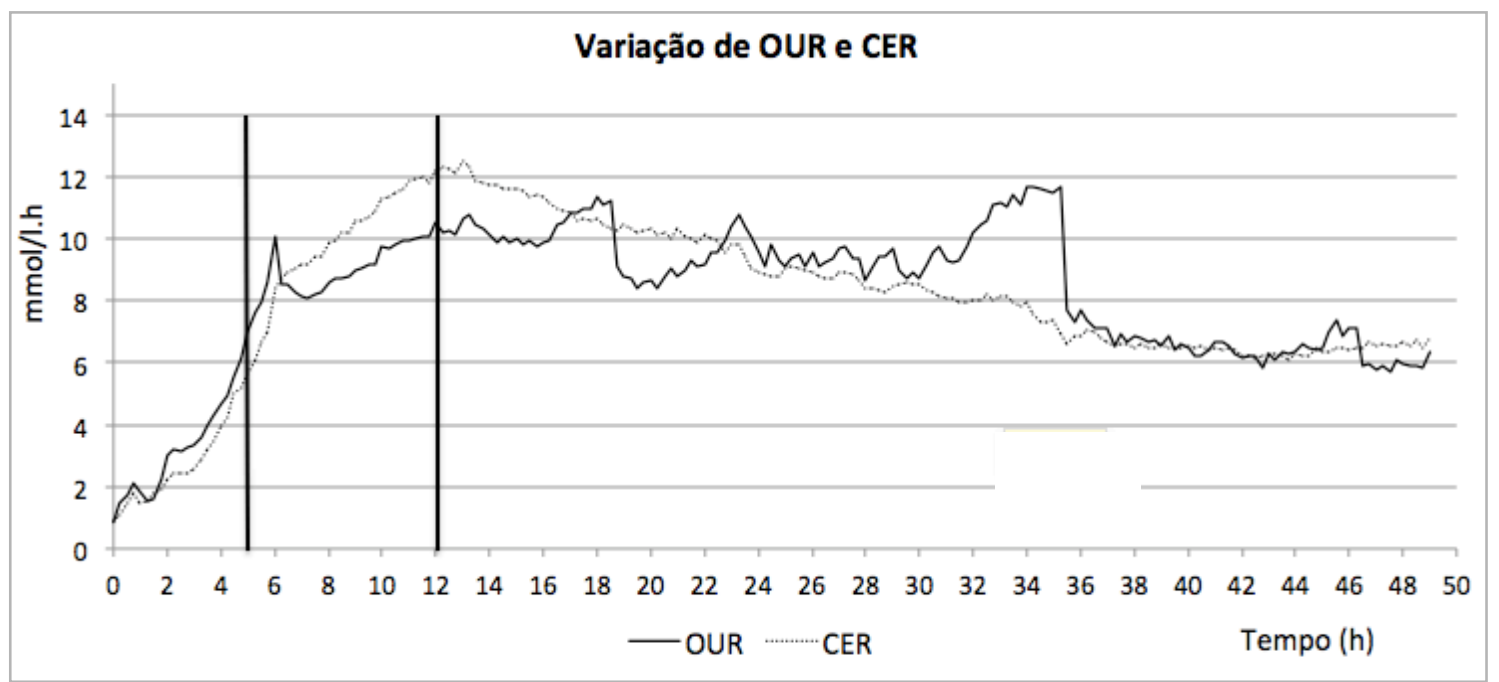

Nota: Barras verticais indicam intervalo analisado (5 a 12 horas).

Nesta fase, assim como no experimento EB1, houve acúmulo associado ao crescimento celular. Na fase posterior a $12 \mathrm{~h}$, a velocidade da concentração celular tende a manter-se constante e a velocidade de síntese do PHB decresce em relação ao período anterior. A velocidade máxima específica de crescimento foi igual a $0,09 \mathrm{~h}^{-1}\left(\mathrm{R}^{2}: 0,9362\right)$. A biomassa total foi igual a 14,18 g/l (figura 13). 
Figura 13 - Curvas de concentração de glicose, PHB e XR para cálculo de balanço de carbonos. Curva de LnXr utilizada para cálculo de velocidade específica de crescimento.

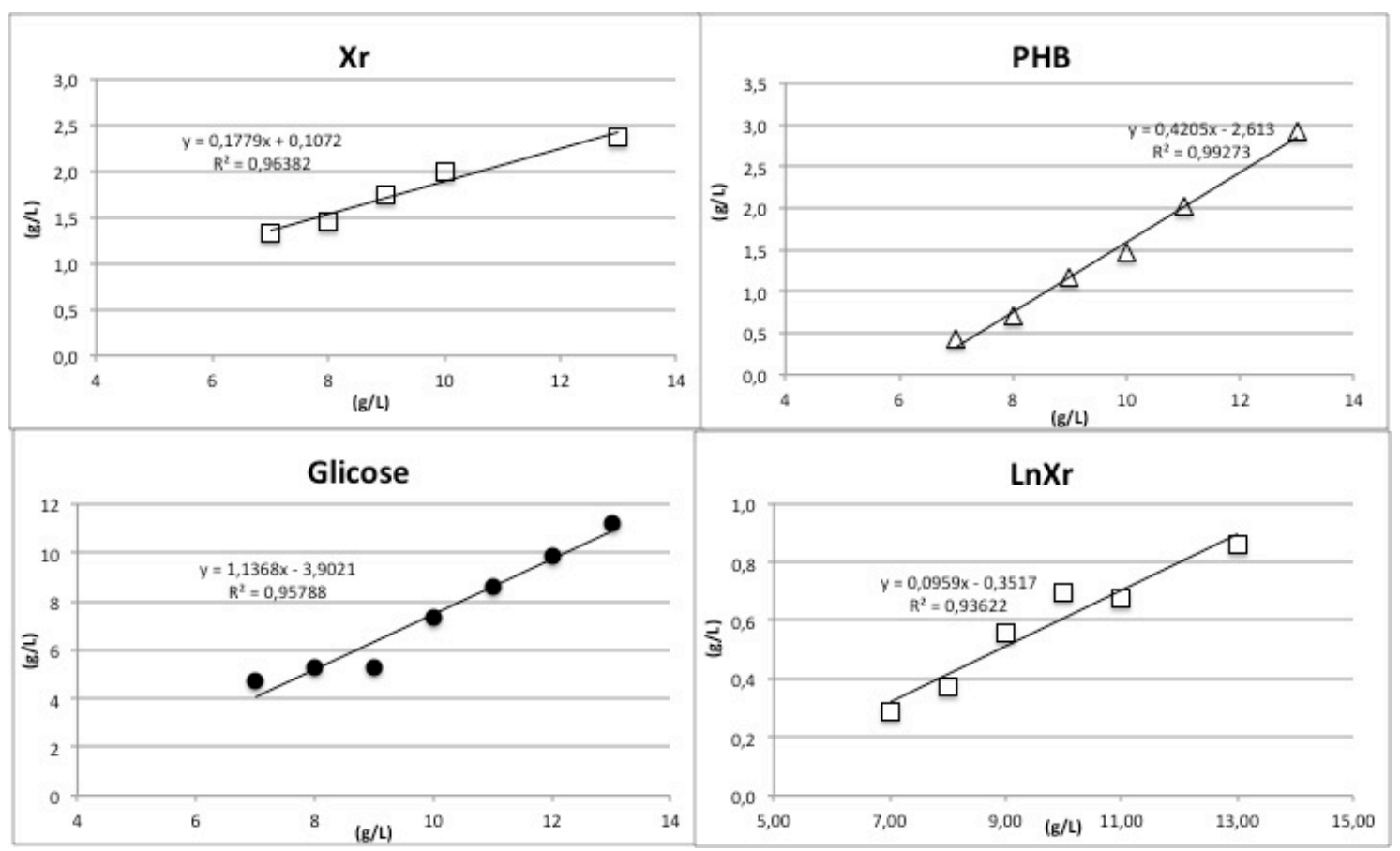

Já o balanço de carbonos calculado para o primeiro estado pseudo-estacionário foi igual a $100,04 \%$, demonstrando, mais uma vez, que no primeiro estado pseudo-estacionário, os carbonos desviam-se para a produção de biomassa, $\mathrm{PHB}$ e $\mathrm{CO}_{2}$ e não há produção de outros compostos como ácidos, por exemplo. As velocidades de glicose, $\mathrm{PHB}, \mathrm{Xr}$ e $\mathrm{CO}_{2}$ foram, respectivamente: $37,89 \mathrm{mmol} / \mathrm{l} . \mathrm{h}, \quad 19,53 \mathrm{mmol} / \mathrm{l} . \mathrm{h}, \quad 7,37 \mathrm{mmol} / \mathrm{l} . \mathrm{h}$ e $11 \mathrm{mmol} / \mathrm{l} . \mathrm{h}$. Comparativamente ao experimento realizado no biorreator com oferta de sacarose, a velocidade de consumo de açúcares e produção de $\mathrm{CO}_{2}$ obtidas neste cultivo corresponderam a quase $50 \%$ dos respectivos valores do experimento anterior.

A conversão de glicose em biomassa $\left(\mathrm{Y}_{\mathrm{Xr} / \mathrm{C}}\right)$ calculada para o período pseudoestacionário (no intervalo 7 a 12 horas) foi igual a $0,17 \mathrm{~g} / \mathrm{g}$. Já o $\mathrm{Y}_{\mathrm{PHB} / \mathrm{C}}$ foi de 0,46 g/g, que equivale a $97 \%$ do valor do máximo teórico $(0,48 \mathrm{~g} / \mathrm{g})$.

Podemos concluir de maneira preliminar que no estado pseudo-estacionário analisado, em que ocorre crescimento e acúmulo do polímero, a eficiência máxima de conversão de glicose em PHB foi atingida. 


\subsection{Análise de modos elementares de cultivo de B. sacchari a partir de glicose}

Foram implementados no programa Metatool os dados do artigo publicado por Gomez e colaboradores em 1996, no qual estudou-se a produção de PHB por IPT101 (na época, ainda não identificada como Burkholderia sacchari) e outros isolados a partir de fontes de carbono como sacarose e mistura de glicose e frutose. O valor de acúmulo de PHB em relação à massa seca obtido no artigo (aproximadamente 68\%) foi utilizado como restrição aos resultados gerados pelo programa de forma a verificar a distribuição de fluxos metabólicos nesta condição. O fator de conversão de sacarose em PHB calculado no artigo para este experimento foi de $0,29 \mathrm{~g} / \mathrm{g}$. Com este dado, selecionou-se dos modos elementares gerados pelo Metatool, o que gerava um fator de conversão similar (apêndice F).

Paralelamente, utilizou-se o dado de $80 \%$ de acúmulo de PHB em relação à MSC para a análise dos fluxos metabólicos nesta condição. Dessa maneira, foi realizada a análise de modos elementares, com o objetivo de verificar os fluxos do metabolismo da linhagem quando ocorre o máximo teórico (obtido no estado pseudo-estacionário do experimento com glicose em biorreator) e compará-lo aos fluxos gerados pelo programa na condição de acúmulo obtida no artigo $(68,5 \%)$.

Estes modos elementares foram selecionados de acordo com a similaridade dos valores de conversão de carboidrato em biomassa calculados nestas condições com os valores experimentais obtidos. Para cultivo a partir de sacarose com 68,5\% de PHB em relação à $\mathrm{MSC}$, o $\mathrm{Y}_{\mathrm{PHB} / \mathrm{C}}$ foi igual a $0,29 \mathrm{~g} / \mathrm{g}$, para o experimento em biorreator a partir de glicose, $80 \%$ de $\mathrm{PHB}$, o $\mathrm{Y}_{\mathrm{PHB} / \mathrm{C}}$ foi de $0,46 \mathrm{~g} / \mathrm{g}$.

$\mathrm{O} \mathrm{Y}_{\mathrm{PHB} / \mathrm{C}}$ calculado no modo elementar selecionado para o acúmulo a partir de sacarose foi exatamente igual ao obtido por no artigo comparado $(0,29 \mathrm{~g} / \mathrm{g})$. Ou seja, este modo elementar representa os fluxos metabólicos obtidos neste experimento, em que não ocorreu a eficiência máxima da linhagem, ou seja, este valor está abaixo do calculado através da fórmula (equação 1). Já no experimento utilizando glicose como fonte de carbono, o $\mathrm{Y}_{\mathrm{PHB} / \mathrm{C}}$ do período pseudo-estacionário analisado (em que ocorreu acúmulo e crescimento simultaneamente) correspondeu a $0,37 \mathrm{~g} / \mathrm{g}$ e $\mathrm{Y}_{\mathrm{Xr} / \mathrm{C}}$ a 0,16 . Ao calcular o valor máximo teórico deste período, encontrou-se que estes eram iguais. Ou seja, neste período, B. sacchari conseguiu converter carboidratos em PHB com sua eficiência máxima. Analisando os modos elementares gerados pelo programa Metatool, um modo elementar contendo estes valores de eficiência máxima foi encontrado e este foi, então, identificado como sendo correspondente 
ao deste experimento e sendo, portanto, a distribuição de fluxos metabólicos característica de quando a linhagem obtem a conversão de carboidratos em PHB mais eficiente possível.

Ainda, ao analisar as diferenças entre o direcionamento dos fluxos de ambos modos elementares obtidos nos dois experimentos, pode-se perceber que o correspondente ao acúmulo de $80 \%$ de PHB a partir de glicose possui fluxo nas reações chamadas GLN (Gliconeogênese), que formam uma apresentação cíclica da via Entner-Doudoroff que, por sua vez, gera poder redutor (NADPH), necessário para a síntese de polihidroxialcanoatos, já que a enzima acetoacetil-CoA redutase (phaB) é NADPH dependente (figuras 14 e 15).

Além disso, este modo elementar não possui fluxo em várias reações do Ciclo de Krebs (CK), reduzindo a parcela de carbono direcionada à respiração celular, desviando-a para a produção do polímero (figura 15).

Estas duas características do metabolismo desta linhagem influem positivamente na eficiência de síntese de PHB e devem ser consideradas quando deseja-se buscar parâmetros de cultivo objetivando atingir o máximo teórico da linhagem. Além disto, a engenharia metabólica que favoreça estas características nesta linhagem (bloqueando, por exemplo outras reações em que carbonos sejam direcionados a outros intermediários) favoreceriam a obtenção desta eficiência máxima. Ainda, como a condição em que se obteve esta máxima conversão foi quando ocorreu crescimento e acúmulo simultâneos desta linhagem, esta condição deve ser explorada e mantida, através de cultivos contínuos, por exemplo, para obter-se períodos maiores em que a eficiência de produção de PHB seja a máxima teórica. 
Figura 14 - Quadro contendo valores dos fluxos metabólicos gerados pelo programa Metatool, relativos ao fluxo de entrada da sacarose ou glicose (reações SAC e EMP1, respectivamente). Destacados em cinza: valores correspondentes ao modo elementar representando o acúmulo de $80 \%$ de PHB em relação à biomassa, condição em que ocorreu o máximo teórico. Em fundo branco, modo elementar contendo fluxos da condição de $68 \%$ de acúmulo de PHB.

\begin{tabular}{|c|c|c|c|c|c|c|c|c|c|c|c|c|c|c|c|c|c|c|}
\hline $\begin{array}{c}\text { PHB } \\
(\% \text { MSC })\end{array}$ & SAC & EMP1 & FRU & VP1 & ED1 & ED2 & GLN1 & GLN2 & GLN3 & EMP10 & CPD & CK1 & CK2 & CK3 & CK6 & CK7 & CK8 & CGLX1 \\
\hline $80 \%$ & - & 1 & - & 1,18 & 1,18 & 1,18 & 0,19 & 0,19 & 0,19 & 0,74 & 1,81 & 0,02 & 0,02 & 0,02 & 0 & 0 & 0 & 0 \\
\hline \multirow[t]{2}{*}{$68 \%$} & 1 & 1 & 1 & 1,95 & 1,95 & 1,95 & 0 & 0 & 0 & 2,67 & 4,49 & 1,02 & 1,02 & 0,05 & 0,97 & 0,97 & 1,94 & 0,97 \\
\hline & $\begin{array}{c}\text { CGLX } \\
2\end{array}$ & AD1 & AD2 & BIOMASSA & OXFAD & OXNAD & P3HB & BIOTOT & EMP2 & EMP6 & EMP7 & EMP8 & EMP9 & VP6 & VP7 & VP8 & VP9 & VP10 \\
\hline $80 \%$ & 0 & 0,05 & 0 & 0,000018 & 0 & 1 & 0,86 & 0,00 & $-0,18$ & 0,77 & 0,77 & 0,75 & 0,75 & 0,01 & $-0,01$ & $-0,003$ & $-0,003$ & $-0,01$ \\
\hline $68 \%$ & 0,97 & 0 & 0,84 & 0,000046 & 0,97 & 8,52 & 1,16 & 0,00 & $-0,96$ & 1,92 & 1,92 & 1,85 & 1,85 & 0,03 & $-0,03$ & $-0,01$ & $-0,01$ & $-0,02$ \\
\hline
\end{tabular}

Nota: A identificação das reações (SAC, EMP1, FRU, VP1, ED1 etc) encontra-se no apêndice A juntamente com a lista de abreviaturas e siglas 
Figura 15 -Diagrama do mapa metabólico de B. sacchari contendo valores relativos aos fluxos de vias metabólicas obtidos através do software Metatool na condição de acúmulo de $80 \%$ de PHB em que obteve-se eficiência máxima téorica de conversão de carboidratos em PHB. Fluxos são normalizados de acordo com o fluxo de entrada do substrato na célula (GLIEXT $\rightarrow$ G6P).

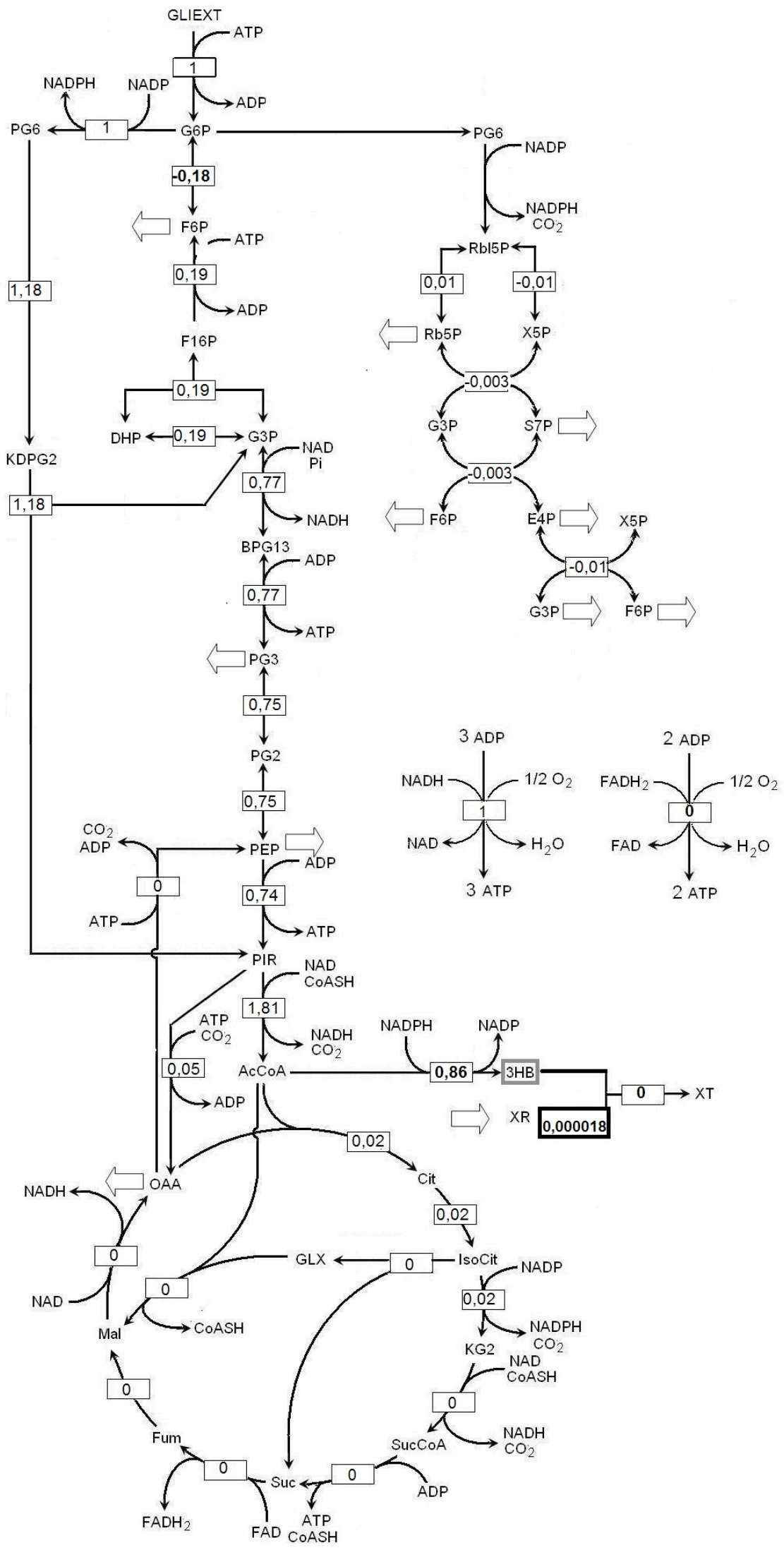


A título de exemplo, recentemente, Taciro (2008), analisando fluxos metabólicos de produção de PHA em Pseudomonas putida, verificou que o passo limitante era a disponibilidade de poder redutor para a biossíntese. Ou seja, para melhorar a produção de PHA, a melhor estratégia seria manipular a via geradora de NADPH (via de EntnerDoudoroff) e não diretamente a via de síntese de PHA como poderia ser óbvio.

A próxima etapa, então correspondeu à exploração do perfil de crescimento da linhagem de forma a estabelecer-se melhor a fase em que ocorre o máximo de eficiência de produção do polímero.

\subsection{Cultivos em biorreator com meio mineral balanceado (MB2) - EB3 e EB4}

Observou-se nos cultivos em biorreator previamente discutidos, que o crescimento exponencial era sempre limitado (figura 8 e 11), sofrendo alguma limitação nutricional, o que poderia impedir a visualização de fases separadas de acúmulo de polímero e crescimento. Visando solucionar este problema, novos experimentos em reator foram realizados, com concentrações aumentadas de cloreto de cálcio e citrato férrico no meio mineral utilizado (meio de cultura identificado como MB2). Aumentou-se em 10 vezes estas concentrações para torná-los abundantes e não limitantes.

Esta estratégia resultou em uma fase exponencial mais expressiva (dados apresentados no apêndice $\mathrm{G}$ e $\mathrm{H}$ e figuras 16 e 17). No experimento em biorreator EB3, a fonte de carboidrato utilizada foi sacarose e em EB4, glicose. 
Figura 16 - Variação de consumo de sacarose, formação de biomassa e produção de PHB durante o cultivo em biorreator (EB3).

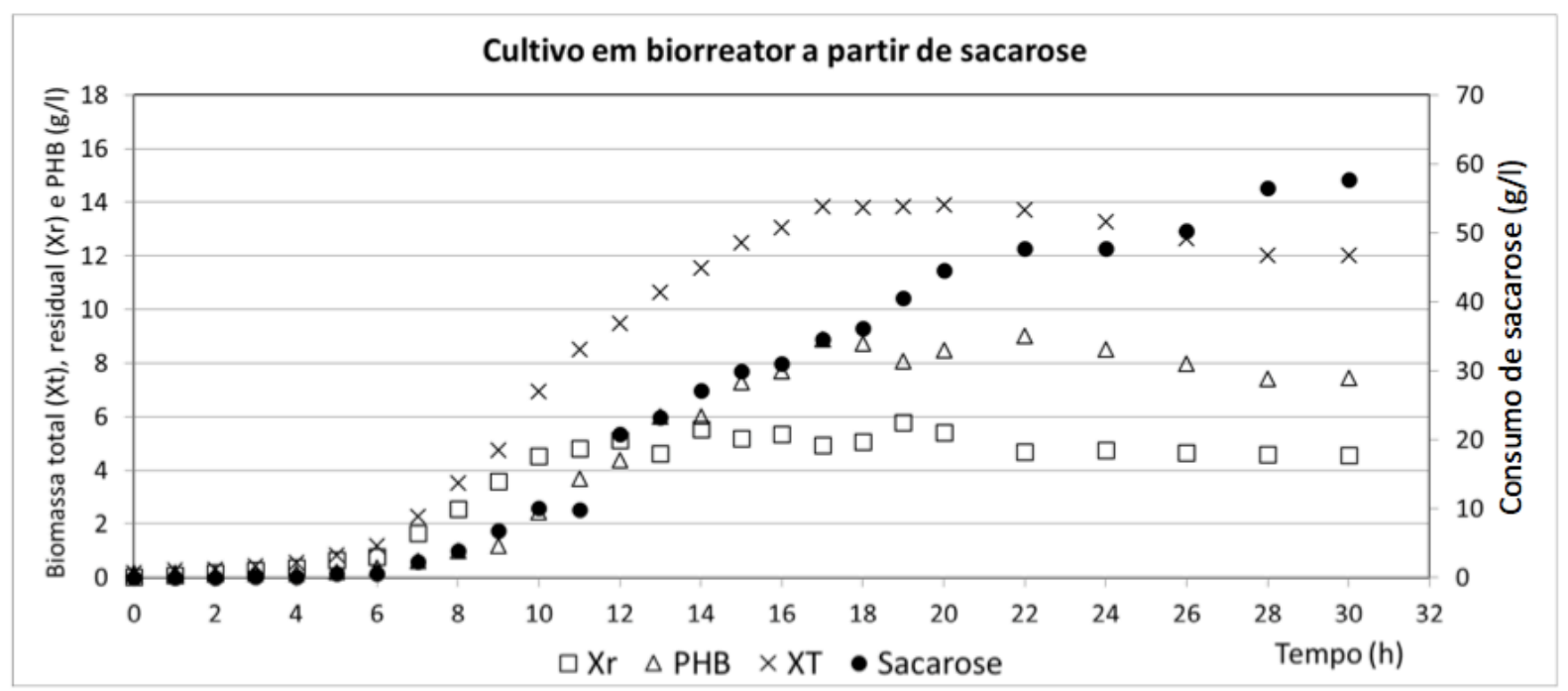

Figura 17 - Variação de consumo de glicose, formação de biomassa e produção de PHB durante o cultivo em biorreator (EB4).

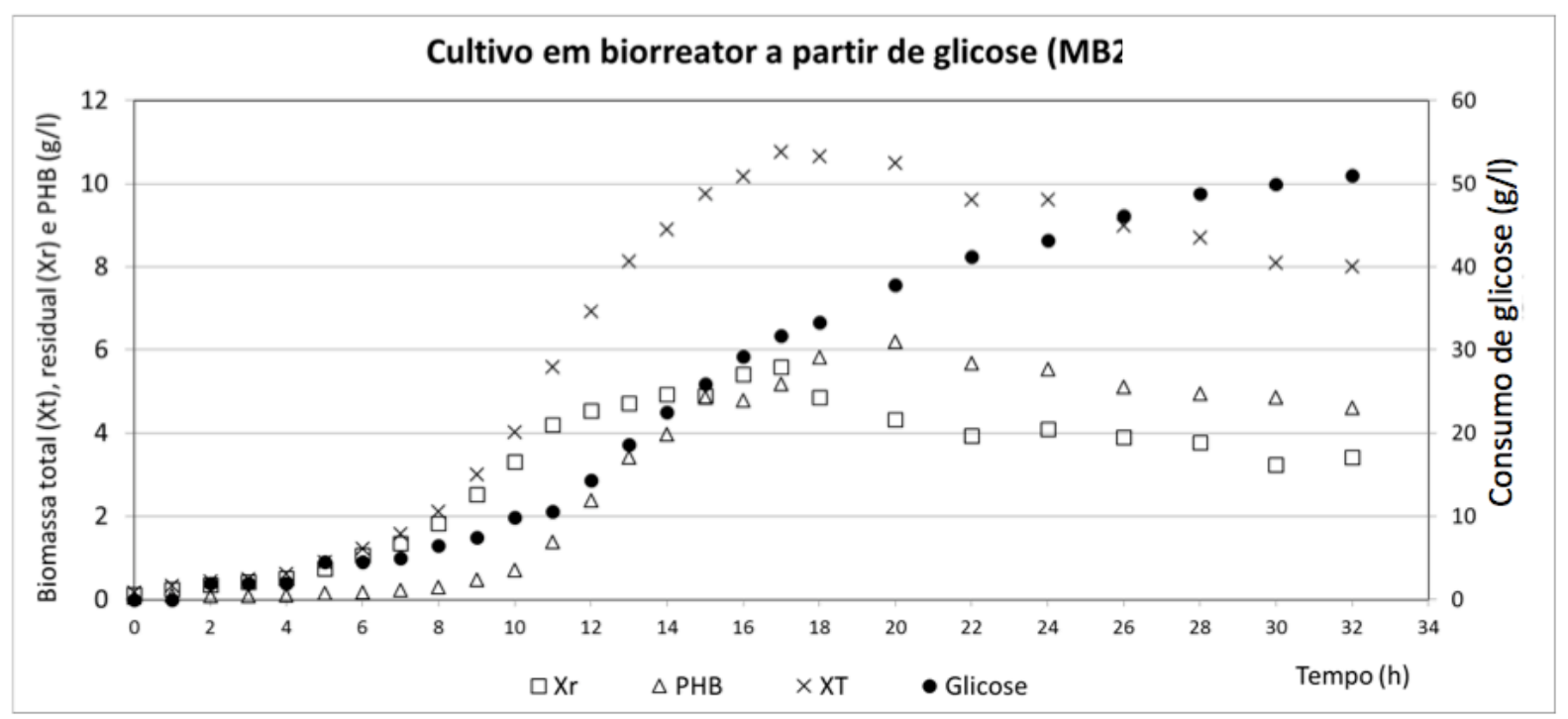

Em ambos experimentos, a limitação de nitrogênio ocorreu em aproximadamente 10 horas. As velocidades máximas específicas de crescimento foi de $0,29 \mathrm{~h}^{-1}$ para o cultivo contendo glicose e $0,45 \mathrm{~h}^{-1}$ com sacarose, muito maiores que as obtidas em EB1 e EB 2 (tabela 9) e comparáveis aos dados publicados por Lopes e colaboradores (2009) que 
obtiveram $\mu_{\text {máx }}$ de $0,37 \pm 0,01 \mathrm{~h}^{-1}$ com Burkholderia sacchari selvagem (LFM101) e 0,35 $\pm 0,01$ $\mathrm{h}^{-1}$ com mutante PTS ${ }^{-}$Glicose $^{+}$de $B$. sacchari LFM828 em meio mineral acrescido de glicose.

Buscou-se períodos pseudo-estacionários, porém, não foi possível obter um balanço de carbonos próximo a $100 \%$ em nenhum dos períodos analisados e portanto, em nenhum destes períodos ocorria o pré-requisito para realizar a análise de fluxos metabólicos, que necessita que os carbonos provenientes do substrato sejam desviados apenas para síntese de biomassa, gás carbônico e PHB.

Tabela 9 - Comparação entre resultados de experimentos em biorreator realizados neste estudo e da literatura.

\begin{tabular}{ccccccc}
\hline & EB1 & EB2 & EB3 & EB4 & $\begin{array}{c}\text { Lopes et al. } \\
(\mathbf{2 0 0 9})^{\mathbf{a}}\end{array}$ & $\begin{array}{c}\text { Pradella et al. } \\
(\mathbf{2 0 1 0})^{\mathbf{b}}\end{array}$ \\
\hline Fonte de carbono & sacarose & glicose & sacarose & glicose & glicose & Sacarose \\
$\mu_{\text {máx }}\left(\mathrm{h}^{-1}\right)$ & 0,08 & 0,09 & 0,45 & 0,29 & 0,37 & 0,41 \\
C. consumido $\left(\mathrm{g} \mathrm{l}^{-1}\right)$ & 31,19 & 51,94 & 64,44 & 51,03 & nd & $\sim 55,00$ \\
MSC final $\left(\mathrm{g} \mathrm{l}^{-1}\right)$ & 16,58 & 14,18 & 13,89 & 10,77 & 6,37 & 10 \\
PHB $(\%$ de MSC) & 84,62 & 69,89 & 65,14 & 60,01 & 63,14 & 35 \\
$\mathrm{Y}_{\text {PHB/C }}\left(\mathrm{g} \mathrm{g}^{-1}\right)$ & 0,40 & 0,29 & 0,25 & 0,16 & 0,29 & nd \\
$\mathrm{Y}_{\text {exp }} / \mathrm{Y}_{\text {máx }}(\%)$ & 100 & 88,50 & 75,80 & 55,2 & nd & nd \\
\hline
\end{tabular}

Notas: MSC final, massa seca obtida no fim do experimento; C. consumido, carboidrato consumido; PHB (\%MSC), porcentagem de PHB em relação à massa seca celular; $\mathrm{Y}_{\mathrm{PHB} / \mathrm{C}}$, eficiência da conversão de carboidrato em PHB; $\mathrm{Y}_{\text {exp }} / \mathrm{Y}_{\text {máx, }}$ relação da eficiência atingida e a máxima teórica.

${ }^{a}$ Lopes et al. (2009): Dados obtidos de experimento com B. sacchari (IPT101) em meio mineral contendo glicose $(15 \mathrm{~g} / \mathrm{l})$. Dados de carboidrato consumido não foi disponibilizado.

${ }^{b}$ Pradella et al. (2010): Dados obtidos de experimento com B. sacchari (IPT189) em meio mineral contendo sacarose em reator airlift. Dados de carboidrato consumido não foi disponibilizado

Também houve síntese de produtos que pela análise por HPLC tinham tempos de retenção próximos a lactato, formiato e acetato, porém não puderam ser identificados. Este novo experimento demonstrou que não foi possível a obtenção da separação de acúmulo de polímero e crescimento através desta estratégia. Igualmente, parte dos carbonos está sendo usada para a síntese de outros compostos que não PHB, este fato resulta em uma eficiência menor do uso do carboidrato para produzir polímero, e claramente não é uma estratégia interessante para este estudo. 
5.6 Cultivo de $B$. sacchari e $C$. necator com limitação variáveis de nitrogênio ou fósforo a partir de diferentes fontes de carbono.

Com o objetivo de encontrar as melhores condições de acúmulo de PHB por B. sacchari e C. necator para utilizá-las nos cultivos contendo substrato marcado com ${ }^{13} \mathrm{C}$, as linhagens foram cultivadas em diferentes fontes de carbono: frutose, glicose ou mistura de frutose e glicose (apenas para $B$. sacchari) sob limitação de nitrogênio ou fósforo em concentrações variadas. Para os meios com limitação em nitrogênio, testou-se as concentrações: 0,$5 ; 1,0 ; 1,5$ g/l de nitrogênio, chamadas de N1, N2 e N3, respectivamente. Nos meios de cultura com limitação em fósforo, as concentrações foram: 0,$06 ; 0,12 ; 0,18 \mathrm{~g} / 1$ de fósforo, respectivamente chamadas de P1, P2 e P3.

A síntese de PHB por B. sacchari foi bastante similar em todos os cultivos contendo glicose e as diferentes limitações de nitrogênio e fósforo, atingiu entre 47 a 51\% de PHB em relação à biomassa total do experimento (tabela 10).

Tabela 10 - Dados de síntese de PHB de cultivo de $B$. sacchari e $C$. necator a partir de glicose.

\begin{tabular}{cccccc}
\hline Carboidrato & Linhagem & Limitação & PHB (g/l) & PHB (\%MSC) & Y $_{\mathbf{P H B} / \mathbf{C}}(\mathbf{g} / \mathbf{g})$ \\
\hline & & N0,5 & $1,58 \pm 0,20$ & $51,05 \pm 2,36$ & $0,20 \pm 0,02$ \\
& N1,0 & $1,53 \pm 0,09$ & $51,12 \pm 2,38$ & $0,20 \pm 0,11$ \\
& \multirow{3}{*}{ B. sacchari } & N1,5 & $1,49 \pm 0,06$ & $50,27 \pm 3,22$ & $0,21 \pm 0,09$ \\
& & P0,06 & $0,94 \pm 0,20$ & $49,97 \pm 7,66$ & $0,19 \pm 0,08$ \\
Glicose & P0,12 & $0,87 \pm 0,16$ & $49,87 \pm 4,90$ & $0,12 \pm 0,02$ \\
& & P0,18 & $0,87 \pm 0,02$ & $47,5 \pm 7,06$ & $0,12 \pm 0,03$ \\
& \multirow{4}{*}{ C. necator } & N0,5 & $0,48 \pm 0,04$ & $28,65 \pm 3,40$ & $0,11 \pm 0,03$ \\
& & N1,0 & $0,49 \pm 0,01$ & $29,69 \pm 0,30$ & $0,08 \pm 0,03$ \\
& & P0,06 & $0,52 \pm 0,03$ & $31,4 \pm 0,96$ & $0,05 \pm 0$ \\
& & P0,12 & $0 \pm 0$ & $0 \pm 0$ & $0 \pm 0$ \\
& & P0,18 & $0 \pm 0$ & $0,08 \pm 0,14$ & $0 \pm 0$ \\
\hline
\end{tabular}

Ainda neste experimento, a linhagem controle, Cupriavidus necator apenas acumulou PHB nos meios de cultura limitados em nitrogênio. O que sugeriria sua preferência por este tipo de limitação, porém, trabalhos de outros autores como Shang, Jiang e Chang (2003), e Squio e colaboradores (2003), utilizaram limitações de fósforo para produzir polímeros biodegradáveis ( $\mathrm{PHB}$ e $\mathrm{P}(3 \mathrm{HB}-\mathrm{co}-3 \mathrm{HV})$ respectivamente). 
Nos experimentos com frutose como fonte de carbono, o maior valor de concentração de PHB produzido por B. sacchari ocorreu sob a limitação de 1,5 g/l de nitrogênio e foi aproximadamente $1,3 \mathrm{~g} / 1$. Já para $C$. necator, a limitação em fósforo foi a que gerou maior concentração, foram obtidos valores próximos a 1,6 g/l. A linhagem $C$. necator não produziu um acúmulo significativo sob a condição de limitação de nitrogênio a 1,5 g/l (tabela 11). $B$. sacchari conseguiu atingir aproximadamente 65\% de PHB em relação a sua biomassa sob essas condições de cultivo.

Tabela 11 - Dados de síntese de PHB de cultivo de B. sacchari e C. necator a partir de frutose.

\begin{tabular}{|c|c|c|c|c|c|}
\hline Carboidrato & Linhagem & Limitação & PHB (g/l) & PHB (\%MSC) & $Y_{\mathrm{PHB} / \mathrm{C}}(\mathrm{g} / \mathrm{g})$ \\
\hline \multirow{12}{*}{ Frutose } & \multirow{6}{*}{ B. sacchari } & $\mathrm{N} 0,5$ & $0,56 \pm 0,17$ & $62,50 \pm 4,36$ & $0,09 \pm 0,02$ \\
\hline & & $\mathrm{N} 1,0$ & $0,91 \pm 0,08$ & $66,04 \pm 1,28$ & $0,12 \pm 0,01$ \\
\hline & & $\mathrm{N} 1,5$ & $1,28 \pm 0,28$ & $65,30 \pm 2,69$ & $0,16 \pm 0,03$ \\
\hline & & P0,06 & $0,20 \pm 0,06$ & $15,61 \pm 4,91$ & $0,03 \pm 0,01$ \\
\hline & & $\mathrm{P} 0,12$ & $0,17 \pm 0,03$ & $13,73 \pm 2,09$ & $0,03 \pm 0$ \\
\hline & & $\mathrm{P} 0,18$ & $0,19 \pm 0,03$ & $14,35 \pm 2,66$ & $0,03 \pm 0,01$ \\
\hline & \multirow{6}{*}{ C. necator } & N0,5 & $0,07 \pm 0,01$ & $9,74 \pm 1,19$ & $0,01 \pm 0$ \\
\hline & & $\mathrm{N} 1,0$ & $0,11 \pm 0,04$ & $12,06 \pm 3,24$ & $0,01 \pm 0$ \\
\hline & & $\mathrm{N} 1,5$ & 0 & $0,39 \pm 0,13$ & 0 \\
\hline & & P0,06 & $1,39 \pm 0,18$ & $46,69 \pm 5,26$ & $0,18 \pm 0,02$ \\
\hline & & $\mathrm{P} 0,12$ & $1,38 \pm 0,22$ & $47,80 \pm 6,36$ & $0,19 \pm 0,03$ \\
\hline & & $\mathrm{P} 0,18$ & $1,54 \pm 0,12$ & $48,75 \pm 1,62$ & $0,24 \pm 0,05$ \\
\hline
\end{tabular}

Quanto aos fatores de conversão de frutose em PHB ( $\left.\mathrm{Y}_{\mathrm{PHB} / \mathrm{C}}\right)$, os maiores valores para B. sacchari ocorreram no cultivo sob limitação de nitrogênio, especialmente na concentração de $0,12 \mathrm{~g} / \mathrm{l}$, sendo este aproximadamente $0,16 \mathrm{~g} / \mathrm{g}$. O maior $\mathrm{Y}_{\mathrm{PHB} / \mathrm{C}}$ para a outra linhagem este foi próximo a $0,24 \mathrm{~g} / \mathrm{g}$ e ocorreu na condição limitante de $0,18 \mathrm{~g} / 1$ de fósforo. Os $\mathrm{Y}_{\mathrm{PHB} / \mathrm{C}}$ de $C$. necator em condições de limitação de nitrogênio foram muito baixos, menores que $0,01 \mathrm{~g} / \mathrm{g}$, enquanto na limitação de fósforo, foram mais de 24 vezes maiores em relação a estes.

Segundo os autores Ryu et al. (1997), Taciro (2008) e Wendlandt e colaboradores (2001), a condição de restrição em fósforo é mais adequada para o acúmulo do polímero, porém estes experimentos mostraram que para $B$. sacchari, a restrição em nitrogênio favorece ainda mais a produção de PHB, como corrobora os trabalhos com Pseudomonas de Kawai (2013); Chinwetkitvanich, Randall e Panswad, (2003) e Wen e colaboradores (2010).

A condição de cultivo com oferta de glicose e limitação de nitrogênio foi escolhida para 
a realização do experimento contendo substrato marcado com ${ }^{13} \mathrm{C}$, já que ofereceu condições de produção de PHB para ambas linhagens.

\subsection{Cultivos com glicose contendo carbonos marcados $\left({ }^{13} \mathrm{C}\right)$}

Cultivaram-se Burkholderia sacchari e Cupriavidus necator nas condições anteriormente citadas para ensaios em agitador rotativo (tabela 12). Além de triplicatas biológica, duplicatas analíticas também foram analisadas por Cromatografia Gasosa associada a Espectrometria de Massa (CG-MS) segundo indicado na metodologia. Amostras do préinóculo foram retiradas para a determinar a porcentagem de acúmulo de PHA durante este período. Uma mistura de 20:80 de glicose marcada com ${ }^{13} \mathrm{C}$ e não-marcada foi utilizada como fonte de carbono. A molécula de glicose contendo todos os carbonos marcados $\operatorname{com}{ }^{13} \mathrm{C}$ foi a escolhida para a realização do experimento.

Tabela 12 - Resultados de experimento utilizando substrato marcado $\operatorname{com}{ }^{13} \mathrm{C}$ e não marcado (20:80).

\begin{tabular}{ccc}
\cline { 2 - 3 } & B. sacchari & C. necator \\
\hline $\mathrm{MSC}(\mathrm{g} / \mathrm{l})$ & $6,18 \pm 0,16$ & $8,79 \pm 0,20$ \\
$\mathrm{pH}$ & $6,54 \pm 0,02$ & $6,57 \pm 0$ \\
$\mathrm{Xr}(\mathrm{g} / \mathrm{l})$ & $2,23 \pm 0,12$ & $1,67 \pm 0,10$ \\
$\mathrm{PHB}(\mathrm{g} / \mathrm{l})$ & $3,95 \pm 0,09$ & $7,12 \pm 0,26$ \\
$\mathrm{PHB}(\%)$ & $63,86 \pm 1,23$ & $80,95 \pm 1,40$ \\
$\mathrm{G}_{\text {cons }}(\mathrm{g} / \mathrm{l})$ & $21 \pm 0,41$ & $21 \pm 0,41$ \\
$\mathrm{Y}_{\mathrm{PHB} / \mathrm{C}}$ & $0,19 \pm 0$ & $0,34 \pm 0,01$ \\
$\mathrm{Y}_{\mathrm{Xr} / \mathrm{C}}$ & $0,08 \pm 0,01$ & $0,05 \pm 0$ \\
\hline
\end{tabular}

Notas: MSC, massa seca celular; Xr, biomassa residual; PHB, concentração final de PHB; $\mathrm{G}_{\text {cons }}$, glicose consumida; $\mathrm{Y}_{\mathrm{PHB} / \mathrm{C}}$, conversão de carboidrato em PHB; $\mathrm{Y}_{\mathrm{Xr} / \mathrm{C}}$, conversão de carboidrato (glicose) em $\mathrm{Xr}$.

A linhagem $C$. necator atingiu acúmulo cerca de $21 \%$ maior que $B$. sacchari, também obteve uma biomassa 29,7\% maior que a da linhagem em comparação. A eficiência de conversão de $C$. necator foi 1,78 vezes a de LFM101, fato já esperado já que este microorganismo converte açúcares em PHB na sua eficiência máxima teórica, enquanto $B$. sacchari utiliza apenas $80 \%$ de sua eficiência máxima.

A mistura de carbonos marcados e não marcados em substratos utilizados para o rastreamento de carbonos possibilita a identificação das vias metabólicas utilizadas para a 
síntese do PHB em algumas condições, também define como as parcelas de carbono são desviadas para vias metabólicas através da análise de isotopômeros e suas distribuições.

A primeira informação imporante para esta análise é que as vias metabólicas EntnerDoudoroff (ED) e Embden-Meyerhof-Parnas (EMP) não causam, sozinhas, o embaralhamento dos carbonos das moléculas acetil-CoA. Contudo, as frutose-6-fosfato que são metabolizadas na Via das Pentoses-Fostato (VP) sofrem embaralhamento de carbonos. Este embaralhamento só poderá ser visualizado na molécula de acetil-CoA formada caso ela siga para a via de ED, se a próxima via metabólica for a EMP, e não a ED, este embaralhamento não pode ser visualizado e os acetil-CoA formados não conterão mistura de carbonos marcados e não marcados (figura 18).

Figura 18 - Padrões de embaralhamentos de carbonos da molécula de acetil-CoA originada a partir de frutose-6-fosfato contendo carbonos marcados (coloridos) e não marcados (pretos) fornecidos pela mistura de glicose marcada e não marcada com ${ }^{13} \mathrm{C}$. A molécula de acetilCoA formada terá embaralhamento de carbonos apenas se for originada através da frutose-6fosfato que for metabolizada pela Via das Pentoses (VP) e pela Enter-Doudoroff (ED), caso ela seja metabolizada apenas pela VP ou pela VP e pela Embden-Meyerhof-Parnas (EMP), os acetil-CoA formados não terão carbonos marcados e não marcados na mesma molécula (não sofrerão embaralhamento). Circulo azul envolvendo moléculas de acetil-CoA destacam a situação em que o embaralhamento de carbonos ocorre.

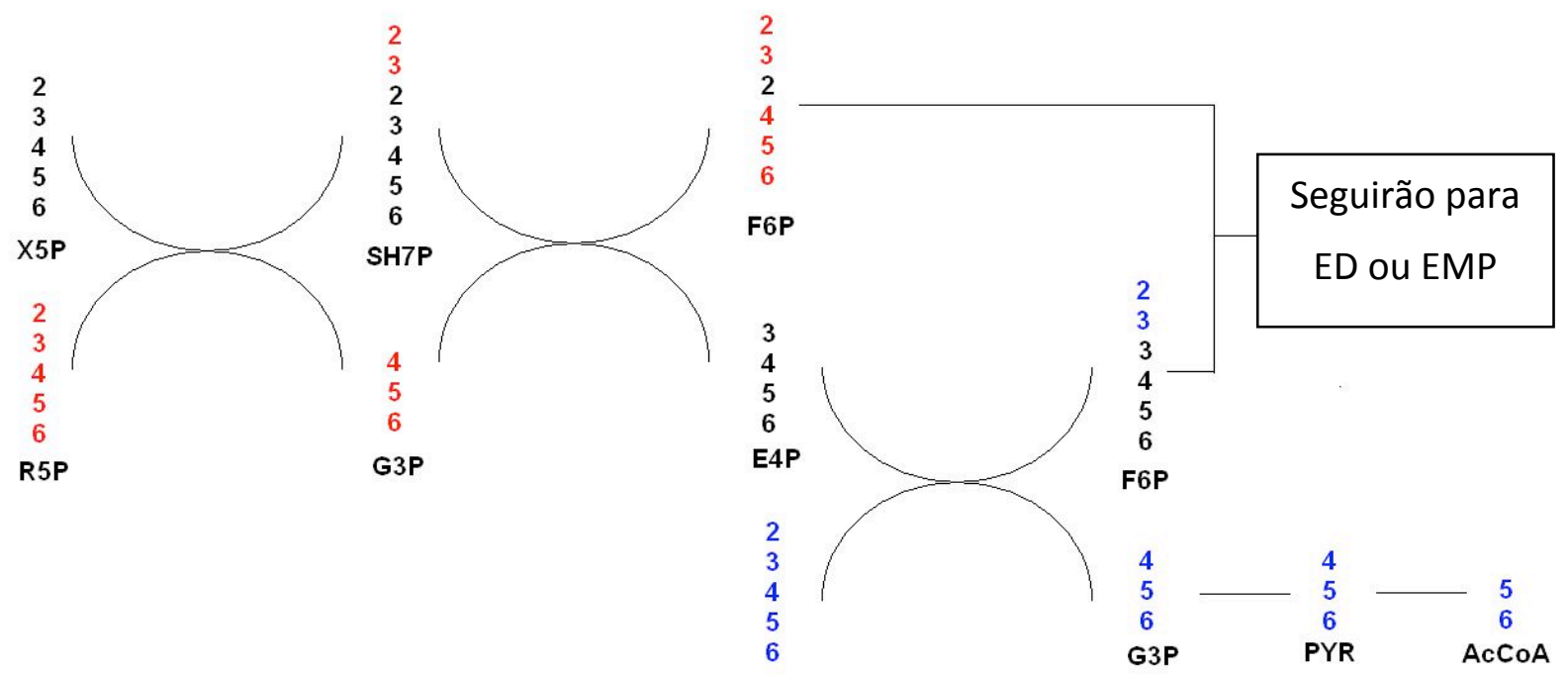


(Continuaçãoo da figura 18)
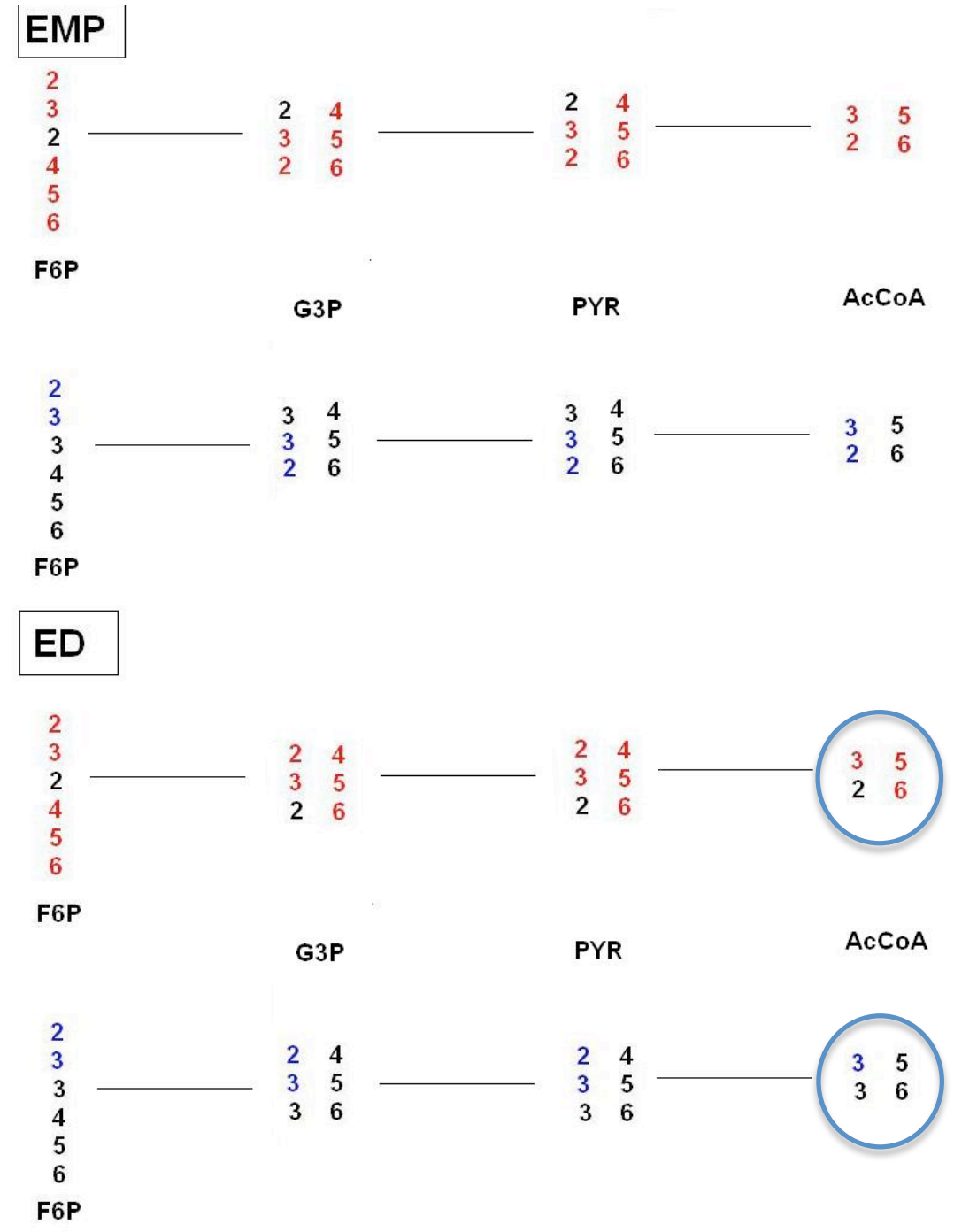

Fonte: Kawai (2013).

A quebra do propil-éster (3HB) pela análise de CG-MS forma fragmentos característicos 87,89 e $131 \mathrm{~m} / \mathrm{z}$ (massa/ carga) (figura 19) contendo carbonos provenientes de moléculas de acetil-CoA que podem conter carbonos marcados ou não, dependendo das vias metabólicas utilizadas (figura 18). 
Figura 19 - Fragmentos m/z: 87, 89 e 131 resultantes da quebra do propil-éster do monômero $3 \mathrm{HB}$ contendo carbonos provenientes de acetil-CoA.

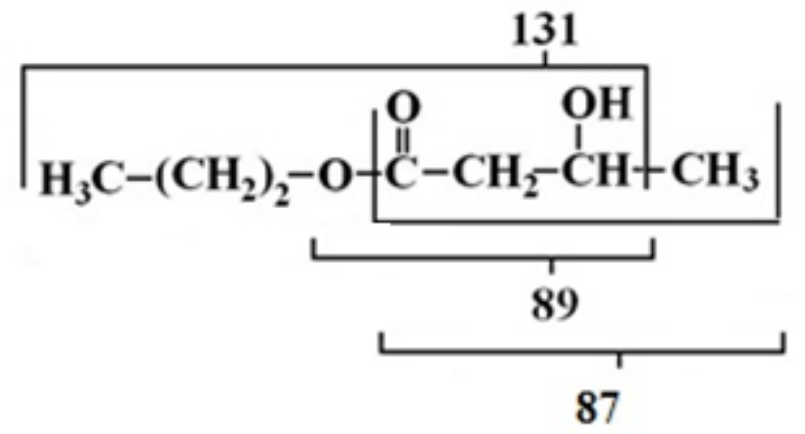

Fonte: Kawai, 2013 - modificada.

Estes fragmentos apresentam isotpômeros de massa e posição, sendo os primeiros chamados de $\mathrm{M}+1, \mathrm{M}+2$ e $\mathrm{M}+3$ e $\mathrm{M}+4$ (o último, $\mathrm{M}+4$, somente no caso do fragmento 87 que contém quatro carbonos provenientes de duas moléculas de acetil-CoA, demais casos contém apenas três carbonos destas moléculas). Os fragmentos 87 e 89 apresentam em seus espectros, picos que sofrem interferência, já que os isotopômeros $\mathrm{M}+2$ e $\mathrm{M}+3$ do fragmento 87 aparecem no mesmo tempo de retenção que os isotopômeros $\mathrm{M}, \mathrm{M}+1$ do fragmento 89 (figura 20). Isto dificulta a análise da distribuição destes fragmentos, já que eles não podem ser definidos. Para solucionar este problema, considerou-se a contribuição de cada isotopômero para o pico formado (a partir de uma análise de CG-MS feita anteriorente de cada pico separadamente) e estabeleceu-se uma relação. Desta forma, foi possível separar a distribuição dos isotopômeros dos dois fragmentos, 87 e 89. 
Figura 20 - Cromatograma de CG-MS da amostra BS1A correspondente a análise dos propil-ésteres produzidos por $B$. sacchari. Setas indicam os fragmentos m/z: 87, 89 (em cinza) e 131. TR: tempo de retenção.

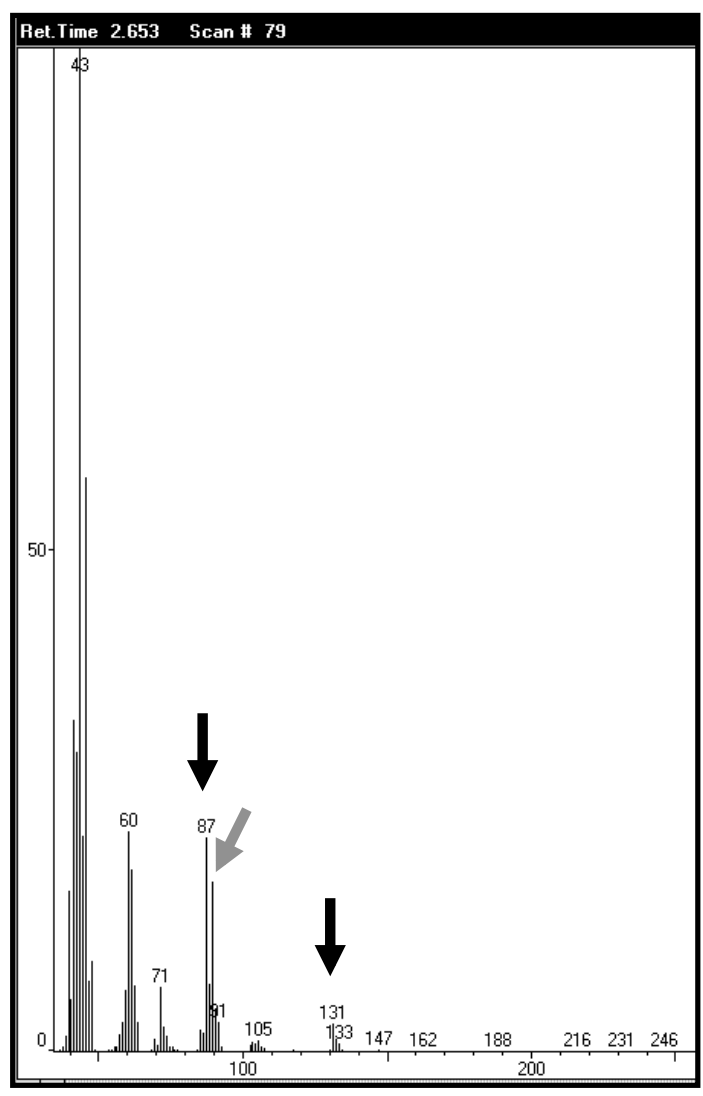

\begin{tabular}{|c|c|c|}
\hline \multirow[b]{2}{*}{ TR } & \multicolumn{2}{|r|}{ Isotopômero } \\
\hline & Intensidade & de Massa \\
\hline 87.10 & 21.37 & $\mathrm{M}$ \\
\hline 88.10 & 6.73 & $M+1$ \\
\hline 89.10 & 16.90 & $M+2 / M$ \\
\hline 90.10 & 4.36 & $M+3 / M+1$ \\
\hline 91.10 & 2.97 & $M+2$ \\
\hline 92.15 & 0.51 & $M+3$ \\
\hline$\ldots$ & $\ldots$ & $\ldots$ \\
\hline 131.10 & 2.81 & $\mathrm{M}$ \\
\hline 132.10 & 1.23 & $M+1$ \\
\hline 133.15 & 0.79 & $M+2$ \\
\hline 134.05 & 0.27 & $M+3$ \\
\hline
\end{tabular}

É possível, através do estudo da distribuição dos carbonos marcados e não-marcados nas moléculas de acetil-CoA um cálculo estimado da distribuição dos isotopômeros de massa dos fragmentos característicos para o caso das vias metabólicas utilizadas pelas frutoses-6fosfato serem a VP e ED, ou VP e EMP (tabelas 13 e 14). Estes cálculos são feitos a partir do pressuposto que estas moléculas não seguem novamente para a VP, indiferentemente do número de vezes, o que modificaria estes valores. 
Tabela 13 - Cálculo da frequência de ocorrências dos diferentes isotopômeros do fragmento $\mathrm{m} / \mathrm{z}=131$ e $\mathrm{m} / \mathrm{z}=89$ considerando o metabolismo de glicose marcada $(20 \%)$ e não marcada $(80 \%)$ pela via das pentoses e ED. Cores indicam a procedência dos carbonos do fragmento segundo a molécula de acetil-CoA que o compõe (Acetil-CoA 1 ou Acetil-CoA 2).

\begin{tabular}{|c|c|c|c|c|c|c|c|c|c|c|c|c|c|}
\hline \multirow{2}{*}{$\begin{array}{c}\text { Fragmento } \\
\mathrm{m} / \mathrm{z}=131 \text { e } 89\end{array}$} & \multicolumn{5}{|c|}{ Acetil-CoA 1} & \multicolumn{5}{|c|}{ Acetil-CoA 2} & \multicolumn{3}{|c|}{ Frequência Isotopômero } \\
\hline & OO & OX & XO & $\mathbf{X X}$ & Frequência (A) & $\mathrm{OO}$ & $\mathrm{OX}$ & $\mathrm{XO}$ & $\mathrm{XX}$ & Frequência (B) & $(A \times B)$ & $\mathbf{M}+(\mathbf{1}$, & ou 3) \\
\hline 000 & 0,736 & 0,000 & 0,000 & 0,000 & 0,736 & 0,736 & 0,064 & 0,000 & 0,000 & 0,800 & 0,588 & 0,588 & $\mathrm{M}$ \\
\hline XOO & 0,000 & 0,000 & 0,064 & 0,000 & 0,064 & 0,736 & 0,064 & 0,000 & 0,000 & 0,800 & 0,051 & & \\
\hline OXO & 0,000 & 0,064 & 0,000 & 0,000 & 0,064 & 0,736 & 0,064 & 0,000 & 0,000 & 0,800 & 0,051 & 0,249 & $\mathrm{M}+1$ \\
\hline OOX & 0,736 & 0,000 & 0,000 & 0,000 & 0,736 & 0,000 & 0,000 & 0,064 & 0,136 & 0,200 & 0,147 & & \\
\hline XXO & 0,000 & 0,000 & 0,000 & 0,136 & 0,136 & 0,736 & 0,064 & 0,000 & 0,000 & 0,800 & 0,108 & & \\
\hline OXX & 0,000 & 0,064 & 0,000 & 0,000 & 0,064 & 0,000 & 0,000 & 0,064 & 0,136 & 0,200 & 0,012 & 0,134 & $\mathrm{M}+2$ \\
\hline XOX & 0,000 & 0,000 & 0,064 & 0,000 & 0,064 & 0,000 & 0,000 & 0,064 & 0,136 & 0,200 & 0,012 & & \\
\hline $\mathbf{X X X}$ & 0,000 & 0,000 & 0,000 & 0,136 & 0,136 & 0,000 & 0,000 & 0,064 & 0,136 & 0,200 & 0,027 & 0,027 & $\mathrm{M}+3$ \\
\hline
\end{tabular}

1 - Acetil-CoA que contribui com dois carbonos para os fragmentos de propil-éster $\mathrm{m} / \mathrm{z}=131$ e 89 .

2 - Acetil-CoA que contribui com apenas um carbono para os fragmentos de propil-éster m/z = 131 e 89.

$\mathrm{O}$ - carbono não marcado $\mathrm{X}$ - carbono marcado.

Fonte: Kawai, 2013 
Tabela 14 - Cálculo da frequência de ocorrências dos diferentes isotopômeros do fragmento $\mathrm{m} / \mathrm{z}=87$ considerando o metabolismo de glicose marcada $(20 \%)$ e não marcada $(80 \%)$ pela via das pentoses e ED.

\begin{tabular}{|c|c|c|c|c|c|c|c|c|c|c|c|c|c|}
\hline \multirow{2}{*}{$\begin{array}{c}\text { Fragmento } \\
\mathbf{m} / \mathbf{z}=87\end{array}$} & \multicolumn{5}{|c|}{ Acetil-CoA 1} & \multicolumn{5}{|c|}{ Acetil-CoA 2} & \multicolumn{3}{|c|}{ Frequência Isotopômero } \\
\hline & OO & OX & XO & XX & Frequência (A) & OO & OX & XO & XX & Frequência (B) & $(A \times B)$ & $M+(1,2$ & 3 ou 4) \\
\hline 0000 & 0,736 & 0,000 & 0,000 & 0,000 & 0,736 & 0,736 & 0,000 & 0,000 & 0,000 & 0,736 & 0,542 & 0,542 & $\mathrm{M}$ \\
\hline XOOO & 0,000 & 0,000 & 0,064 & 0,000 & 0,064 & 0,736 & 0,000 & 0,000 & 0,000 & 0,736 & 0,047 & & \\
\hline OXOO & 0,000 & 0,064 & 0,000 & 0,000 & 0,064 & 0,736 & 0,000 & 0,000 & 0,000 & 0,736 & 0,047 & & \\
\hline OOXO & 0,736 & 0,000 & 0,000 & 0,000 & 0,736 & 0,000 & 0,000 & 0,064 & 0,000 & 0,064 & 0,047 & 0,188 & $M+1$ \\
\hline OOOX & 0,736 & 0,000 & 0,000 & 0,000 & 0,736 & 0,000 & 0,064 & 0,000 & 0,000 & 0,064 & 0,047 & & \\
\hline XOOX & 0,000 & 0,000 & 0,064 & 0,000 & 0,064 & 0,000 & 0,064 & 0,000 & 0,000 & 0,064 & 0,004 & & \\
\hline OXOX & 0,000 & 0,064 & 0,000 & 0,000 & 0,064 & 0,000 & 0,064 & 0,000 & 0,000 & 0,064 & 0,004 & & \\
\hline OOXX & 0,736 & 0,000 & 0,000 & 0,000 & 0,736 & 0,000 & 0,000 & 0,000 & 0,136 & 0,136 & 0,1001 & 0,2082 & $\mathrm{M}+2$ \\
\hline XXOO & 0,000 & 0,000 & 0,000 & 0,136 & 0,136 & 0,736 & 0,000 & 0,000 & 0,000 & 0,736 & 0,1001 & & \\
\hline OXXO & 0,000 & 0,064 & 0,000 & 0,000 & 0,064 & 0,000 & 0,000 & 0,064 & 0,000 & 0,064 & 0,004 & & \\
\hline XОXO & 0,000 & 0,000 & 0,064 & 0,000 & 0,064 & 0,000 & 0,000 & 0,064 & 0,000 & 0,064 & 0,004 & & \\
\hline XXOX & 0,000 & 0,000 & 0,000 & 0,136 & 0,136 & 0,000 & 0,064 & 0,000 & 0,000 & 0,064 & 0,009 & & \\
\hline OXXX & 0,000 & 0,064 & 0,000 & 0,000 & 0,064 & 0,000 & 0,000 & 0,000 & 0,136 & 0,136 & 0,009 & 0,04 & $\mathrm{M}+3$ \\
\hline XOXX & 0,000 & 0,000 & 0,064 & 0,000 & 0,064 & 0,000 & 0,000 & 0,000 & 0,136 & 0,136 & 0,009 & & \\
\hline XXXO & 0,000 & 0,000 & 0,000 & 0,136 & 0,136 & 0,000 & 0,000 & 0,064 & 0,000 & 0,064 & 0,009 & & \\
\hline XXXX & 0,000 & 0,000 & 0,000 & 0,136 & 0,136 & 0,000 & 0,000 & 0,000 & 0,136 & 0,136 & 0,018 & 0,018 & $\mathrm{M}+4$ \\
\hline
\end{tabular}

Acetil-CoA 1 contribui com dois carbonos para os fragmentos de propil-éster $\mathrm{m} / \mathrm{z}=87$.

Acetil-CoA 2 contribui com apenas dois carbono para os fragmentos de propil-éster $\mathrm{m} / \mathrm{z}=87$.

$\mathrm{O}$ - carbono não marcado $\mathrm{X}$ - carbono marcado.

Fonte: Kawai, 2013 
A partir da comparação dos valores estimados para as possibilidades de vias metabólicas utilizadas (VP e ED ou VP e EMP) com os valores de distribuição obtidos experimentalmente para $B$. sacchari e $C$. necator, pode-se concluir que o metabolismo utilizado pelas duas linhagens é composto por VP e ED, já que os valores de distribuição estimados e experimentais são muito similares (tabela 15). Ou seja, conclui-se que a via EMP não foi utilizada nesta rede metabólica, já que houve embaralhamento de carbonos e, como discutido anteriormente, no caso das vias VP e EMP, o acetil-CoA formado não apresenta embaralhamento.

Tabela 15 - Cálculo da frequência de distribuição dos diferentes isotopômeros dos fragmentos $\mathrm{m} / \mathrm{z}=87,89$ e 131 experimental comparada à estimada para o fluxo via VP e ED para as linhagens $B$. sacchari e $C$. necator.

\begin{tabular}{|c|c|c|c|c|c|}
\hline & \multicolumn{5}{|c|}{ B. sacchari } \\
\hline Fragmentos & $\mathrm{M}$ & $\mathrm{M}+1$ & $\mathrm{M}+2$ & $\mathrm{M}+3$ & $\mathrm{M}+4$ \\
\hline 87 & $0,42 \pm 0,01$ & $0,13 \pm 0,01$ & $0,31 \pm 0,01$ & $0,083 \pm 0,01$ & $0,06 \pm 0,01$ \\
\hline 87 estimado & 0,39 & 0,13 & 0,32 & 0,1 & 0,05 \\
\hline 89 & $0,67 \pm 0,01$ & $0,18 \pm 0,01$ & $0,12 \pm 0,01$ & $0,02 \pm 0,01$ & - \\
\hline 89 estimado & 0,67 & 0,2 & 0,11 & 0,02 & - \\
\hline 131 & $0,541 \pm 0,02$ & $0,25 \pm 0,02$ & $0,15 \pm 0,01$ & $0,05 \pm 0,01$ & - \\
\hline \multirow[t]{2}{*}{131 estimado } & 0,59 & 0,25 & 0,13 & 0,027 & - \\
\hline & \multicolumn{5}{|c|}{ C. necator } \\
\hline Fragmentos & $\mathrm{M}$ & $\mathrm{M}+1$ & $\mathrm{M}+2$ & $\mathrm{M}+3$ & $\mathrm{M}+4$ \\
\hline 87 & $0,43 \pm 0,01$ & $0,12 \pm 0,01$ & $0,32 \pm 0,01$ & $0,08 \pm 0,01$ & $0,05 \pm 0,01$ \\
\hline 87 estimado & 0,39 & 0,13 & 0,32 & 0,1 & 0,05 \\
\hline 89 & $0,70 \pm 0,01$ & $0,17 \pm 0,01$ & $0,11 \pm 0,01$ & $0,02 \pm 0,01$ & - \\
\hline 89 estimado & 0,67 & 0,2 & 0,11 & 0,02 & - \\
\hline 131 & $0,56 \pm 0,02$ & $0,25 \pm 0,03$ & $0,15 \pm 0,02$ & $0,05 \pm 0,01$ & - \\
\hline 131 estimado & 0,59 & 0,25 & 0,13 & 0,027 & - \\
\hline
\end{tabular}

A análise qualitativa dos resultados dos experimentos com carbono marcado permite concluir que as duas linhagens testadas utilizam VP e ED para a formação de $\mathrm{P}(3 \mathrm{HB})$ (tabela 15), logo a justificativa para a diferença entre as eficiências de conversão de açúcares em 
PHB de B. sacchari e C. necator não pode ser a escolha destas vias metabólicas. Descartada esta hipótese, é possível que a análise quantitativa destes fluxos, ou seja a distribuição de carbonos nestas vias metabólicas, possa ser uma solução para esta diferença.

\subsection{Influência da produção de hidrogênio na síntese de PHB}

\subsubsection{Introdução do projeto “Influência da produção de hidrogênio na síntese de PHB”.}

Dentro do contexto do estudo do melhoramento da eficiência de produção de PHB a partir de carboidratos, um projeto realizado no laboratório do Prof. Patrick Hallenbeck, da Université de Montréal, Canadá, objetivou estudar a produção de PHB em linhagens fotossintéticas selvagens e mutantes produtoras de hidrogênio através da variação de diferentes parâmetros como intensidade luminosa e limitação de nutriente (nitrogênio).

A produção de $\mathrm{H}_{2}$ também tem sido bastante estudada uma vez que hidrogênio é um combustível alternativo por ser puro e renovável. Além disso, seu conteúdo energético é de $122 \mathrm{~kJ} / \mathrm{g}$, que é 2,75 vezes maior que o de um combustível composto por hidrocarbonetos (KAPDAN; HARGI, 2006). A produção do bio-hidrogênio, sintetizado através de vias metabólicas, é uma abordagem atrativa quando comparada a outros métodos de produção como a eletrólise da água, processos termo-químicos e radiolíticos já que é menos intensiva energeticamente e a emissão global de $\mathrm{CO}_{2}$ não deteriora o ambiente se considerarmos a análise de seu ciclo de vida (CHONGCHAROENTAWEESUK et al., 2011).

A importância de estudar a interação entre os intermediários das vias metabólicas consiste no objetivo biotecnológico de se aumentar a eficiência do produto industrial desejado, seja este $\mathrm{H}_{2}$ ou PHB. Tendo em vista este contexto, o objetivo deste projeto foi estudar a interação de parâmetros que sua interferência na síntese destes produtos já foram anteriormente demonstradas em diferentes linhagens e condições de cultivo. A título de exemplo, no trabalho de Ghosh e Hallenbeck (2012) foi testada a linhagem JP91 de $R$. capsulatus em diferentes intensidades de luz, concentrações de glutamato e de glicerol, utilizando o desenho de experimento Box-Behnken para otimização da produção de hidrogênio. Diferentemente, este estudo verificou a interação simultânea destes parâmetros não só na síntese de hidrogênio, mas também de PHB.

Luz e nitrogênio são variáveis que exercem grande influência no metabolismo destes produtos. O comportamento da luz é um fator importante pois ela potencia os efeitos da 
regulação da nitrogenase, e também age no fluxo da cadeia de transporte de elétrons (VIGNAIS et al., 1985). A luz também pode modular a distribuição do produto final, como também a duração da fase lag e da cinética de crescimento (GHOSH et al., 2012).

Já as concentrações de nitrogênio são importantes para a razão entre carbono e nitrogênio $(\mathrm{C}: \mathrm{N})$ no meio de cultura. Uma quantidade reduzida de nitrogênio logo no início do cultivo resulta em baixo crescimento celular e baixa conversão de hidrogênio, enquanto o tempo total da fermentação aumenta com uma razão maior entre carbono e nitrogênio inicial. Por outro lado, quando há excesso de nitrogênio fixado no meio, a repressão da nitrogenase pode ocorrer (GHOSH et al., 2012), visando a produção do PHB, uma menor concentração de nitrogênio e maior quantidade de carbono disponível é necessária, já que a síntese do polímero é estimulada quando ocorre limitação de nutrientes como nitrogênio ou ferro e há excesso de fonte de carbono. Ou seja, um equilíbrio entre estes dois fatores, carbono e nitrogênio, deve ocorrer para que a produção de hidrogênio e PHB ocorra.

Bactérias fotossintéticas podem produzir intracelularmente polihidroxialcanoatos (PHA) como material de reserva (LORRUNGRUANG et al., 2006), entretanto, poucos estudos foram realizados caracterizando este processo, e menor atenção foi dada à produção a partir de materiais renováveis como o glicerol e o melaço de cana-de-açúcar. Algumas bactérias fotossintéticas não-sulfúricas produzem copolímeros de PHA a partir de diferentes fontes de carbono, sintetizam, principalmente, poliésteres C4 e C5 e são encontradas tipicamente no meio ambiente. (DEMARCO, 2005). Estudo realizado com Rhodopseudomonas palustris, espécie que foi utilizada neste projeto, demonstra essa vantagem: a linhagem apresentou a síntese de PHB quando cultivada em ambiente externo, com temperatura controlada em biorreator subaquático, desejando-se simular as condições ambientais de pântano, onde a espécie pode ser encontrada (CARLOZZI; SACCHI, 2001). Apesar dessas vantagens, existe pouca informação sobre a produção de PHA por bactérias não-sulfúricas fotossintéticas comparado às bactérias não-fotossintetizantes (DEMARCO, 2005).

Bactérias fotossintéticas não sulfúricas podem ser produtoras de hidrogênio quando apresentam um ou mais tipos de nitrogenase (ligadas a cofatores como molibdênio, vanádio ou ferro) e condições de luz, ausência de oxigênio, amônio e gás nitrogênio. Hidrogenases, como a [Fe-Fe]-hidrogenase, também produzem $\mathrm{H}_{2}$, mas são responsáveis por menos de $10 \%$ da produção total deste composto (KOKU et al., 2002). Na ausência de amônio e nitrogênio, a 
nitrogenase age como uma enzima não-específica que converte o próton $\mathrm{H}^{+}$em $\mathrm{H}^{+}$com elétrons ou seja, forma $\mathrm{H}_{2}$ (WU et al., 2012).

Esta enzima é a responsável pela fixação do nitrogênio em amônia. Ela utiliza os elétrons da cadeia de transporte de elétrons da membrana fotossintética, que foi estimulada pela energia luminosa, para formar amônia, com a concomitante síntese de $\mathrm{H}_{2}$ através do gasto de ATP (equação 2). Na ausência de oxigênio, é o fotossistema PS-I que se ativa, que, ao contrário do PS-II, requer um ácido orgânico e não gera oxidação da água. Sem a separação da molécula de água, o ambiente se mantém anoxigênico e ideal para a ativação da nitrogenase.

$8 \mathrm{e}^{-}+8 \mathrm{H}^{+}+\mathrm{N}_{2}+16 \mathrm{ATP}+16 \mathrm{H}_{2} \mathrm{O}=2 \mathrm{NH}_{3}+\mathbf{H}_{2}+16 \mathrm{ADP}+16 \underline{\mathrm{P}}_{\mathrm{i}} \quad$ (equação 2)

Já é conhecido que a regulação da sua atividade é complexa e depende de diversos fatores, como o crescimento celular, distribuição energética da célula, presença de oxigênio e intensidade da luz. Esta enzima é vulnerável a oxigênio e amônia, foi comprovado, por exemplo, que a troca de glutamato para cloreto de amônia, como fonte de nitrogênio, diminui em $50 \%$ a produção de $\mathrm{H}_{2}$ por $R$. palustris (OH et al., 2004).

As vias de síntese de hidrogênio e polímero competem entre si, já que as duas necessitam de elétrons, poder redutor (NADPH) e possuem intermediários em comum (figura 21). Portanto, micro-organismos que sintetizam os dois produtos podem ter valores de eficiência menores, comparados à situação em que se considera a síntese de um único produto. O comportamento de B. sacchari e C. necator na produção de PHB em diferentes substratos, estas linhagens, que não são fototróficas, mas quimiorganotróficas, não são produtoras de $\mathrm{H}_{2}$, e portanto servem como comparação para a análise da competição da via de PHB sobre o metabolismo de produção de $\mathrm{H}_{2}$. O estudo em que este caso possa existir é importante para se compreender não apenas a influência de uma via metabólica sobre a outra, mas também no mecanismo celular que regula os processos envolvidos.

Neste trabalho foram analisadas as produções de hidrogênio e polihidroxibutirato por tipos selvagens bacterianos e respectivos mutantes em que a via de produção de hidrogênio foi bloqueada, favorecendo-se, teoricamente, a produção de PHA. 
Figura 21 - Visão geral da produção de hidrogênio por bactérias fotossintéticas nãosulfúricas através da enzima nitrogenase.

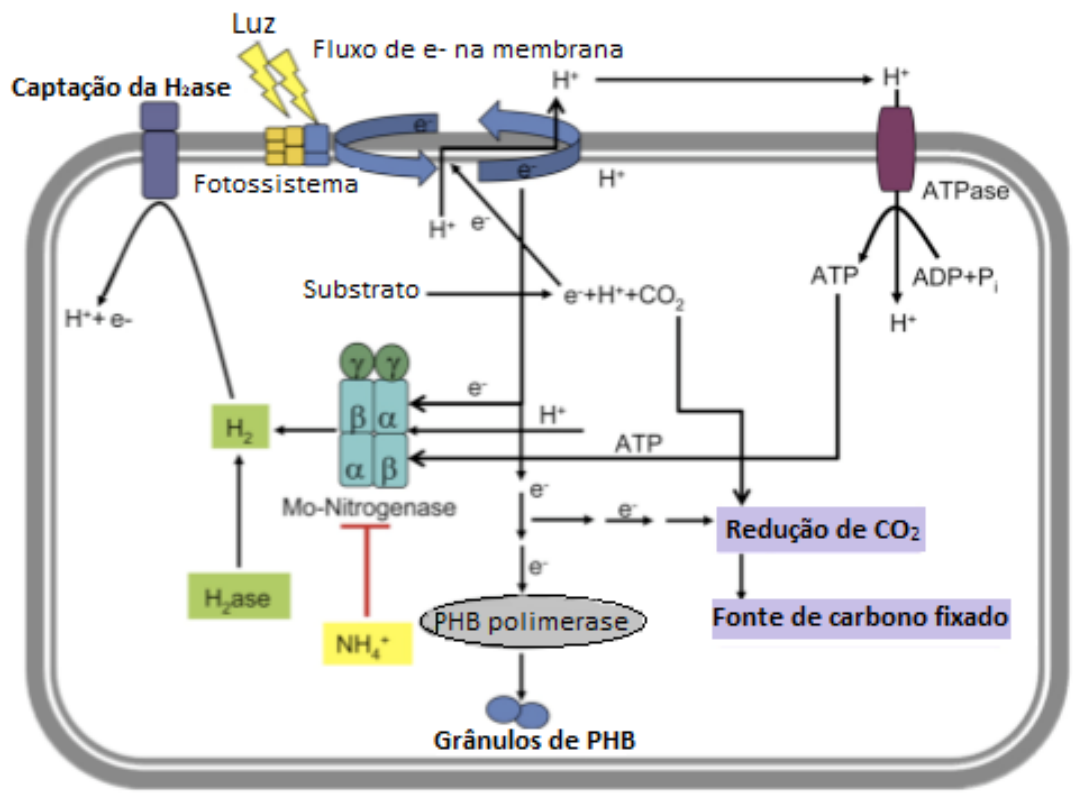

Notas: Energia luminosa é absorvida pelo centro de reação do fotossistema (bacterioclorofila P870) e este, por consequência, doa elétron a uma série de transportadores pertencentes à cadeia de transporte de elétrons. Este processo gera força próton motriz que é utilizada para a síntese de ATP pela enzima ATPase. Os elétrons gerados neste processo são utilizados para o metabolismo de síntese de PHB, que é formado pela PHB polimerase, e de $\mathrm{H}_{2}$, produzido, no exemplo, pela Mo-nitrogenase, simultaneamente à fixação de nitrogênio pela formação de amônia. Fonte: Kars e Gündüz (2010) - traduzida.

Atualmente, três linhagens pertencentes a este grupo são mais estudadas devido a sua versatilidade na produção de PHA a partir de fontes de carbono distintas: Rhodospirilum, Rhodobacter e Rhodopseudomonas (DEMARCO, 2005). As duas últimas foram utilizadas neste projeto com o objetivo de avaliar a sua produção de PHB.

O uso de materiais renováveis é um dos principais meios de diminuir o custo de produção de PHA, já que o valor do substrato orgânico corresponde à maior parcela do preço final do plástico biodegradável (LEE, 1996). Neste estudo foram testadas as fontes de carbono melaço de cana-de-açúcar e glicerol, ambos sem sofrer tratamento e provenientes de indústrias. 


\subsubsection{Metodologia do projeto "Influência da produção de hidrogênio na síntese de PHB”.}

\subsubsection{Linhagens}

Os micro-organismos utilizados nos experimentos visando à produção de PHB e hidrogênio são pertencentes ao grupo de bactérias fotossintetizantes púrpuras não-sulfúricas: Rodobacter capsulatus tipo selvagem (SB1003), mutante Rhodobacter capsulatus (SB363II), Rhodopseudomonas palustris tipo selvagem (CGA009), mutante Rhodopseudomonas palustris (CGA750). Os mutantes CGA750 e SB363II possuem a supressão do gene nifH e portanto não sintetizam a molibdênio-nitrogenase (figura 22). Estas linhagens foram construídas no trabalho de Oda e colaboradores (2005). Os estoques de cultura foram mantidos em glicerol $10 \%$ em freezer $-20{ }^{\circ} \mathrm{C}$.

Figura 22 - Organização do cluster que contém os genes da enzima nitrogenase-molibdênio. Cluster do gene da nitrogenase-molibdênio

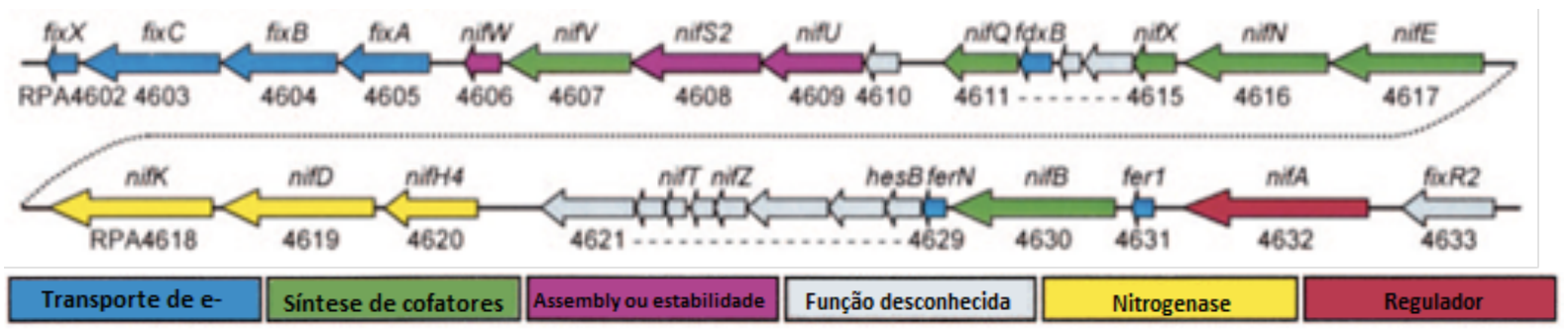

Notas: Genes em azul: responsáveis pelo transporte de elétrons da enzima; verde: formação de cofatores; rosa: assembly ou estabilidade; cinza: função desconhecida; amarelo: nitrogenase; vermelho: genes envolvidos na regulação do cluster da enzima molibdênio-nitrogenase. O gene nifH4, codificador da nitrogenase, foi deletado no mutante CGA750. Fonte: Rey, Hheiniger; Harwood (2007) - modificada.

\subsubsection{Meios de cultura para micro-organismos fotossintéticos}

Meios de cultura apropriados para bactérias fotossintéticas utilizadas (WEAVER; WALL; GEST, 1975) implementados: YPS (0.3\% extrato de levedura, $0.3 \%$ peptona, $1 \mathrm{mM} \mathrm{CaCl}_{2}, 1$ $\mathrm{mM} \mathrm{MgSO}$ ), utilizado para pré-inóculos e culturas estoques, para os experimentos contendo as diferentes fontes de carbono e concentrações de nitrogênio, o meio definido RCV (10 ml de $10 \%\left(\mathrm{NH}_{4}\right)_{2} \mathrm{SO}_{4}, 50 \mathrm{ml}$ de Super sais (tabela 16 e 17), $14 \mathrm{ml} / 1$ de solução a $0.64 \mathrm{KPO}_{4} \mathrm{em}$ pH 6.8 (40 g de $\mathrm{KH}_{2} \mathrm{PO}_{4}$ e $60 \mathrm{~g}$ de $\mathrm{K}_{2} \mathrm{HPO}_{4}$ ), para o volume final de 1 litro de $\mathrm{RCV}$ ). 
Tabela 16 - Solução de super sais do meio RCV.

\begin{tabular}{c|c}
\hline Componente & Concentração \\
\hline $1.0 \% \mathrm{EDTA}$ & $40 \mathrm{ml} / 1$ \\
$20 \% \mathrm{MgSO}_{4} 5 \mathrm{H}_{2} \mathrm{O}$ & $20 \mathrm{ml} / 1$ \\
$7.5 \% \mathrm{CaCl}_{2} 2 \mathrm{H}_{2} \mathrm{O}$ & $20 \mathrm{ml} / 1$ \\
Elementos traços (ver abaixo) & $20 \mathrm{ml} / 1$ \\
$0.5 \% \mathrm{FeSO}_{4} 7 \mathrm{H}_{2} \mathrm{O}$ & $48 \mathrm{ml} / 1$ \\
$0.1 \%$ thiamina-HCl & $20 \mathrm{ml} / 1$ \\
\hline
\end{tabular}

Tabela 17 - Solução de elementos traços do meio RCV.

\begin{tabular}{c|c}
\hline Componente & Concentração \\
\hline $\mathrm{MnSO}_{4} \mathrm{H}_{2} \mathrm{O}$ & $1,58 \mathrm{~g}$ \\
$\mathrm{H}_{3} \mathrm{BO}_{3}$ & $2,8 \mathrm{~g}$ \\
$\mathrm{Cu}\left(\mathrm{NO}_{3}\right)_{2} 3 \mathrm{H}_{2} \mathrm{O}$ & $0,04 \mathrm{~g}$ \\
$\mathrm{ZnSO}_{4} 7 \mathrm{H}_{2} \mathrm{O}$ & $0,24 \mathrm{~g}$ \\
$\mathrm{NaMoO}_{4} 2 \mathrm{H}_{2} \mathrm{O}$ (molibato de & $0,75 \mathrm{~g}$ \\
sódio VI dihidratado) & \\
\hline
\end{tabular}

\subsubsection{Experimentos}

Para a realização dos experimentos com micro-organismos fotossintetizantes, culturas estoques continuas foram mantidas em frascos de $17 \mathrm{~mL}$ contendo YPS a $30{ }^{\circ} \mathrm{C}$ e expostas a, aproximadamente, $100 \mathrm{~W} / \mathrm{m}^{2}$, os frascos foram completamente preenchidos de meio de cultura ou borbulhados com argônio para manter condições anaeróbias. Pré-inóculos com YPS e posteriormente com RCV e a fonte de carbono escolhida (glicerol, ou melaço de canade-açúcar, ou acetato) durante 48 h foram realizados nestas mesmas condições, porém em garrafas de $200 \mathrm{~mL}$.

Após 48h, frascos de $17 \mathrm{~mL}$ foram preenchidos com RCV e melaço de bagaço-decana ou acetato, para Rhodobacter capsulatus e glicerol para Rhodopseudomonas palustris 
(concentração final das fontes de carbono igual a $15 \mathrm{M}$ ). Os tubos foram borbulhados com argônio e completamente lacrados. Os parâmetros intensidade luminosa (100, 200 e 300 $\left.\mathrm{W} / \mathrm{m}^{2}\right)$ e níveis de nitrogênio $(0,01 ; 0,06 ; 0,12 \mathrm{mM})$ foram avaliados em todos os cultivos. As concentrações de nitrogênio utilizadas foram indicadas por Merugu e colaboradores (2010) e correspondiam à variação que representou maior produção de PHB neste estudo. Para a manter a temperatura a $30^{\circ} \mathrm{C}$ foi utilizado um recipiente de vidro (aproximadamente $30 \times 20 \mathrm{x}$ $20 \mathrm{~cm}$ ) preenchido com água, contendo um aquecedor de aquário e um termômetro (figura 23). Para garantir as variações de intensidade luminosa, foi mantida a distância entre os diferentes tubos e estas variações foram previamente verificada através de fotômetro (modelo HD2102.1, marca Delta Ohm).

Figura 23 - Fotografia do modelo de experimento realizado neste estudo, cultivos foram feitos em triplicata.

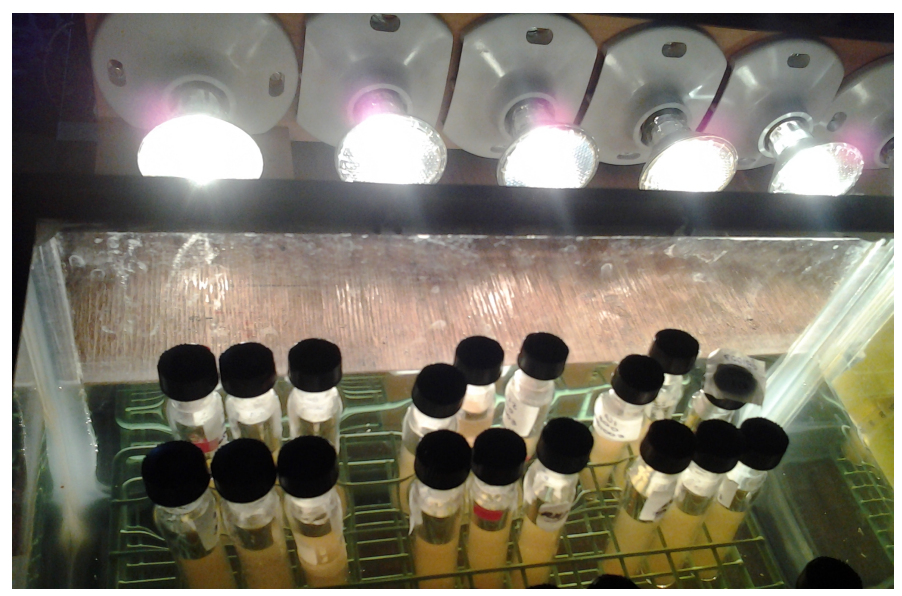

\subsubsection{Desenho Experimental (Design of Experiments - DoE e Response Surface Methodology - RSM)}

Para o desenho experimental (DoE), optou-se pela realização de experimento fatorial completo (full factorial) pois esta análise permite o estudo da interação entre os parâmetros desejados simultaneamente, o que outros métodos estatísticos destinados à otimização da produção não permitem. Os dois parâmetros escolhidos para serem testados foram: luz (100, 200 e $\left.300 \mathrm{~W} / \mathrm{m}^{2}\right)$ e concentração de nitrogênio no meio $(0,01 ; 0,06 ; 0,12 \mathrm{mM})$, estes foram escolhidos por sua influência na produção de hidrogênio e PHB, como discutido anteriormente. O modelo incluía três níveis de duas variáveis (nitrogênio e luz), contidos em um bloco e, como resposta, escolheu-se a quantidade de PHB produzida gerando um modelo 
$3^{2}$. Escolheu-se adicionar duas réplicas, além dos dados originais, para que o modelo gerado fosse mais confiável. Os programas de estatística Minitab (Minitab inc., 2006, disponível em minitab.com) e Statistica (StatSoft, 2010, disponível em statsoft.com) foram utilizados para a determinação do modelo, número de experimentos e réplicas.

As análises de medição de PHA foram realizadas segundo o método descrito por Law e Slepecky (1961), amplamente utilizado, já que no laboratório não havia coluna esperífica para medição de propil-ésteres. Resumidamente, a metodologia se baseia na conversão de polihidroxibutirato em ácido crotônico, por ebulição em ácido sulfúrico concentrado. O ácido crotônico, por sua vez, pode ser medido em espectrofotômetro (235 mu). Os valores obtidos foram relacionados à curva padrão feita anteriormente utilizando o padrão polihidroxibutirato da marca Sigma-Aldrich para gerar as concentrações reais do polímero (figura 24).

Figura 24 - Gráfico da curva padrão de concentração de PHB. OD obtida em 235 nm.

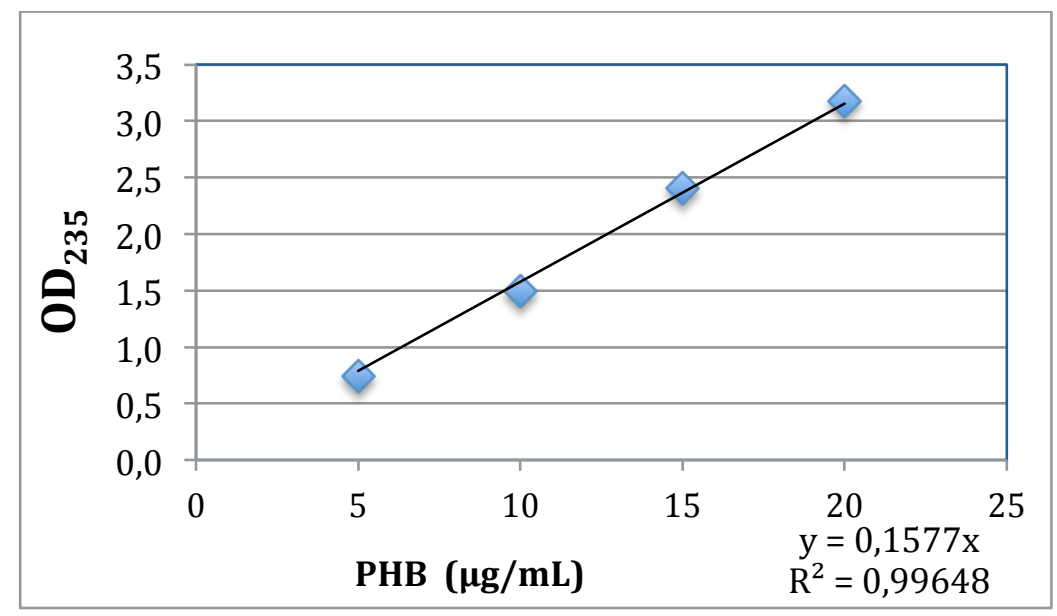

Os valores de biomassa foram obtidos através de Dendidade Óptica (DO) medida no comprimento de onda $600 \mathrm{~nm}$ em espectrofotômetro e comparados a curva de crescimento realizada previamente.

Os micro-organismos foram cultivados em luz e oferta de fonte de carbono (acetato, melaço de cana-de-açúcar ou glicerol em concentração final de 1\%) de modo a observar a eficiência destes substratos.

Para todos os experimentos, para a análise de DoE e RSM, optou-se por um experimento fatorial completo de $3^{2}$, ou seja, três níveis de duas variáveis, duas repetições (totalizando triplicatas) em um bloco o que resultou em 27 runs. 


\subsubsection{Resultados}

5.8.3.1 Rhodobacter capsulatus (selvagem: SB 1003, mutante: SB363II)

- Melaço de cana-de-açúcar

A estimativa da composição de açúcares do melaço da cana-de-açúcar em relação à todos os compostos (UNITED STATES SUGAR CORPORATION. Molasses \& Liquid Feeds Division (2003). Typical Composition of U. S. Sugar's Heavy Mill Run Cane Molasses): 35,9\% sacarose, 5,6\% fructose, 2,6\% glicose, ou seja, aproximadamente $50 \%$ de açúcares.

O estudo foi realizado nas condições descritas anteriormente. Não se detectou produção de $\mathrm{H}_{2}$ em SB363II (mutante) como era esperado, já que este não sintetiza nitrogenase, porém o tipo selvagem também não produziu. Isto pode ser justificado pela preferência de bactérias fotossintéticas não-sulfúricas em produzir hidrogênio a partir ácidos orgânicos simples como malato, lactato ao uso de açúcares para a mesma finalidade (KARS; GÜNDÜZ, 2010; KOKU et al., 2002)

O conteúdo de nitrogênio no melaço de cana é de aproximadamente 1\% (UNITED STATES SUGAR CORPORATION. Molasses \& Liquid Feeds Division (2003). Typical Composition of U. S. Sugar's Heavy Mill Run Cane Molasses). É sabido que a nitrogenase sofre um efeito em curto prazo na presença de $\mathrm{NH}_{4}{ }^{+}$em bactérias fotossintéticas (ZUMFT; CASTILLO, 1978), que pode ser causado pela inibição da utilização de elétrons por esta enzima (HAAKER et al., 1982), esta quantidade de nitrogênio contida no melaço de cana-deaçúcar não-tratado, possivelmente, aumentou a concentração inicial do meio de cultura, que deveria ser limitante, tornando-a inibitória para a enzima.

Para o tipo selvagem, os melhores valores de porcentagem de PHB foram obtidos na condição de $300 \mathrm{~W} / \mathrm{m}^{2}$ e $0,12 \mathrm{mM}$ de nitrogênio (tabela 18), como se pode notar na zona vermelha do gráfico de superfície de resposta apresentado abaixo (figura 25). Também é possível observar que os resultados obtidos por esta linhagem mostram uma tendência à melhor produção de PHB quando há maior oferta de luz, sendo a variação de nitrogênio não tão significativa na determinação da eficiência de produção do polímero (PHB), a zona 
vermelha do gráfico preenche a região em que a luz é máxima em todas as concentrações de nitrogênio.

Tabela 18 - Comparação entre os resultados das médias das triplicatas da produção de PHB por SB1003 (selvagem) e SB363II (mutante) em melaço de cana-de-açúcar em porcentagem da relação da quantidade em gramas de PHB na biomassa total (PHB (g)/ biomassa $(\mathrm{g})$ ).

\begin{tabular}{|c|c|c|c|c|c|c|}
\hline & \multicolumn{2}{|c|}{$100 \mathrm{~W} / \mathrm{m}^{2}$} & \multicolumn{2}{|c|}{$200 \mathrm{~W} / \mathrm{m}^{2}$} & \multicolumn{2}{|c|}{$300 \mathrm{~W} / \mathrm{m}^{2}$} \\
\hline $\begin{array}{l}\text { Nit. } \\
(\mathrm{mM})\end{array}$ & SB1003 & SB363II & SB1003 & SB363II & SB1003 & SB363II \\
\hline 0,01 & 6,19 & 20,04 & 10,11 & 15,65 & 8,57 & 21,17 \\
\hline 0,06 & 6,31 & 15,89 & 7,63 & 15,38 & 9,79 & 27,76 \\
\hline 0,12 & 4,94 & 18,20 & 3,90 & 20,19 & 26,30 & 11,44 \\
\hline
\end{tabular}

Nota: Desvios-padrão foram menores que 15.

Figura 25 - Superfície de resposta dos dados coletados no experimento de SB1003 com melaço de cana-de-açúcar.

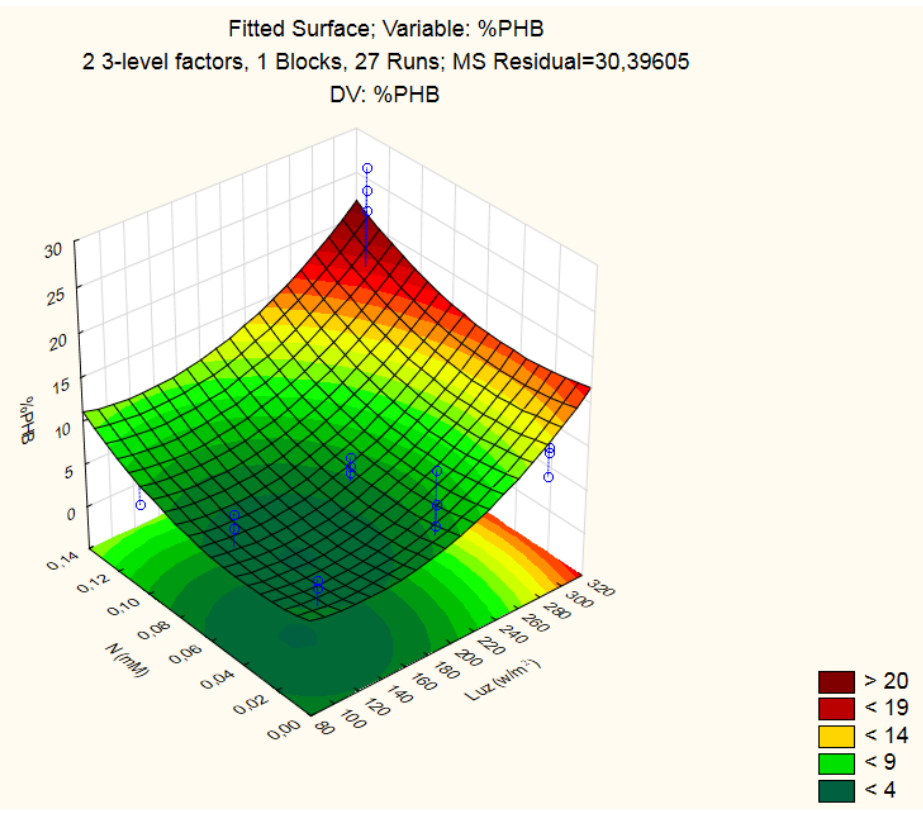

O gráfico de Pareto (figura 26), que demonstra se a relação entre os parâmetros é estatisticamente significativa (valores de "p" acima de 0,05 ) ou não, confirma que o efeito da variação da luz sobre a produção de PHB foi estatisticamente significativa, sendo o valor p do efeito da luz linear igual a 3,490664, ou seja, maior que 0,05 . O efeito da luz da produção de hidrogênio em uma linhagem de Rhodobacter capsulatus já havia sido visto por Ghosh e 
Hallenbeck (2012), que testaram a influência deste parâmetro e notaram que ele afetou as interação das concentrações de glicose ou glutamato na atividade da nitrogenase. Já o efeito da variação da concentração de nitrogênio, tanto linear quanto quadrático, não foi estatisticamente significativo $(\mathrm{p}<0,05)$.

Figura 26 - Gráfico de Pareto relativo ao experimento com SB1003 e melaço de cana-deaçúcar mostrando a padronização do efeito de cada parâmetro. (L): linear, (Q): quadrático.

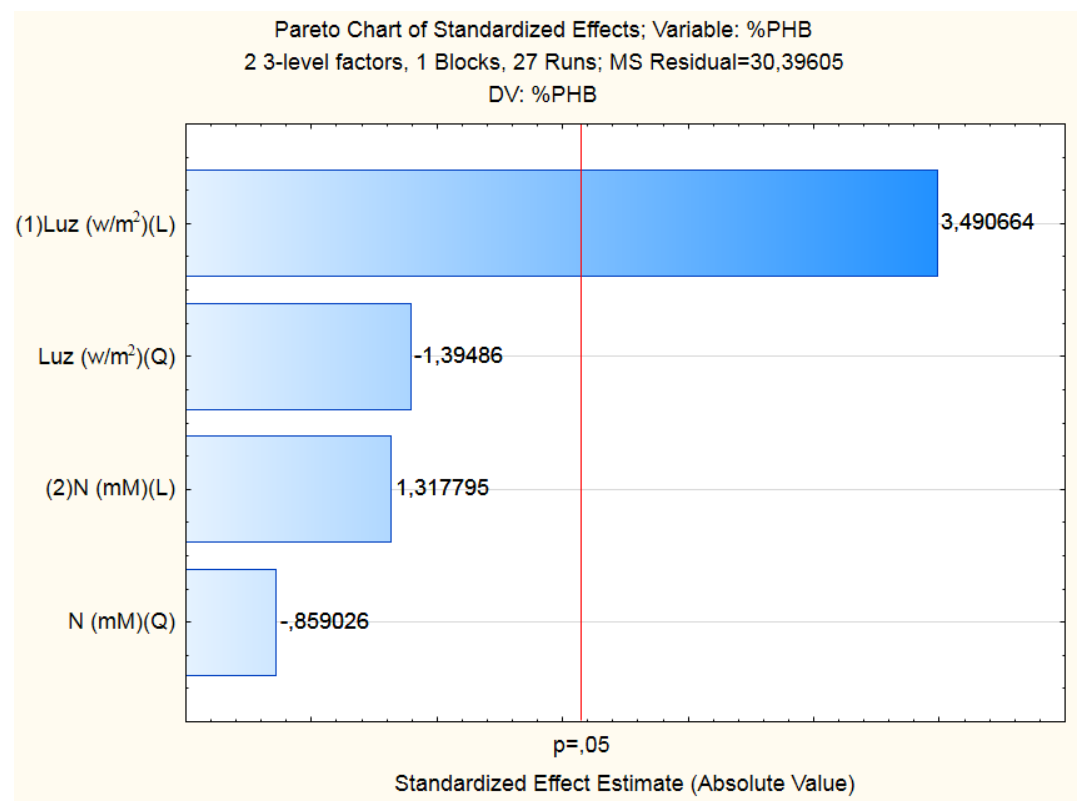

Os experimentos com a linhagem mutante (SB363II), em relação ao tipo selvagem, demonstraram um aumento significativo na porcentagem de PHB de uma forma geral, considerando todas as condições testadas (exceto a máxima). Na condição de $200 \mathrm{~W} / \mathrm{m}^{2}$ de intensidade luminosa e $0,12 \mathrm{mM}$ de concentração de nitrogênio no meio de cultura, por exemplo, este aumento de produção foi de aproximadamente $80 \%$.

Porém, os resultados de porcentagem de PHB apresentados pelo mutante nas diferentes condições, quando comparados entre si, são similares, não apresentando nenhuma tendência clara e não havendo efeitos estatisticamente significativos dos parâmetros testados $(\mathrm{p}<0,05)$. (figuras 27 e 28). 
Figura 27 - Superfície de resposta dos dados coletados no experimento de SB363II com melaço de cana-de-açúcar.

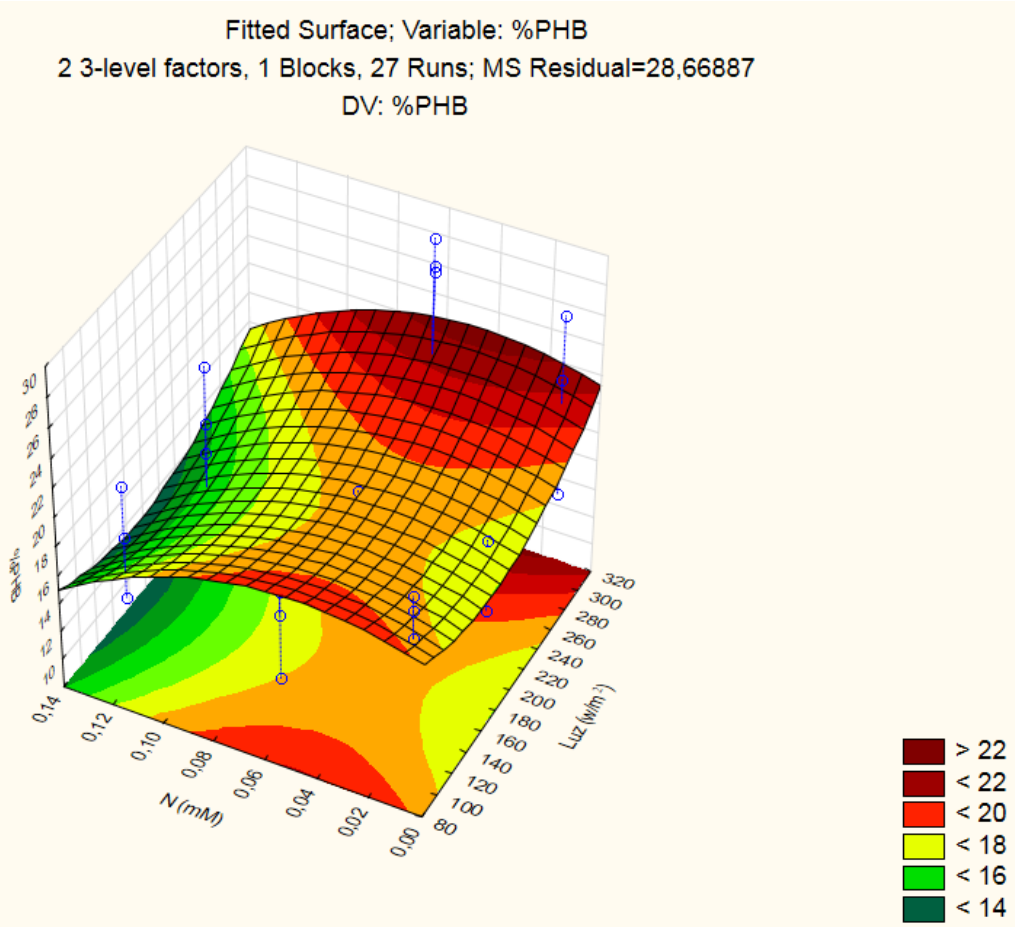

Figura 28 - Gráfico de Pareto relativo ao experimento com SB636II e melaço de cana-deaçúcar mostrando a padronização do efeito de cada parâmetro. (L): linear, (Q): quadrático.

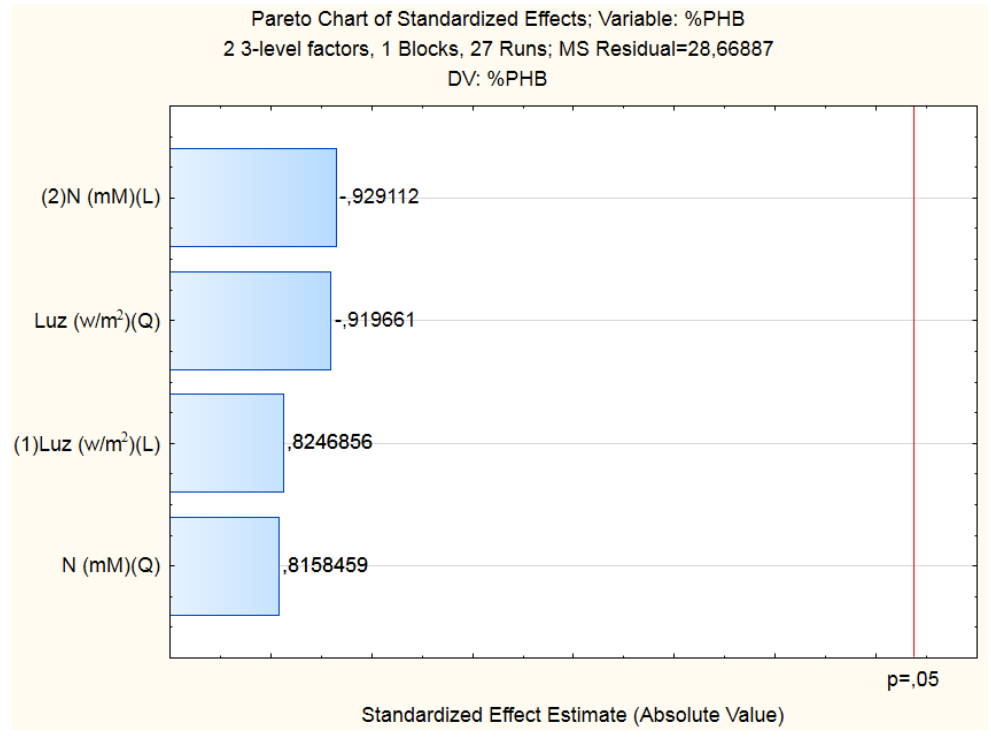

- Acetato 
A fonte de carbono acetato foi escolhida, pois foi comprovado no estudo de $\mathrm{Wu}$ e colaboradores em 2012 que a linhagem WP3-5 de Rhodopseudomonas palustris consegue produzir $\mathrm{PHB}$ e $\mathrm{H}_{2}$ a partir deste substrato, além de propionato, e demonstrou a competição das vias metabólicas de produção destes dois compostos, obteve, neste estudo, maior fator de conversão de substrato em hidrogênio após a linhagem atingir a maior porcentagem de acúmulo de PHB. Os experimentos utilizando acetato como fonte de carbono geraram os seguintes valores de porcentagem de PHB em relação à biomassa (tabela 19).

Tabela 19 - Comparação entre os resultados das médias das triplicatas de produção de PHB por SB1003 (selvagem) e SB363II (mutante) com acetato em porcentagem da relação da quantidade em gramas de PHB na biomassa total (PHB (g)/ biomassa (g)).

\begin{tabular}{|c|c|c|c|c|c|c|}
\hline \multirow[b]{2}{*}{$\begin{array}{l}\text { Nit. } \\
(\mathrm{mM})\end{array}$} & \multicolumn{2}{|c|}{$100 \mathrm{~W} / \mathrm{m}^{2}$} & \multicolumn{2}{|c|}{$200 \mathrm{~W} / \mathrm{m}^{2}$} & \multicolumn{2}{|c|}{$300 \mathrm{~W} / \mathrm{m}^{2}$} \\
\hline & SB1003 & SB363II & SB1003 & SB363II & SB1003 & SB363II \\
\hline 0,01 & 13,42 & 43,60 & 8,32 & 56,25 & 5,38 & 56,55 \\
\hline 0,06 & 14,73 & 30,77 & 9,01 & 54,05 & 13,18 & 28,86 \\
\hline 0,12 & 37,92 & 18,20 & 13,52 & 31,17 & 24,34 & 53,11 \\
\hline
\end{tabular}

Nota: Desvio padrão para dados de SB1003 foi de aproximadamente 10, para SB363II, 17.

O mutante (SB363II), comparado ao tipo selvagem, na condição de maior intensidade luminosa e menor concentração de nitrogênio, obteve um aumento na porcentagem de PHB de até 10 vezes. Em outras condições, como em $100 \mathrm{~W} / \mathrm{m}^{2}$ e $0,06 \mathrm{mM}$, este aumento foi de aproximadamente $50 \%$.

Neste experimento, como esperado, o tipo selvagem apresentou produção de $\mathrm{H}_{2}$ (tabela 20), porém muito inferior a estudos de produção de $\mathrm{H}_{2}$ a partir de acetato utilizando outras linhagens como $R$. palustris que obteve o máximo de produção igual a $2,2 \mathrm{ml} \mathrm{H} / 1 . \mathrm{h}^{-1}$ em estudo realizado por Barbosa e colaboradores (2001). É possível notar que a maior intensidade de luz acarretou em acréscimo da produção de $\mathrm{H}_{2}$. Isto se deve ao fato da luz ser um dos reguladores da atividade da nitrogenase, a atividade enzimática aumenta quando há 
maior intensidade luminosa (STEVENS, VERTONGHEN, DEVOS, DELEY, 1984) e da luz estimular a síntese de nitrogenases (ÖZSOY, 2012).

Tabela 20 - Produção média de hidrogênio (em nmol) por SB1003 (selvagem) com acetato.

\begin{tabular}{cccc} 
& $100 \mathrm{~W} / \mathrm{m}^{2}$ & $200 \mathrm{~W} / \mathrm{m}^{2}$ & $300 \mathrm{~W} / \mathrm{m}^{2}$ \\
\hline $0,01 \mathrm{mM}$ & 0 & 0 & 79,62 \\
$0,06 \mathrm{mM}$ & 46,08 & 81,92 & 0 \\
$0,12 \mathrm{mM}$ & 0 & 0 & 49,15 \\
\hline
\end{tabular}

Com respeito aos dados gerados pelo tipo selvagem (SB1003), ao observarmos o gráfico da superfície de resposta (figura 29), podemos notar que parece haver uma relação direta entre o aumento da quantidade de nitrogênio e o aumento da porcentagem de PHB.

Figura 29 - Superfície de resposta dos dados coletados no experimento de SB1003 com acetato.

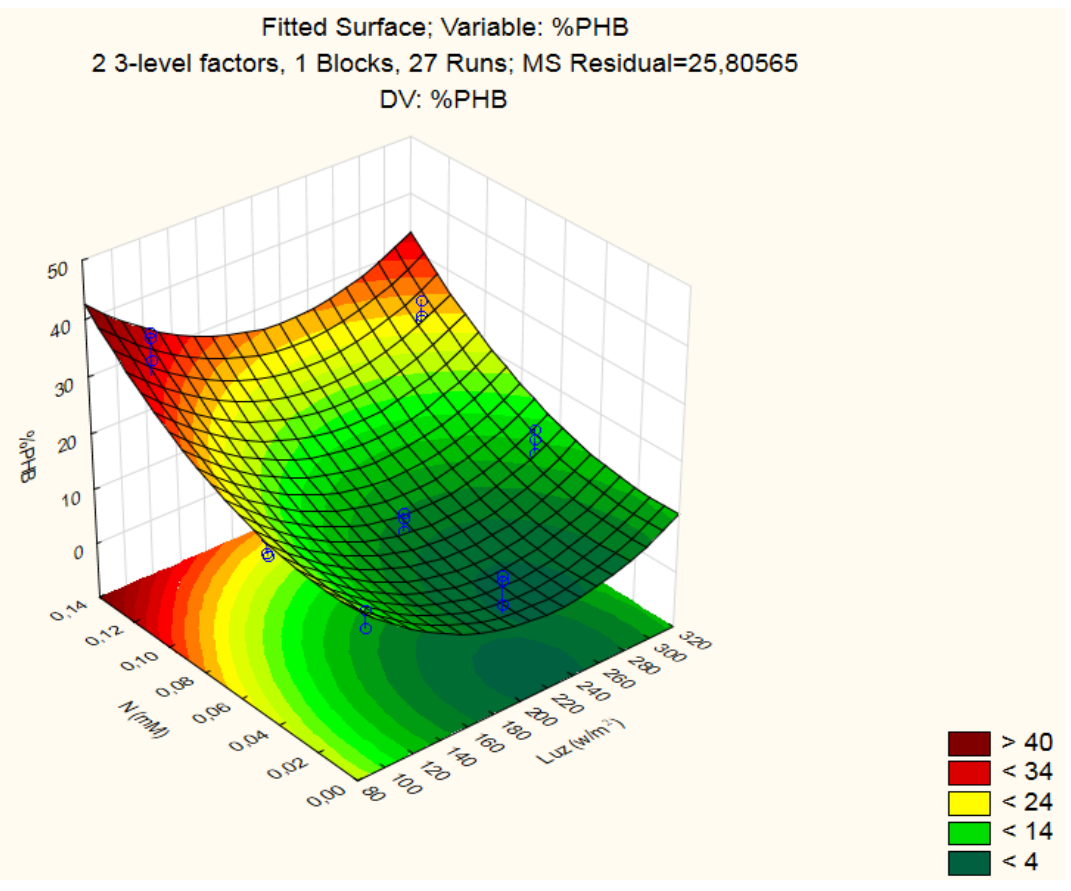


Este comportamento é contrário ao estudado em C. necator ( $R$. eutropha) durante o projeto de mestrado da aluna, em meios de cultura contendo diferentes limitações de nitrogênio e fósforo (figura 30), onde a limitação de nitrogênio favoreceu o aumento de síntese de PHB quando utilizou-se frutose como fonte de carbono. A linhagem citada não é produtora de hidrogênio e não realiza fotossíntese, portanto não exibe atividade da enzima nitrogenase. Porém este efeito em $R$. capsulatus pode ser justificado pelo fato de uma maior concentração de nitrogênio poder causar um efeito inibidor na nitrogenase, acarretando na interrupção da produção de $\mathrm{H}_{2}$ e redirecionamento do poder redutor e demais intermediários para a síntese de PHB, gerando maiores porcentagens nos experimentos com mais concentrados em nitrogênio.

Figura 30 - Gráfico de barras contendo dados de porcentagem de PHB em relação à biomassa coletados em cultivo com $R$. eutropha $(C$. necator) e $B$. sacchari em meio contendo limitação de nitrogênio ou fósforo e frutose como fonte de carbono.

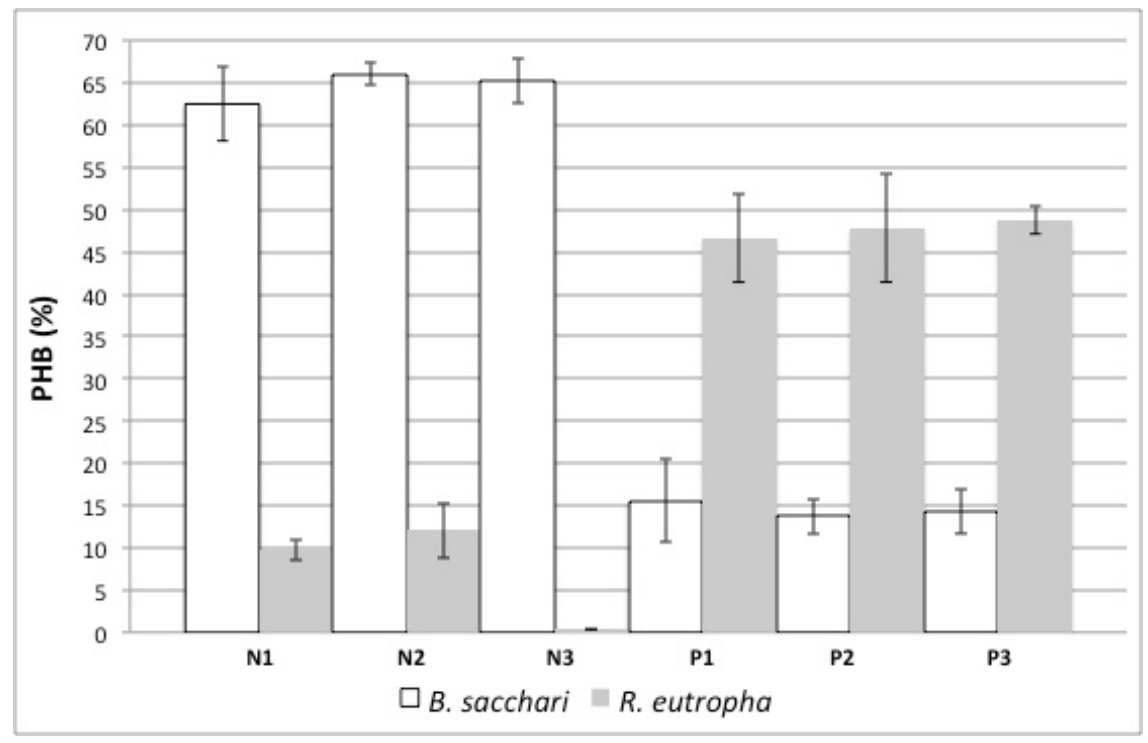

Notas: Concentrações de nitrogênio utilizadas foram: 0,5;1,0;1,5 g/1 para N1, N2, N3 respectivamente. Concentrações de fósforo: 0,$06 ; 0,12 ; 0,18$ g/l para P1, P2, P3 respectivamente. Experimento realizado em triplicata, gráfico contêm as médias e desvios-padrão.

Já o parâmetro intensidade luminosa mostra a tendência a uma relação indireta, mas não está clara neste gráfico. Porém ao analisarmos o gráfico de Pareto (figura 31), podemos verificar que uma relação entre os efeitos parece existir, sendo quanto menor a quantidade de luz, maior a porcentagem de PHB (valor negativo no gráfico indicando relação indireta). Esta 
relação pode ser justificada pelo fato da nitrogenase ter maior atividade em maior intensidade luminosa, desviando os intermediários para a produção de $\mathrm{H}_{2}$ e com isto, diminuindo a produção de $\mathrm{PHB}$, em baixa luminosidade, o efeito é inverso.

Figura 31 - Gráfico de Pareto relativo ao experimento com SB1003 e acetato mostrando a padronização do efeito de cada parâmetro. (L): efeito linear, $(\mathrm{Q})$ : efeito quadrático.

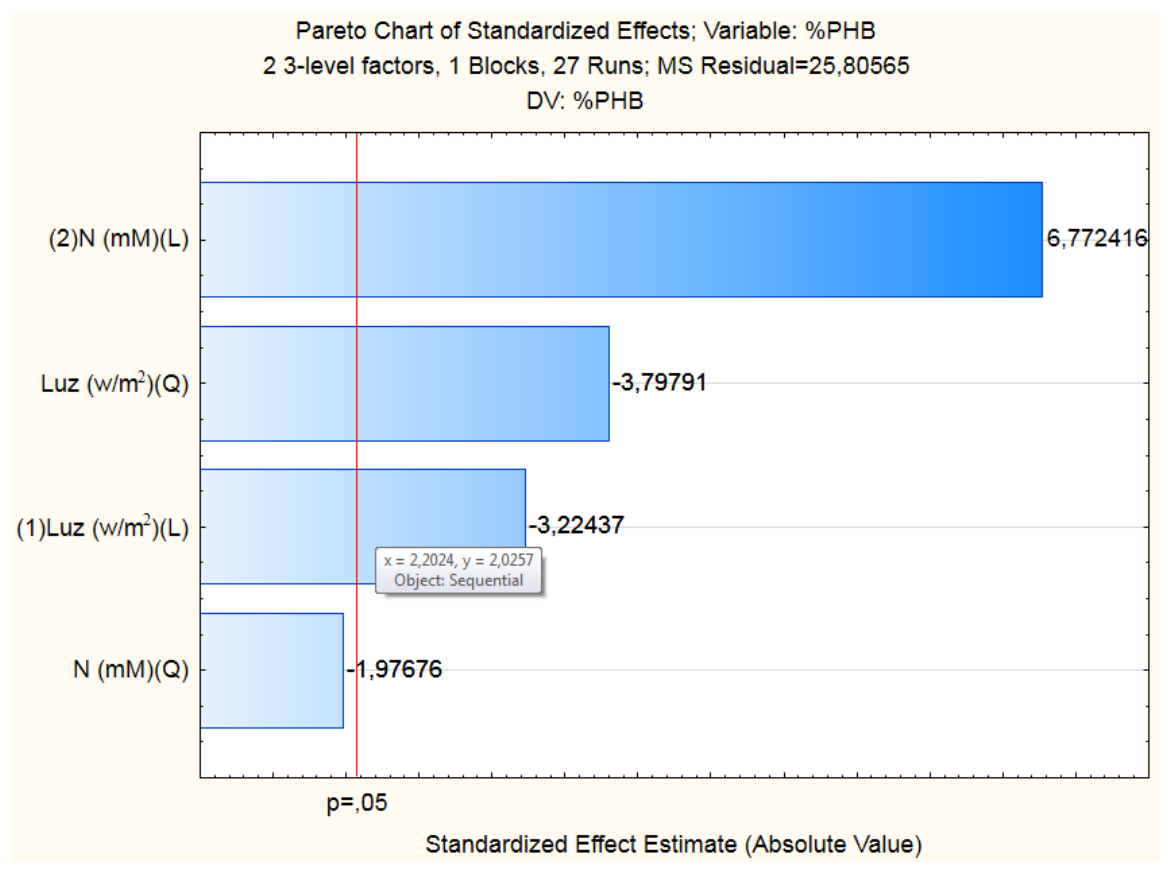

O mutante (SB363II), que não codifica a nitrogenase, apresentou melhores valores de produção de PHB em menores concentrações de nitrogênio. Este resultado pode ser visto como a indução da produção de polímero pelo estresse causado pela limitação de nitrogênio, que é uma condição que favorece este comportamento. O gráfico de superfície (figura 32) de resposta indica que pode haver uma tendência a maior produção de PHB quando a intensidade de luz é o valor intermediário $\left(200 \mathrm{~W} / \mathrm{m}^{2}\right)$ ou maior que ele (figura 33$)$. 
Figura 32 - Superfície de resposta dos dados coletados no experimento de SB363II com acetato.

Fitted Surface; Variable: \%PHB

2 3-level factors, 1 Blocks, 27 Runs; MS Residual=99,32612

DV: \%PHB

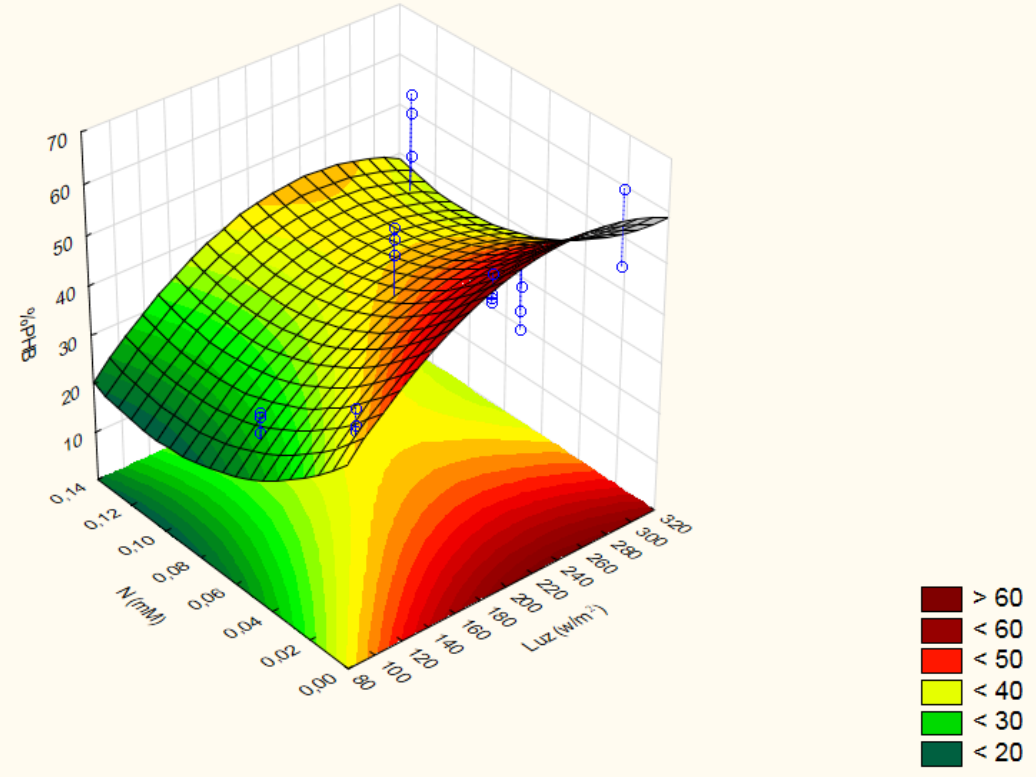

Figura 33 - Gráfico de Pareto relativo ao experimento com SB363II e acetato mostrando a padronização do efeito de cada parâmetro. (L): efeito linear, (Q): efeito quadrático.

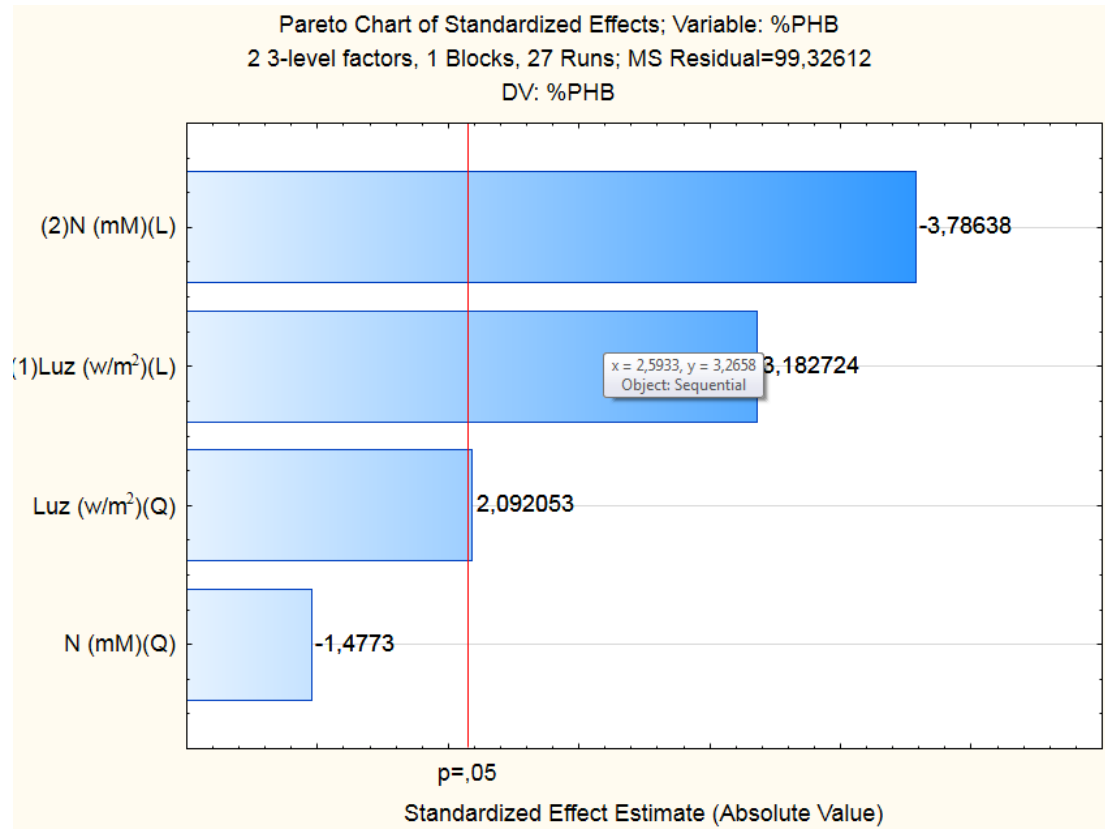




\subsubsection{Rhodopseudomonas palustris}

\section{- Glicerol cru}

Os tipos selvagem (CGA009) e mutante (CGA750) de Rhodopseudomonas palustris foram testados quanto a produção de PHB em meio contendo glicerol cru já que a linhagem não metaboliza açúcares para produção do polímero, proveniente de resíduo industrial, como fonte de carbono. Os dados das porcentagens de PHB produzido estão apresentados na tabela 21. A maior produção pelo tipo selvagem (CGA009) se deu na maior concentração de nitrogênio e $200 \mathrm{~W} / \mathrm{m}^{2}$.

O mutante (CGA750) obteve o maior valor com a menor concentração de nitrogênio, similar ao experimento com SB363II em acetato, e mesma intensidade luminosa, $200 \mathrm{~W} / \mathrm{m}^{2}$, porém, de forma geral, a produção do polímero pelo mutante não sofreu muitas alterações nestas variações dos parâmetros escolhidos. É possível que um estudo contendo maior amplitude de intensidade de luz e concentração de nitrogênio gere resultados mais claros em relação à interação destes parâmetros.

Tabela 21 - Comparação entre os resultados das médias das triplicatas de produção de PHB por CGA009 (selvagem) e CGA750 (mutante) com glicerol em porcentagem da relação da quantidade em gramas de PHB na biomassa total (PHB (g)/ biomassa (g)).

\begin{tabular}{ccccccc} 
& \multicolumn{2}{c}{$100 \mathrm{~W} / \mathrm{m}^{2}$} & & $200 \mathrm{~W} / \mathrm{m}^{2}$ & \multicolumn{2}{c}{$300 \mathrm{~W} / \mathrm{m}^{2}$} \\
\hline $\begin{array}{c}\text { Nit. } \\
(\mathrm{mM})\end{array}$ & CGA009 & CGA750 & CGA009 & CGA750 & CGA009 & CGA750 \\
0,01 & 5,21 & 15,20 & 8,11 & 16,21 & 15,87 & 11,53 \\
0,06 & 1,64 & 13,28 & 15,17 & 13,92 & 11,85 & 14,78 \\
0,12 & 13,60 & 13,42 & 23,00 & 13,90 & 22,52 & 13,35 \\
\hline
\end{tabular}

Nota: Desvio padrão dos dados de CGA009 e CGA750 foi menor que 11.

O gráfico de superfície de resposta (figura 34) dos dados gerados no experimento com o tipo selvagem indica que pode haver uma tendência a maiores valores de síntese de PHB em condições de maior concentração de nitrogênio e maior intensidade de luz, mostrando que possivelmente a concentração mais baixa de nitrogênio não parece favorecer a produção do polímero. 
Figura 34 - Superfície de resposta dos dados coletados no experimento de CGA009 com glicerol.

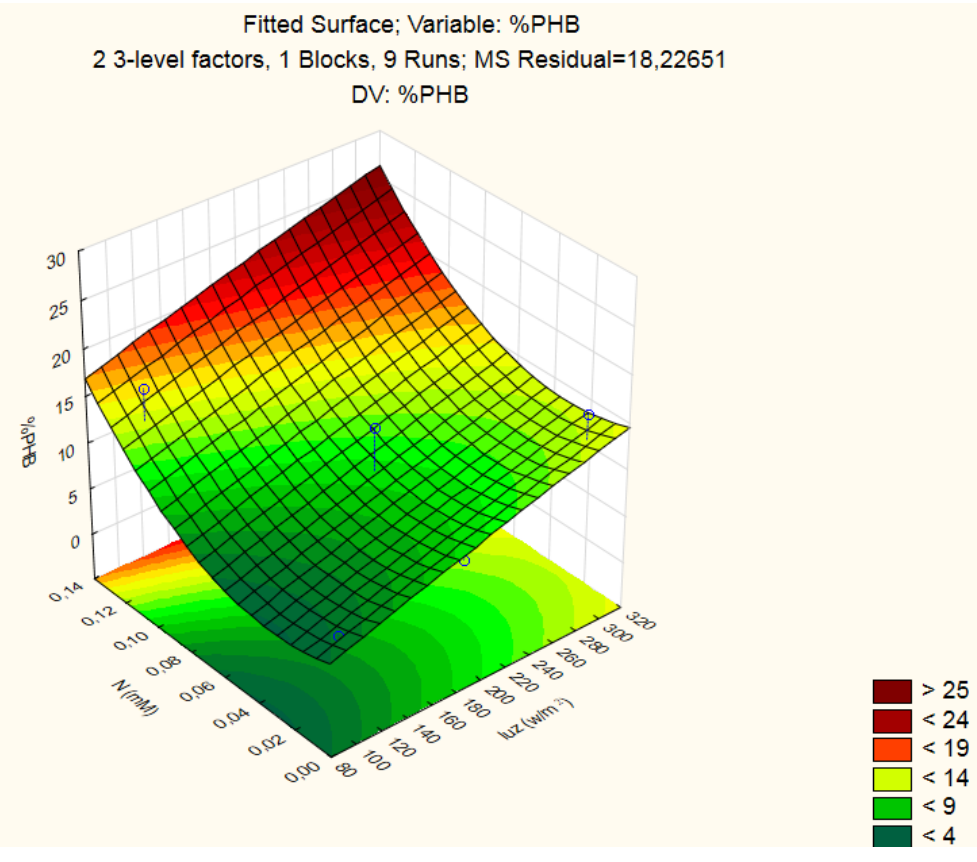

Porém, o gráfico de Pareto (figura 35) apresenta que a relação entre os dois parâmetros escolhidos (luz e nitrogênio) não são estatisticamente significativas nos níveis utilizados (a variação da concentração de nitrogênio e a intensidade luminosa).

Figura 35 - Gráfico de Pareto relativo ao experimento com CGA009 e glicerol mostrando a padronização do efeito de cada parâmetro. (L): efeito linear, (Q): efeito quadrático.

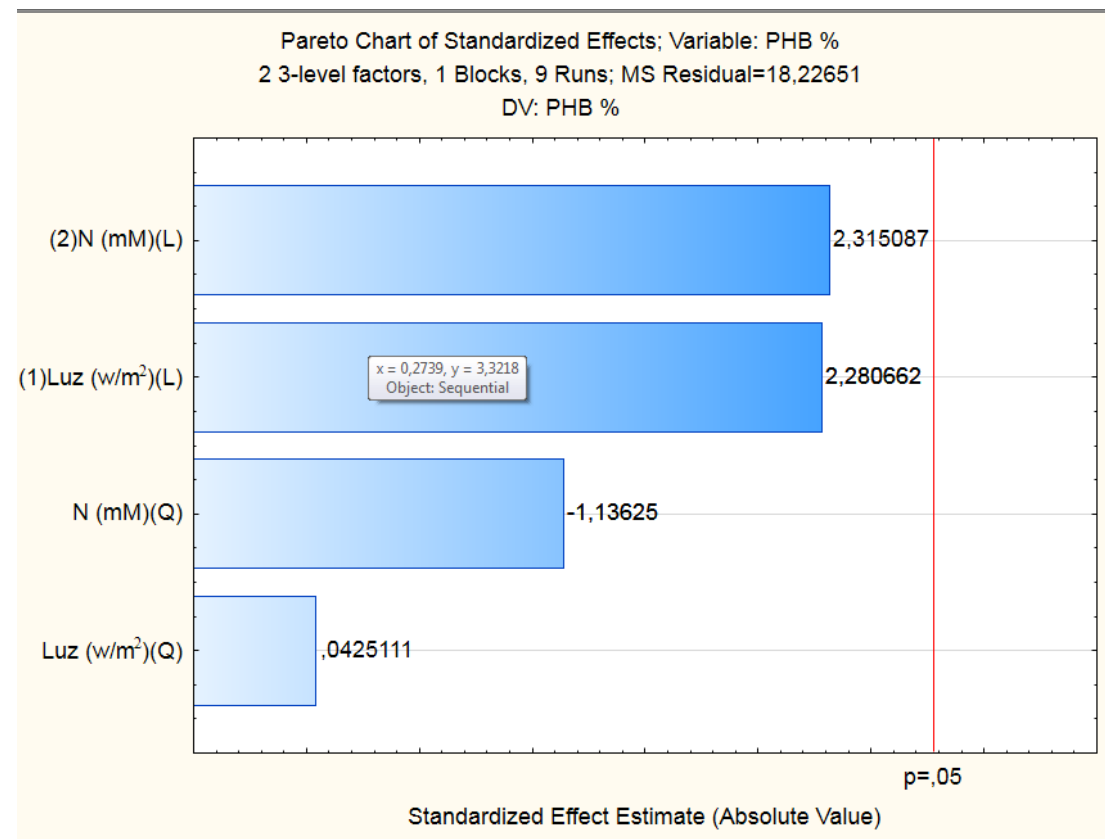


Os dados coletados do experimento com o mutante mostram a indicação de uma relação também inversa (figura 36), em que menores concentrações de nitrogênio e de luz produzem maiores porcentagens de PHB. Porém, também neste caso, o gráfico de Pareto (figura 37) demonstra que não existe uma relação estatisticamente significativa. Apesar disto, estes resultados podem evidenciar que estudos com variações mais indicadas, mas seguindo essas relações, poderiam esclarecer de forma mais robusta a relação entre estes parâmetros.

Figura 36 - Superfície de resposta dos dados coletados no experimento de CGA750 com glicerol.

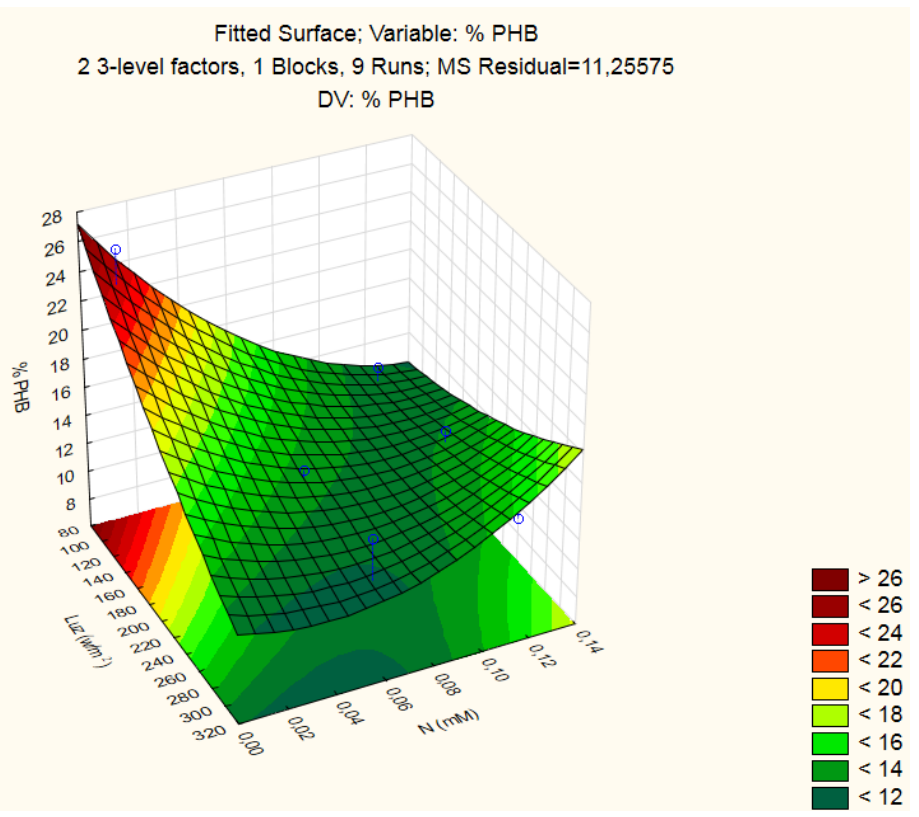


Figura 37 - Gráfico de Pareto relativo ao experimento com CGA009 e glicerol mostrando a padronização do efeito de cada parâmetro. (L): efeito linear, $(\mathrm{Q})$ : efeito quadrático.

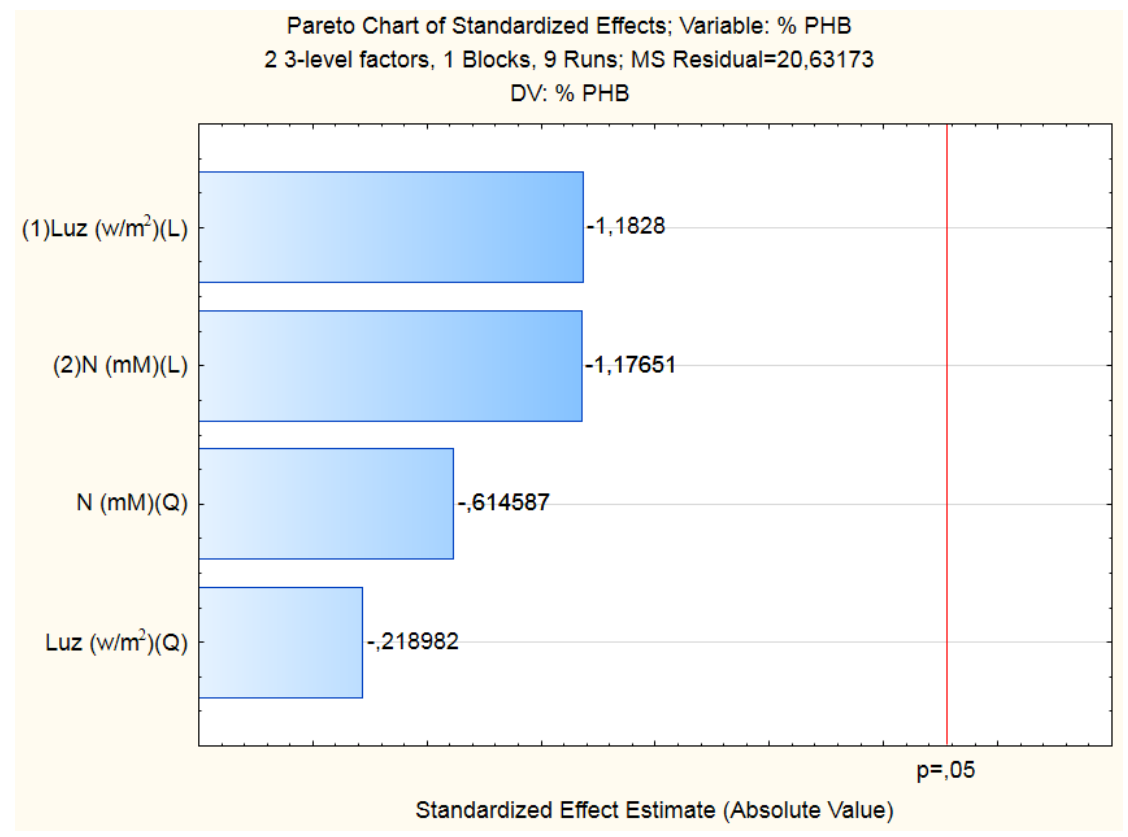

Uma comparação dos resultados obtidos nos experimentos realizados neste trabalho pode ser visualizada na tabela 22.

Tabela 22 - Comparação entre os experimentos de produção de $\mathrm{PHB}$ e $\mathrm{H}_{2}$ realizados com SB1003, SB 363II, CGA009 e CGA750.

\begin{tabular}{|c|c|c|c|c|c|}
\hline & Luz & Nitrogênio & $\begin{array}{l}\text { \%PHB } \\
\text { máx }\end{array}$ & $\mathrm{H}_{2}$ & $\begin{array}{l}\text { Fonte de } \\
\text { carbono }\end{array}$ \\
\hline SB1003 & _ & + & 37,92 & $\mathrm{~S}$ & \multirow{2}{*}{ Acetato } \\
\hline SB363II & $\mathrm{N}$ & - & 56,55 & ND & \\
\hline SB1003 & - & $\mathrm{N}$ & 26,30 & ND & \multirow{2}{*}{$\begin{array}{l}\text { Melaço } \\
\text { de cana }\end{array}$} \\
\hline SB363II & $\mathrm{N}$ & $\mathrm{N}$ & 27,76 & ND & \\
\hline CGA009 & $\mathrm{N}$ & $\mathrm{N}$ & 23,00 & ND & \multirow{2}{*}{$\begin{array}{c}\text { Glicerol } \\
\text { Cru }\end{array}$} \\
\hline CGA750 & $\mathrm{N}$ & $\mathrm{N}$ & 16,21 & ND & \\
\hline
\end{tabular}

Notas: Sinais "+" e "-“ indicam relação direta ou indireta, respectivamente, com a produção de PHB. ND: não foi detectado; N: não apresentou relação.

Os experimentos com SB363II em melaço de cana-de-açúcar não conseguiram determinar um tipo de interação relacionada a produção de PHB com os parâmetros testados por razões discutidas anteriormente. $\mathrm{O}$ experimento com acetato demonstrou que o mutante perde a relação da interação luz e PHB devido ao bloqueio da enzima nitrogenase, que sofre 
efeitos em sua atividade em relação à intensidade luminosa e como comprovado por Chongcharoentaweesuk, Zhang e Mavituna (2011), a produção de hidrogênio por bactérias púrpuras não-sulfúricas é principalmente relacionada à enzima nitrogenase.

\subsubsection{Conclusões do projeto "Influência da produção de hidrogênio na síntese de PHB”.}

$\mathrm{O}$ experimento que produziu maior quantidade de $\mathrm{PHB}$ em relação à biomassa foi $\mathrm{o}$ que utilizou SB363II (mutante) com acetato (56,55\%), os demais experimentos demonstraram valores similares. Já se é conhecido que acetato é uma fonte de carbono interessante para a produção de PHB. A síntese do polímero em melaço de cana-de-açúcar não foi aquém da obtida em acetato, o que pode evidenciá-la como uma fonte de carbono em potencial para esta finalidade, já que é resíduo de indústrias de agricultura. Porém, estudos visando a otimização destas condições são necessários para a determinação e o aumento da eficiência do uso do melaço de cana-de-açúcar para esta finalidade pois mesmo o valor de 56,55\% de PHB em relação a biomassa produzido por $R$. capsulatus ainda é inferior as porcentagens de acúmulo obtidas por linhagens como C. necator e Burkholderia sacchari que chegam a acumular mais de $70 \%$ de PHB em diferentes tipos de açúcar.

Os experimentos feitos neste estudo permitiram identificar algumas relações de interação entre os parâmetros intensidade luminosa e concentração de nitrogênio nas linhagens avaliadas. Pode-se observar que o tipo selvagem SB1003, que sintetiza a enzima nitrogenase, exibiu uma relação indireta de interação com a luz, e que no caso do mutante, esta interação é anulada por esta enzima não ser sintetizada. Portanto, pode-se verificar o comportamento metabólico da linhagem Rhodobacter capsulatus na produção de PHB favorecido pelo bloqueio de síntese da enzima em questão, o que acarretou na maior influência da concentração do nitrogênio pelo respectivo mutante. Esta condição demonstrou uma boa estratégia para aumentar a eficiência de produção da linhagem.

Já para Rhodopseudomonas palustris, não foi possível determinar a influência do bloqueio da via de produção de $\mathrm{H}_{2}$, pois, possivelmente, a variação escolhida para os parâmetros não foi suficiente.

É sabido que a produção de $\mathrm{H}_{2}$ não só compete com a produção de $\mathrm{PHB}$ por intermediários e poder redutos, como também apresenta relações ainda mais complexas ainda não definidas. Estudos como o de Wu, Liou e Lee (2012) descrevem que o PHB intracelular é 
benéfico para a produção de $\mathrm{H}_{2}$, indicando que o PHB possui outras funções ainda não conhecidas.

As análises de PHB pelo método Law e Slepecky (1961) não demostraram serem precisas, já que os valores de produção de PHB variaram muito em uma mesma triplicata e em alguns casos eram muito distantes do esperado, o que tornou a análise dos resultados menos assertiva. A análise de PHB utilizando cromatógrafo gasoso equipado com coluna para a análise de propil-ésteres seria uma solução eficaz para melhorar estas medidas, porém, apesar do laboratório possuir este equipamento, ele não continha a coluna adequada e esta não poderia ser comprada, já que seu custo é muito alto.

Além da falta de robustez do método de obtenção de dados de PHB, uma análise estatística mais profunda seria necessária para a avaliação dos dados obtidos por DoE e RSM, já que apenas foi realizada uma observação simples e desconsiderando fatores importantes como erro e residual dos modelos gerados.

Portanto, este estudo mostra apenas uma observação inicial da interação destes parâmetros. Ele não pode estabelecer modelos matemáticos devido à falta de acurácia das medidas de PHB, e falta de conhecimentos estatísticos avançados para a aplicação de modelo matemático e suas respectivas análises. 


\section{CONCLUSÃO E PERSPECTIVAS FUTURAS}

Neste projeto, comprovou-se as eficiências de conversão de carboidratos em PHB de 80 a 88 e de 90 a 100\% apresentadas por Burkholderia sacchari e Cupriavidus necator, respectivamente, como previamente calculadas no artigo Gomez et al. 1996 e testaram-se novas fontes de carbono, que resultaram em eficiências similares.

O experimento de B. sacchari em biorreator utilizando glicose como fonte de carbono obteve, durante um estado pseudo-estacionário estabelecido, o valor máximo teórico de conversão de substrato em PHB. Este resultado sugere que processos de cultivo nestas condições, em que, principalmente, ocorre crescimento e acúmulo simultaneamente, favoreçam esta eficiência máxima e portanto se apresentam como uma estratégia que aumentaria a produtividade de PHB em um processo industrial.

Além disso, neste estudo, foi determinado, através de experimentos de rastreamento de carbonos marcados e não-marcados, que Burkholderia sacchari e Cupriavidus necator apresentam as mesmas rotas de síntese de PHB, o que indica que a menor eficiência de $B$. sacchari comparada a $C$. necator (linhagem que atinge o máximo teórico da conversão) pode ser justificada por diferenças nos fluxos destas rotas metabólicas e não pelo uso de vias metabólicas distintas.

Como perspectiva futura, este trabalho sugere a implementação dos dados obtidos nos experimentos com substrato marcado em software que gere a distribuição de carbonos nas vias metabólicas desta linhagem, de forma a confirmar de forma experimental os gerados neste trabalho através do programa Metatool. Também sugere-se que sejam realizados novos cultivos em biorreator visando estender a fase de crescimento e acúmulo da linhagem estudada para a obtenção de períodos mais longos em que esta característica ocorre já que ela gera a eficiência máxima de conversão de carboidrato em $\mathrm{P}(3 \mathrm{HB})$ de $B$. sacchari.

A importância destes resultados não está apenas no fato da melhor caracterização da produção do polímero biodegradável $\mathrm{P}(3 \mathrm{HB})$, nos níveis de bioprocessos e rotas metabólicas, por uma linhagem que metaboliza um substrato mais barato mas também porque estabelece uma importante estratégia para a implementação desta linhagem em indústrias que produzem este polímero. 


\section{REFERÊNCIAS $\mathbf{S}^{1}$}

ANDERSON, A. J.; DAWES, E. A. Occurrence, metabolism, metabolic role and industrial uses of bacterial polyhydroxyalkanoates. Microbiol. Rev., v. 54, p. 450-472, 1990.

BARBOSA, M. J.; ROCHA, J. M. S.; TRAMPER, J.; WIJFFELS, R. H. Acetate as a carbon source for hydrogen production by photosynthetic bactéria. Journal of Biotechnology, v. 85, n. 1, p. 25-33, 2001.

BRÄMER, C. O.; VANDAMME, P.; SILVA, L. F.; GOMEZ, J. G. C.; STEINBÜCHEL, A. Burkholderia sacchari sp. nov: a polyhydroxyalkanoate-accumulating bacterium isolated from soil of a sugar-cane plantation in Brazil. Int. J. Microbiol. Ecol., v. 51, p. 1709-1713, 2001.

BRÄMER, C. O. et al. Identification of the 2- methylcitrate pathway involved in the catabolism of propionate in the polyhydroxyalkanoate-producing strain Burkholderia sacchari IPT101 and analysis of a mutant accumulating a copolyester with higher 3-hidroxyvalerate content. Applied and Environmental Microbiology, v. 68, p. 271-279, 2002.

CARLOZZI, P.; SACCHI, A. Biomass production and studies on Rhodopseudomonas palustris grown in an outdoor, temperature controlled, underwater tubular photobioreactor. $J$ Biotechnol., v. 88, n. 3, p. 239-249, 2001.

CHANPRATEEP, S. Current trends in biodegradable polyhydroxyalkanoates. Journal of Bioscience and Bioengineering, v. 110, n. 6, p. 621-632, 2010.

CHANPRATEEP, S.; KATAKURA, Y.; SHIMIZU, H;, VSETKOOP, S.; KULPREECHA, S.; SHIOYA, S. Characterization of new isolated Ralstonia eutropha strain A-04 and kinetic study of biodegradable copolyester poly(3-hydroxybutyrate-co-4-hydro-xybutyrate) production. J. Ind. Microbiol. Biotechnol., v. 35, p. 1205-1215, 2008.

CHEN, X.; ALONSO, A. P.; ALLEN, D. K.; REED, J. L.; SHACHAR-HILL, Y. Synergy between ${ }^{13} \mathrm{C}$-metabolic flux analysis and flux balance analysis for understanding metabolic adaptation to anaerobiosis in E. coli. Metabolic Engineering., v. 13, p. 38-48, 2011.

CHINWETKITVANICH, S.; RANDALL, C. W.; PANSWAD, T. Effects of phosphorus limitation and temperature on PHA production in activated sludge. Water Science and Technology, v. 50, p. 135-143, 2004.

CHONGCHAROENTAWEESUK, P.; ZHANG, J.; MAVITUNA, F. Metabolic Flux Balance Analysis of the primary metabolism for hydrogen production in purple non-sulfur bacteria. In J. Biosc., Biochem., Bioinf., v. 1, n. 1, 2011.

DEMARCO, S. Advances in polyhydroxyalkanoate production in bacteria for biodegradable plastics. Basic Biotechnology eJournal, v. 1, p. 1-4, 2005.

\footnotetext{
${ }^{1}$ De acordo com:

ASSOCIAÇÃO BRASILEIRA DE NORMAS TÉCNICAS. NBR 6023: informação e documentação: referências: elaboração. Rio de Janeiro, 2002.
} 
FONSECA, G. G. Análise de Fluxos Metabólicos em Kluyveromyces marxianus utilizando substratos marcados com ${ }^{13} \mathrm{C}$. Tese (Doutorado) - Universidade de São Paulo, São Paulo, 2007.

GHOSH, D.; SOBRO, I. F.; HALLENBECK, P. C. Stoichiometric conversion of biodiesel derived crude glycerol to hydrogen: Response surface methodology study of the effects of light intensity and crude glycerol and glutamate concentration. Bioresource Technology, v. 106, p. 154-160, 2012.

GÓMEZ, E. F.; MICHEL, F. C. Biodegradability of conventional and bio-based plastics and natural fiber composites during composting, anaerobic digestion and long-term soil incubation. Polymer Degradation and Stability, v. 98, n. 12, p. 2583-2591, 2013.

GOMEZ, J. G. C.; RRODRIGUES, M. F. A.; Alli, R. C. P.; TORRES, B. B.; BUENO NETTO, C.L.; OLIVEIRA, M. S.; SILVA, L. F. Evaluation of soil gram-negative bacteria yielding polyhydroxyalkanoic acids from carbohydrates and propionic acid. Appl. Microbiol. Biotechnol., v. 45, p. 785-79, 1996.

GOMEZ, J. G. C. Produção por Pseudomonas sp de polihidroxialcanoatos contendo monômeros de cadeia média a partir de carboidratos: avaliação da eficiência, modificação da composição e obtenção de mutantes. Tese (Doutorado em Microbiologia) - Instituto de Ciências Biomédicas, Universidade de São Paulo, São Paulo, 2000.

GUMEL, A. M.; ANNUAR, M. S. M.; CHISTI, Y. Recent Advances in the Production, Recovery and Applications of Polyhydroxyalkanoates. Journal of Polymers and the Environment, v. 21, n. 2, p. 580-605, 2013.

HAAKER, H. C.; LAANE, HELLINGWERF, K.; HOUWER, B.; KONINGS, W. N.; VEEGER, C. Short-term regulation of the nitrogenase activity in Rhdopseudomonas sphaeroides. Eut. J. Biochetn., v. 127, p. 639-645, 1982.

JENDROSSEK, D.; HANDRICK, R. Microbial degradation of polyhydroxyalkanoates. Annu. Rev. Microbiol., v. 56, p. 403-432, 2002.

JOHNSTONE, B. A throw away answer. Far Eastern Econ. Rev. v. 147, n. 6, p. 62-63, 1990.

KAPDAN, K. I.; HARGI, F. Bio-hydrogen production from waste materials. Enzyme and Microbial Technology, v. 38, p. 569-582, 2006.

KALIA, V. C.; RAIZADA, N.; SONAKYA, V. Bioplastics. J. Sci. Ind. Res., v. 59, p. 433445, 2000a.

KARS, G.; GÜNDÜZ, U. Towards a super $\mathrm{H}_{2}$ producer: Improvements in photofermen-tative biohydrogen production by genetic manipulations. International Journal of Hydrogen Energy, v. 35, n. 13, p. 6646-6656, 2010.

KAWAGUCHI, Y.; DOI, Y. Structure of native poly(3-hydroxybutyrate) granules characterized by X-ray diffraction. FEMS Microbiol., v. 70, p.151, 1990. 
KAWAI, L. A. Melhoramento da eficiência de produção de polihidroxialcanoatos por Pseudomonas sp. através da análise molecular e modificação genética. Dissertação (Mestrado em Ciências Biológicas (Microbiologia)) - Universidade de São Paulo, Coordenação de Aperfeiçoamento de Pessoal de Nível Superior. Orientador: José Gregério Cabrera Gomez, 2013.

KHANNA, S.; SRIVASTAVA, A. K. Recent advances in microbial polyhydroxyalkanoates. Process Biochemistry., v. 40, n. 2, p. 607-619, 2005.

KOKU, H.; EROGLU, I.; GUNDUZ, U.; YUCEL, M.; TURKER, L. Aspects of the metabolism of hydrogen production by Rhodobacter sphaeroides. International Journal of Hydrogen Energy, v. 27, n. 11-12, p. 1315-1329, 2002.

LAW, J. H.; SLEPECKY, R. A. Assay of poly-hydroxybutyric acid. J. Bacteriology, v. 82, p. 33-36, 1961.

LEE, S. Y.; YIM, K. S.; CHANG, H. N., CHANG, Y. K. Construction of plasmids, estimation of plasmid stability and use of stable plasmids for the production of poly(3hydroxybutyric) acid by recombinant Escherichia coli. J. Biotechnol. v. 32, p. 203-211, 1994.

LEE, S. Y. Bacterial polyhydroxyalkanoates. Biotechnol. Bioeng., v. 49, p. 1-14, 1996a.

LEE, S. Y. Plastic bacteria: Progress and prospects for polyhydroxyalkanoate production in bacteria. Trends Biotechnol. v. 14, p. 431-438, $1996 \mathrm{~b}$.

LOPES, M. S. et al. Screening of bacteria to produce polyhydroxyalkanoates from xylose. World J. Microbiol. Biotechnol., v.25, p. 1751-1756, 2009.

LORRUNGRUANG, C.; MARTTHONG, J.; SASAKI, K.; NOPARATNARAPORN, N. Selection of photosynthetic bacterium Rhodobacter sphaeroides $14 \mathrm{~F}$ for poluhydroxyalkanoate production with two stage aerobic dark cultivation. J. Bioscience and Bioengineering, v. 102, n. 2, p. 128-131, 2006.

MADISON, L. L.; HUISMAN, G. W. Metabolic engineering of poly(3-hydroxyalkanoates): from DNA to plastic. Microbiol. Mol. Biol. Rev., v. 63, n. 1, p. 21-53, 1999.

MENDONÇA, T. T. et al. Exploring the potential of Burkholderia sacchari to produce polyhydroxyalkanoates. J A ppl Microbiol. 2013.

MERUGU, R.; GIRISHAM, S.; REDDY, S. M. Production of PHB (polyhydroxybutyrate) by Rhodopseudomonas palustris KU003 under nitrogen limitation. Int. J. Appl. Biol. Pharm. Technol., v. 2, p. 676-678, 2010.

MÜLLER H. M., SEEBACH D. Poly(hydroxyalkanoates): A fifith class of physiologically important biopolymer? Angew. Chem. Int. Edit. (English), v.32, p.477-502, 1993.

NEIDHARDT, F. C.; INGRAHAM, J. L.; SCHAECHTER, M. Phisiology of the bacterial cell: a molecular approach. Sunderland, Mass.: Sinauer Associates, 1990. 506 p. 
NONATO, R. V.; MANTELATO, P. E.; ROSSEL, C. E. V. Integrated production of biodegradable plastic, sugar and ethanol. Applied Biotechnology, v. 57, p.1-5, 2001.

ODA, Y.; SUDIP, K.; REY. F. E.; WU, L.; LIU, X.; YAN, T.; ZHOU, J.; HARWOOD, C. Functional Genomic Analysis of three nitrogenase isozymes in the photosynthetic bacterium Rhodopseudomonas palustris. J. Bacteriology, v. 187, n. 22, p. 7784-7794, 2005.

$\mathrm{OH}, \mathrm{Y}$. Photoproduction of hydrogen from acetate by a chemoheterotrophic bacterium Rhodopseudomonas palustris P4. Int. J. Hydrogen Energy, v. 29, p. 1115-1121, 2004.

ÖZSOY, B. Hydrogen and poly-beta-hydroxy-butyric acid production and expression analyses of related genes in Rhodobacter capsulatus at different acetate concentrations Trabalho de dissertação de mestrado - Middle East Technical University, Ancara, Turquia, 2012 .

PEREIRA, H.; LEMOS, P. C.; REIS, M. A. M.; CRESPO, J. P. S. G.; CARRONDO, M. J. T.; SANTOS, H. Model for carbon metabolism in biological phosphorus removal process based on in vivo C-NMR labeling experiments. Water Res., v. 30, p. 2128-2138, 1996.

PFEIFFER, T.; SANCHEZ-VALDENEBRO, I.; NUNO, J.; MONTERO F.; SCHUSTER, S. METATOOL: for studying metabolic networks. Bioinformatics, v. 15, p. 251-257, 1999.

POIRIER, Y.; NAWRATH, C.; SOMMEVILLE, C. Production of polyhydroxyalkanoates, a family of biodegradable plastics and elastomers, in bacteria and plants. Nature Biotechnology. v. 13, p. 142-150, 1995.

PRADELlA, J. G. C.; TACIRO, M. K.; MATEUS, A. Y. P. High-cell-density poly (3hydroxybutyrate) production from sucrose using Burkholderia sacchari culture in airlift bioreactor. Bioresource Technology, v. 101, p. 8355-8360, 2010.

PREUSTING, H. A.; NIJENHUIS; WITHOLT, B. Physical characteristics of poly(3hydroxyalkanoates) and poly(3-hydroxyalkanoates) produced by Pseudomonas oleovorans grown on aliphatichydrocarbons. Macromolecules, v. 23, p. 4220-4224, 1990.

RAMSAY, B. A.; LOMALIZA, K. CHAVARIE C.; DUBE, B.; BATILLE, P.; RAMSAY, J. Production of poly- $\beta$-hydroxybutyric-co- $\beta$-hydroxyvaleric acids. Appl. Environ. Microbiol., v. 56, p. 2093-2098, 1990.

REDDY, C. S. K.; GHAI, R.; RASHMI; KALIA, V. C. Polyhydroxyalkanoates: an overview. Bioresource Technology, v. 87, n. 2, p. 137-46, 2003.

REY, F. E.; HEINIGER, E. K.; HARWOOD, C. S. Redirection of Metabolism for Biological Hydrogen Production. Appl. Environ. Microbiol., v. 73, n. 5, p. 1665-1671, 2007.

RIIS, V.; MAI, W. Gas chromatographic determination of poly- $\beta$-hydroxybutyric acid in microbial biomass after hydrochloric acid propanolysis. Notes, v. 445, p. 285-289, 1988.

RYU, H. W. et al. Production of poly(3-hydroxybutyrate) by high cell density fed-batch culture of Alcaligenes eutrophus with phosphate limitation. Biotechnology and Bioengineering, v. 55, p. 28-32, 1997. 
ROCHA, R. C. S.; SILVA, L. F.; TACIRO, M. K.; PRADELLA, J. G. C. Production of poly(3- hydroxybutyrate-co-3-hydroxyvalerate) $\mathrm{P}(3 \mathrm{HB}-\mathrm{co}-3 \mathrm{HV})$ with a broad range of $3 \mathrm{HV}$ content at high yields by Burkholderia sacchari IPT 189. World Journal of Microbiology and Biotechnology, v. 24, p. 427-431, 2008.

SAUER, U.; LASKO, D. R.; FIAUX, J.; HOCHULI, M.; GLASER, R.; SZYPERSKI, T.; WÜTHRICH, K.; BAILEY, J. E. Metabolic flux ratio analysis of genetic and environmental modulations of Escherichia coli central carbon metabolism. J. Bacteriol., v. 181, p. 66796688, 1999.

SCHNELL, J. A; TREYVAUD-AMIGUET, V.; ARNASON, J. T.; JOHNSON, D. A. Expression of polyhydroxybutyric acid as a model for metabolic engineering of soybean seed coats. Transgenic Research, v. 21, n. 4, p. 895-899, 2012.

SCHUSTER, S.; HILGETAG, S. On elementary flux modes in biochemical reaction systems at steady state. J. Biol. Syst., v. 2, p. 165-182, 1994.

SHANG, L.; JIANG, M.; CHANG, H. N. Poly(3-hydroxybutyrate) synthesis in fed-batch culture of Ralstonia eutropha with phosphate limitation under different glucose concentrations. Biotechnology Letters, v. 25, n. 17, p. 1415-9, 2003.

SONG, S. S.; HEIN, S., STEINBÜCHEL, A. Production of poly(4-hydroxybutyric acid) by fed-batch cultures of recombinant strains of Escherichia coli. Biotechnol. Lett., v. 21, p. 193197, 1999.

SQUIO, C. R.; MARANGONI, C.; DE VECCHI, C. S.; ARAGÃO, G. M. F. Phosphate feeding strategy during production phase improves poly(3-hydroxybutyrate-co-3hydroxyvalerate) storage by Ralstonia eutropha. A pplied microbiology and biotechnology, v. 61, n. 3, p. 257-60, 2003.

SRIDEWI, J.; BHUBALAN, K.; SUDESH, K. Degradation of commercially important polyhydroxyalkanoates in tropical mangrove ecosystem. Polym. Degrad. Stab., v. 91, p. 2931-2940, 2006.

STEINBÜCHEL, A.; SCHLEGEL, H. G. Physiology and molecular genetics of poly $(\beta-$ hydroxyalkanoic acid) synthesis in Alcaligenes eutrophus. Mol. Microbiol., v. 5, p. 535-542, 1991.

STEVENS, P.; VERTONGHEN, C.; DEVOS, P.; DELEY, J. The effect of temperature and light intensity on hydrogen production by different Rhodopseudomonas capsulate strains. Biotechnol. Let., v. 6, n. 277-282, 1984.

SZYPERSKI, T. Biosynthetically directed fractional ${ }^{13} \mathrm{C}$-labeling of proteinogenic amino acids: An efficient analytical tool to investigate intermediary metabolism. Eur. J. Biochem., v. 232, p. 433-448, 1995.

TACIRO, M. K. Processo contínuo de produção de polihidroxialcanoatos de cadeia média (PHAMCL) sob limitação múltipla de nutrientes. 2008. Tese (Doutorado em Biotecnologia) Biotecnologia, Universidade de São Paulo, São Paulo, 2008. 
TRINH, C. T.; WLASCHIN, A.; SRIENC, F. Elementary Mode Analysis: A useful metabolic pathway analysis tool for characterizing cellular metabolism. Appl. Microbio. Biotechnol. v. 81, n.5, p. 813-826, 2010.

VIGNAIS, P. M.; COLBEAU, A.; WILLISON, J. C.; JOUANNEAU, Y. Hydrogenase, nitrogenase and hydrogen metabolism in the photosynthetic bacteria. Adv. Micro.b Physiol., v. 26, p. 155-234, 1985.

WANG, J. G.; BAKKEN, L. R. Screening of soil bactéria for poly-beta-hydroxybutyric acid production and its role in the survival of starvation. Microb. Ecol., v. 35, p. 94-101, 1998.

WEAVER, P. F.; J. D. WALL; GEST, H. Characterization of Rhodopsuedomonas capsulata. Arch. Microbiol., v. 105, p. 207-216, 1975.

WEN, Q. et al. Effects of phosphorus and nitrogen limitation on PHA production in activated sludge. Journal of Environmental Sciences, v. 22, p. 1602-1607, 2010.

WENDLANDT, K. et al. Producing poly-3-hydroxybutyrate with a high molecular mass from methane. Journal of Biotechnology, v. 86, p. 127-133, 2001.

WIECHERT, W. C-13 metabolic flux analysis. Metabolic. Eng., v.3, p. 195-206. 2001

WITTMANN, C.; HANS, M.; HEINZLE, E. In vivo analysis of intracellular amino acids labelings by GC/MS. A nal Biochem., v. 307, p. 379-382, 2002.

WU, S. C.; LIOU, S. Z.; LEE, C. M. Correlation between bio-hydrogen production and polyhydroxybutyrate (PHB) synthesis by Rhodopseudomonas palustris WP3-5. Bior. Technol., v. 113, p. 44-50, 2012.

ZHANG, H.; OBIAS, V.; GONYER, K.; DENNIS, D. Production of polyhydroxyalkanoates in sucrose-utilizing recombinant Escherichia coli and Klebisiella strains. Appl. Environ. Microbiol., v. 60, p. 1198-1205, 1994.

ZUMFT, W. G.; CASTILLO, F. Regulatory properties of the nitrogenase from Rhodopseudomonas palustris. Arch. Microbiol., v. 177, p. 53-60, 1978. 
APÊNDICE A - Arquivo de entrada contendo vias metabólicas centrais e de síntese de PHB de B. sacchari a partir de sacarose.

\author{
\# Crescimento e Biossíntese de P3HB por Burkholderia sacchari \\ -ENZREV (Reações reversíveis) \\ EMP2 EMP6 EMP7 EMP8 EMP9 VP6 VP7 VP8 VP9 VP10
}

-ENZIRREV (Reações irreversíveis)

SAC EMP1 FRU VP1 ED1 ED2 GLN1 GLN2 GLN3 EMP10 VP5 CPD CK1 CK2 CK3 CK4 CK5 CK6 CK7 CK8 CGLX1 CGLX2 AD1 AD2 BIOMASSA OXFAD OXNAD P3HB BIOTOT

-METINT (Metabólitos internos)

Gliext Fruext G6P F6P PG6 KDPG2 NADP NADPH PIR G3P DHP F16P BPG13 PG3 PG2 PEP CoASH Rb15P Rb5P X5P S7P E4P AcCoA OAA Cit IsoCit KG2 SucCoA Suc Fum Mal GLX FAD FADH2 NAD NADH XR 3HB

-METEXT (Metabólitos externos)

Sac ADP ATP CO2 XT

-CAT (Reações)

$\mathrm{SAC}: \mathrm{Sac}=$ Fruext + Gliext .

EMP1 : Gliext + ATP $=$ G6P + ADP .

FRU $:$ Fruext + ATP $=$ F6P + ADP.

EMP2 : G6P $=$ F6P .

$\mathrm{VP} 1: \mathrm{G} 6 \mathrm{P}+\mathrm{NADP}=\mathrm{PG} 6+\mathrm{NADPH}$.

$\mathrm{ED} 1: \mathrm{PG} 6=\mathrm{KDPG} 2$.

$\mathrm{ED} 2: \mathrm{KDPG} 2=\mathrm{PIR}+\mathrm{G} 3 \mathrm{P}$.

GLN1 : G3P $=$ DHP .

GLN2 : G3P + DHP $=$ F16P .

GLN3 : F16P $=$ F6P .

EMP6 : G3P + NAD $=$ BPG13 + NADH .

EMP7 : BPG13 + ADP = PG3 + ATP

EMP8 : PG3 $=$ PG2 .

EMP9 : PG2 = PEP .

$\mathrm{EMP} 10: \mathrm{PEP}+\mathrm{ADP}=\mathrm{PIR}+\mathrm{ATP}$.

$\mathrm{VP} 5: \mathrm{PG} 6+\mathrm{NADP}=\mathrm{NADPH}+\mathrm{Rb} 15 \mathrm{P}+\mathrm{CO} 2$.

$\mathrm{VP} 6: \mathrm{Rb} 15 \mathrm{P}=\mathrm{Rb} 5 \mathrm{P}$.

$\mathrm{VP7}: \mathrm{Rb} 15 \mathrm{P}=\mathrm{X} 5 \mathrm{P}$.

$\mathrm{VP} 8: \mathrm{Rb} 5 \mathrm{P}+\mathrm{X} 5 \mathrm{P}=\mathrm{S} 7 \mathrm{P}+\mathrm{G} 3 \mathrm{P}$.

VP9: G3P + S7P $=$ E4P + F6P .

$\mathrm{VP} 10: \mathrm{X} 5 \mathrm{P}+\mathrm{E} 4 \mathrm{P}=\mathrm{F} 6 \mathrm{P}+\mathrm{G} 3 \mathrm{P}$.

$\mathrm{CPD}: \mathrm{PIR}+\mathrm{NAD}+\mathrm{CoASH}=\mathrm{AcCoA}+\mathrm{NADH}+\mathrm{CO} 2$.

$\mathrm{CK} 1: \mathrm{OAA}+\mathrm{AcCoA}=\mathrm{Cit}+\mathrm{CoASH}$.

CK2 : $\mathrm{Cit}=$ IsoCit .

$\mathrm{CK} 3:$ IsoCit $+\mathrm{NADP}=\mathrm{KG} 2+\mathrm{NADPH}+\mathrm{CO} 2$.

$\mathrm{CK} 4: \mathrm{KG} 2+\mathrm{NAD}+\mathrm{CoASH}=\mathrm{SucCoA}+\mathrm{NADH}+\mathrm{CO} 2$.

$\mathrm{CK} 5: \mathrm{SucCoA}+\mathrm{ADP}=\mathrm{Suc}+\mathrm{ATP}+\mathrm{CoASH}$.

CK6 : Suc + FAD $=$ Fum + FADH2 .

CK7 : Fum $=$ Mal .

$\mathrm{CK} 8: \mathrm{Mal}+\mathrm{NAD}=\mathrm{OAA}+\mathrm{NADH}$.

CGLX1 : IsoCit $=$ GLX + Suc

CGLX2: GLX $+\mathrm{AcCoA}=\mathrm{Mal}+\mathrm{CoASH}$.

$\mathrm{AD} 1: \mathrm{PIR}+\mathrm{CO} 2+\mathrm{ATP}=\mathrm{OAA}+\mathrm{ADP}$.

$\mathrm{AD} 2: \mathrm{OAA}+\mathrm{ATP}=\mathrm{PEP}+\mathrm{ADP}+\mathrm{CO} 2$.

BIOMASSA : 205 G6P + 71 F6P + 897 Rb5P + 361 E4P + 129 G3P + 1496 PG3 + 519 PEP + 2833 PIR + 3748 AcCoA + $1079 \mathrm{KG} 2+1787 \mathrm{OAA}+3547 \mathrm{NAD}+18225 \mathrm{NADPH}+18485 \mathrm{ATP}=1 \mathrm{XR}+18485 \mathrm{ADP}+3547 \mathrm{NADH}+18225 \mathrm{NADP}$ +3748 CoASH .

OXFAD $:$ FADH $2+2 \mathrm{ADP}=\mathrm{FAD}+2 \mathrm{ATP}$.

$\mathrm{OXNAD}: \mathrm{NADH}+3 \mathrm{ADP}=\mathrm{NAD}+3 \mathrm{ATP}$.

$\mathrm{P} 3 \mathrm{HB}: 2 \mathrm{AcCoA}+1 \mathrm{NADPH}=3 \mathrm{HB}+2 \mathrm{CoASH}+1 \mathrm{NADP}$.

BIOTOT : $252913 \mathrm{HB}+\mathrm{XR}=\mathrm{XT}$. 
APÊNDICE B - Tabela contendo dados obtidos no experimento com Burkholderia sacchari de estudos da eficiência de conversão de carboidratos em PHB.

\begin{tabular}{|c|c|c|c|c|c|c|}
\hline Tempo & $\begin{array}{l}\text { Fonte de } \\
\text { Carbono }\end{array}$ & $\begin{array}{c}\text { Carboidrato } \\
\text { consumido } \\
(\mathrm{g} / \mathrm{l})\end{array}$ & PHB (g/l) & PHB (\%) & $\operatorname{MSC}(g / l)$ & $\mathrm{Y}_{\mathrm{PHB} / \mathrm{C}}$ \\
\hline \multirow{4}{*}{$24 \mathrm{~h}$} & Glicose & $8,03 \pm 0,68$ & $2,08 \pm 0,12$ & $52,94 \pm 0,5,27$ & $3,94 \pm 0,21$ & - \\
\hline & Frutose & $9,82 \pm 0,07$ & $3,14 \pm 0,19$ & $67,13 \pm 3,53$ & $4,67 \pm 0,05$ & - \\
\hline & GF & $7,61 \pm 0,05$ & $1,90 \pm 0,11$ & $54,90 \pm 5,17$ & $3,48 \pm 0,14$ & - \\
\hline & Sacarose & $5,93 \pm 0,63$ & $1,87 \pm 0,17$ & $51,44 \pm 4,04$ & $3,64 \pm 0,09$ & - \\
\hline \multirow{4}{*}{$48 \mathrm{~h}$} & Glicose & $10 \pm 0$ & 2,66 & $62,86 \pm 0,97$ & $4,32 \pm 0,13$ & 0,27 \\
\hline & Frutose & $10 \pm 0$ & $2,41 \pm 0,26$ & $60,98 \pm 1,34$ & $3,95 \pm 0,38$ & 0,24 \\
\hline & GF & $10 \pm 0$ & $2,62 \pm 0,17$ & $61,09 \pm 1,87$ & $4,28 \pm 0,15$ & 0,26 \\
\hline & Sacarose & $10 \pm 0$ & 2,75 & 62,46 & $4,35 \pm 0,08$ & 0,28 \\
\hline \multirow{4}{*}{$72 \mathrm{~h}$} & Glicose & $10 \pm 0$ & $1,68 \pm 0,04$ & $47,39 \pm 1,61$ & $3,55 \pm 0,15$ & - \\
\hline & Frutose & $10 \pm 0$ & $2,07 \pm 0,09$ & $54,17 \pm 1,46$ & $3,83 \pm 0,08$ & - \\
\hline & GF & $10 \pm 0$ & $1,82 \pm 0,08$ & $47,80 \pm 0,95$ & $3,82 \pm 0,11$ & - \\
\hline & Sacarose & $10 \pm 0$ & $2,04 \pm 0,12$ & $52,13 \pm 1,33$ & $3,91 \pm 0,16$ & - \\
\hline
\end{tabular}

MSC, Massa seca celular; GF, glicose e frutose; $\mathrm{Y}_{\mathrm{PHB} / \mathrm{C}}$, fator de conversão de carboidratos em PHB. 
APENDICE C - Tabela contendo dados obtidos no experimento com Curpiavidus necator de estudos da eficiência de conversão de carboidratos em PHB.

\begin{tabular}{ccccccc}
\hline \multirow{2}{*}{ Tempo } & $\begin{array}{c}\text { Fonte de } \\
\text { Carbono }\end{array}$ & $\begin{array}{c}\text { Carboidrato } \\
\text { consumido }(\mathrm{g} / \mathrm{l})\end{array}$ & PHB (g/l) & PHB (\%) & MSC (g/l) & Y $_{\text {PHB/C }}$ \\
\hline \multirow{2}{*}{$24 \mathrm{~h}$} & Glicose & $2,94 \pm 0,04$ & $2,87 \pm 0,03$ & $60,19 \pm 0,97$ & $4,77 \pm 0,11$ & - \\
& Frutose & $2,16 \pm 0,20$ & $2,05 \pm 0,07$ & $49,88 \pm 4,86$ & $4,14 \pm 0,28$ & - \\
& GF & $3,30 \pm 0,31$ & $2,68 \pm 0,12$ & $59,97 \pm 0,77$ & $4,47 \pm 0,15$ & - \\
\multirow{3}{*}{$48 \mathrm{~h}$} & Glicose & $9,83 \pm 0,15$ & $4,97 \pm 0,09$ & $71,39 \pm 1,04$ & $6,96 \pm 0,03$ & 0,33 \\
& Frutose & $9,99 \pm 0,01$ & $4,93 \pm 0,24$ & $71,70 \pm 2,53$ & $6,88 \pm 0,12$ & 0,33 \\
& GF & $9,89 \pm 0,07$ & $4,80 \pm 0,10$ & $71,53 \pm 0,65$ & $6,71 \pm 0,15$ & 0,32 \\
$72 \mathrm{~h}$ & Glicose & 10 & $4,62 \pm 0,07$ & $65,39 \pm 2,71$ & $7,07 \pm 0,22$ & - \\
& Frutose & 10 & $5,08 \pm 0,02$ & $71,23 \pm 0,99$ & $7,13 \pm 0,07$ & - \\
& GF & 10 & $4,90 \pm 0,08$ & $70,24 \pm 0,86$ & $6,98 \pm 0,03$ & - \\
\hline
\end{tabular}

MSC, Massa seca celular; GF, glicose e frutose; $\mathrm{Y}_{\mathrm{PHB} / \mathrm{C}}$, fator de conversão de carboidratos em PHB. 
APÊNDICE D - Tabela contendo dados do cultivo de $B$. sacchari realizado em biorreator com sacarose como fonte de carbono e gráfico com curva de $\mathrm{LnXr}$ - EB1.

\begin{tabular}{|c|c|c|c|c|c|c|c|c|c|}
\hline $\begin{array}{c}\text { Tempo } \\
\text { (h) }\end{array}$ & pH & $\begin{array}{c}\text { Nitrogênio } \\
(\mathrm{g} / \mathrm{l})\end{array}$ & $\begin{array}{l}\text { OD } \\
(\%)\end{array}$ & $\begin{array}{c}\begin{array}{c}\text { Volume } \\
(\mathrm{ml})\end{array} \\
\end{array}$ & $\begin{array}{c}\text { PHB } \\
(\%)\end{array}$ & $\begin{array}{l}\mathrm{XT} \\
(\mathrm{g} / \mathrm{l})\end{array}$ & $\begin{array}{l}\text { XR } \\
(g / l)\end{array}$ & $\begin{array}{c}\text { PHB } \\
(\mathrm{g} / \mathrm{l})\end{array}$ & $\begin{array}{c}\text { Hexoses } \\
(\mathrm{g} / \mathrm{l})\end{array}$ \\
\hline 0 & 6,81 & 0,90 & 84,20 & 2001,31 & nd & 0,65 & nd & nd & 0,00 \\
\hline 1 & 6,82 & 0,87 & 71,40 & 1973,76 & 24,71 & 0,79 & 0,59 & 0,20 & 1,62 \\
\hline 2 & 6,80 & 0,86 & 62,80 & 1950,53 & 25,19 & 0,87 & 0,65 & 0,22 & 4,02 \\
\hline 3 & 6,79 & 0,76 & 66,30 & 1930,59 & 20,07 & 0,74 & 0,59 & 0,15 & 4,37 \\
\hline 4 & 6,84 & 0,57 & 58,00 & 1914,27 & 10,13 & 1,43 & 1,29 & 0,14 & 4,65 \\
\hline 5 & 6,80 & 0,47 & 41,50 & 1900,06 & 15,10 & 1,97 & 1,67 & 0,30 & 6,33 \\
\hline 5,03 & 6,80 & nd & 41,50 & 1876,60 & nd & nd & nd & nd & 6,41 \\
\hline 6 & 6,81 & 0,50 & 62,20 & 1908,25 & 36,82 & 2,88 & 1,82 & 1,06 & 6,30 \\
\hline 7 & 6,85 & 0,50 & 61,80 & 1892,62 & 49,35 & 3,87 & 1,96 & 1,91 & 6,91 \\
\hline 8 & 6,87 & 0,50 & 58,90 & 1876,69 & 56,36 & 4,58 & 2,00 & 2,58 & 7,77 \\
\hline 9 & 6,88 & 0,47 & 51,10 & 1860,06 & 61,08 & 5,68 & 2,21 & 3,47 & 8,82 \\
\hline 10 & 6,91 & 0,44 & 52,50 & 1835,83 & 61,84 & 6,85 & 2,61 & 4,24 & 10,61 \\
\hline 11 & 6,86 & 0,43 & 55,80 & 1819,39 & 64,35 & 7,38 & 2,63 & 4,75 & 12,54 \\
\hline 12 & 6,87 & 0,42 & 59,90 & 1797,46 & 64,39 & 8,68 & 3,09 & 5,59 & 14,60 \\
\hline 13 & 6,81 & 0,37 & 61,30 & 1824,66 & 75,61 & 9,27 & 2,26 & 7,01 & 14,38 \\
\hline 14 & 6,81 & 0,40 & 66,80 & 1807,22 & 69,72 & 10,23 & 3,10 & 7,13 & 14,65 \\
\hline 15 & 6,85 & 0,40 & 68,50 & 1786,29 & 26,26 & 10,30 & 7,59 & 2,71 & 15,02 \\
\hline 16 & 6,77 & 0,39 & 69,80 & 1766,56 & 84,62 & 11,51 & 1,77 & 9,74 & 19,08 \\
\hline 16,05 & 6,77 & nd & 75,10 & 1778,97 & nd & nd & nd & nd & 18,94 \\
\hline 17 & 6,77 & 0,37 & 76,00 & 1769,67 & 70,92 & 11,51 & 3,35 & 8,16 & 20,63 \\
\hline 18 & 6,77 & 0,32 & 79,20 & 1751,94 & 69,13 & 10,67 & 3,29 & 7,38 & 22,21 \\
\hline 22,5 & 6,60 & 0,31 & 45,10 & 1752,79 & 83,37 & 12,50 & 2,08 & 10,42 & 25,84 \\
\hline 25,9 & 6,64 & 0,31 & 52,70 & 1743,49 & 69,14 & 14,86 & 4,59 & 10,27 & 29,06 \\
\hline 30,5 & 6,70 & 0,26 & 64,30 & 1734,89 & 77,60 & 14,10 & 3,16 & 10,94 & 31,91 \\
\hline 42,5 & 6,69 & 0,26 & 46,60 & 1775,20 & 76,48 & 16,58 & 3,90 & 12,68 & 31,19 \\
\hline
\end{tabular}

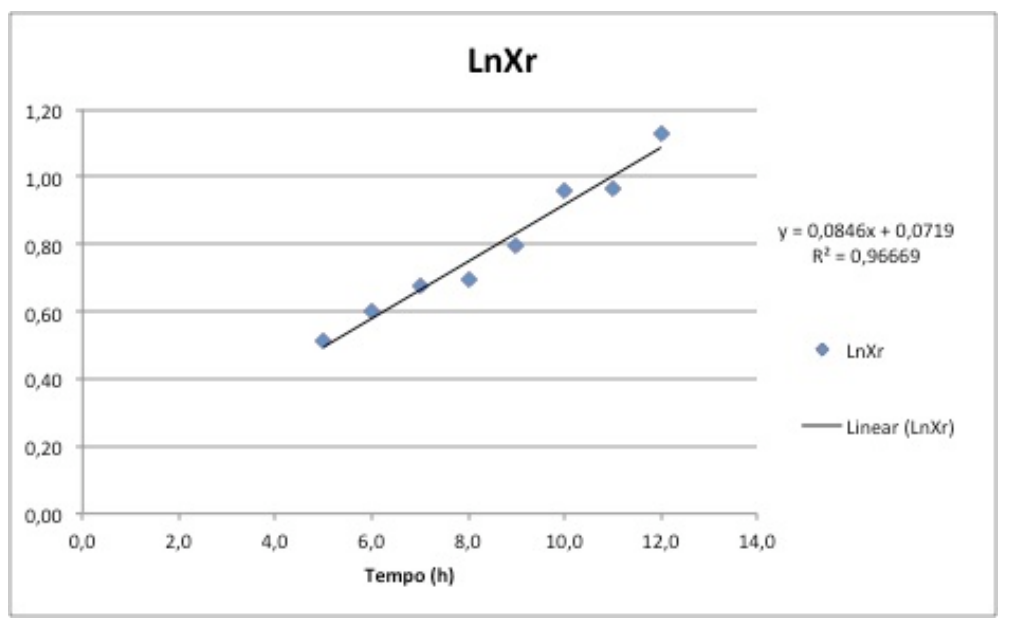


APÊNDICE E- Tabela contendo dados do cultivo de B. sacchari realizado em biorreator com glicose como fonte de carbono e curva de LnXr - EB2

\begin{tabular}{|c|c|c|c|c|c|c|c|c|c|}
\hline $\begin{array}{l}\text { Tempo } \\
\text { (h) }\end{array}$ & pH & $\begin{array}{c}\text { Nitrogênio } \\
(\mathrm{g} / \mathrm{l})\end{array}$ & $\begin{array}{l}\text { OD } \\
(\%)\end{array}$ & $\begin{array}{c}\begin{array}{c}\text { Volume } \\
(\mathrm{ml})\end{array} \\
\end{array}$ & $\begin{array}{c}\text { PHB } \\
(\%)\end{array}$ & $\begin{array}{c}\mathrm{Xt} \\
(\mathrm{g} / \mathrm{l})\end{array}$ & $\begin{array}{c}\mathrm{Xr} \\
(\mathrm{g} / \mathrm{l})\end{array}$ & $\begin{array}{c}\text { PHB } \\
(\mathrm{g} / \mathrm{l})\end{array}$ & $\begin{array}{c}\text { Glicose } \\
(\mathrm{g} / \mathrm{l})\end{array}$ \\
\hline 0,0 & 7,00 & 0,79 & 95,10 & 1980,00 & 28,89 & 0,66 & 0,47 & 0,19 & 1,84 \\
\hline 1,0 & 7,03 & 0,56 & 72,00 & 1958,06 & 24,70 & 0,48 & 0,36 & 0,12 & 3,67 \\
\hline 2,0 & 7,01 & 0,48 & 49,60 & 1933,13 & 28,51 & 0,85 & 0,61 & 0,24 & 2,02 \\
\hline 3,0 & 6,97 & 0,55 & 49,10 & 1912,19 & 26,47 & 0,58 & 0,43 & 0,15 & 1,86 \\
\hline 4,0 & 7,01 & 0,46 & 47,70 & 1892,25 & 20,34 & 0,67 & 0,53 & 0,14 & 2,89 \\
\hline 5,0 & 6,95 & 0,45 & 30,80 & 1866,91 & nd & 0,91 & nd & nd & 4,17 \\
\hline 6,0 & 6,98 & 0,40 & 55,00 & 1846,18 & 16,31 & 1,89 & 1,58 & 0,31 & 4,53 \\
\hline 7,0 & 7,00 & 0,40 & 55,70 & 1824,84 & 24,52 & 1,77 & 1,34 & 0,43 & 7,10 \\
\hline 8,0 & 7,01 & 0,40 & 54,00 & 1803,10 & 32,62 & 2,15 & 1,45 & 0,70 & 8,21 \\
\hline 9,0 & 6,69 & 0,36 & 53,80 & 1781,16 & 39,85 & 2,91 & 1,75 & 1,16 & 8,09 \\
\hline 10,0 & 7,03 & 0,37 & 53,10 & 1758,13 & 42,50 & 3,48 & 2,00 & 1,48 & 11,68 \\
\hline 11,0 & 7,00 & 0,31 & 50,60 & 1733,99 & 50,65 & 3,99 & 1,97 & 2,02 & 13,79 \\
\hline 12,0 & 6,99 & 0,31 & 47,10 & 1710,75 & nd & 4,73 & nd & nd & 16,00 \\
\hline 13,0 & 7,01 & 0,31 & 48,20 & 1677,62 & 55,25 & 5,28 & 2,36 & 2,92 & 18,23 \\
\hline 13,2 & nd & nd & 47,50 & 1694,13 & nd & nd & nd & nd & 18,23 \\
\hline 14,0 & 7,02 & 0,24 & 49,30 & 1680,78 & 62,75 & 5,98 & 2,23 & 3,75 & 18,40 \\
\hline 15,0 & 7,05 & 0,23 & 46,60 & 1659,94 & 64,12 & 6,45 & 2,31 & 4,14 & 20,24 \\
\hline 16,0 & 6,94 & 0,23 & 51,10 & 1637,20 & 62,20 & 6,87 & 2,60 & 4,27 & 21,60 \\
\hline 17,0 & 6,91 & 0,23 & 51,70 & 1611,27 & 69,15 & 7,50 & 2,31 & 5,19 & 22,50 \\
\hline 18,0 & 6,93 & 0,22 & 51,90 & 1587,53 & 59,95 & 7,91 & 3,17 & 4,74 & 23,03 \\
\hline 19,0 & 6,92 & 0,22 & 54,60 & 1566,69 & 63,77 & 8,39 & 3,04 & 5,35 & 25,86 \\
\hline 20,0 & 6,94 & 0,24 & 57,10 & 1542,25 & 65,20 & 8,59 & 2,99 & 5,60 & 27,23 \\
\hline 21,0 & 6,87 & 0,23 & 61,50 & 1519,62 & 64,95 & 8,48 & 2,97 & 5,51 & 28,74 \\
\hline 22,0 & 6,92 & 0,22 & 63,60 & 1496,48 & 69,89 & 9,50 & 2,86 & 6,64 & 29,85 \\
\hline 23,0 & 6,83 & 0,21 & 65,30 & 1471,74 & nd & 7,34 & nd & nd & 31,35 \\
\hline 23,2 & nd & nd & nd & 1490,59 & nd & nd & nd & nd & 31,35 \\
\hline 24,0 & 6,82 & 0,21 & 67,40 & 1481,47 & 66,42 & 9,28 & 3,12 & 6,16 & 32,08 \\
\hline 25,0 & 6,84 & 0,17 & 69,80 & 1458,04 & 63,43 & 10,44 & 3,82 & 6,62 & 34,18 \\
\hline 27,0 & 6,73 & 0,14 & 72,20 & 1439,26 & 63,75 & 11,23 & 4,07 & 7,16 & 37,65 \\
\hline 29,0 & 6,73 & 0,14 & 74,20 & 1419,69 & 69,90 & 11,78 & 3,55 & 8,23 & 39,17 \\
\hline 33,0 & 6,62 & 0,10 & 75,20 & 1405,64 & 57,45 & 11,59 & 4,93 & 6,66 & 44,61 \\
\hline 34,0 & nd & nd & nd & 1381,70 & nd & nd & nd & nd & 44,61 \\
\hline 34,1 & nd & nd & nd & 1413,69 & nd & nd & nd & nd & 44,61 \\
\hline 42,0 & 6,62 & 0,07 & 80,70 & 1417,04 & 52,58 & 13,70 & 6,50 & 7,20 & 49,25 \\
\hline 45,4 & 6,74 & 0,06 & 83,00 & 1397,67 & 67,47 & 14,18 & 4,61 & 9,57 & 50,39 \\
\hline 48,9 & 6,72 & 0,05 & 83,40 & 1376,49 & 65,87 & 13,89 & 4,74 & 9,15 & 51,94 \\
\hline
\end{tabular}


APÊNDICE F - Resumo do arquivo de saída contendo vias metabólicas centrais e de síntese de PHB de B. sacchari a partir de glicose.

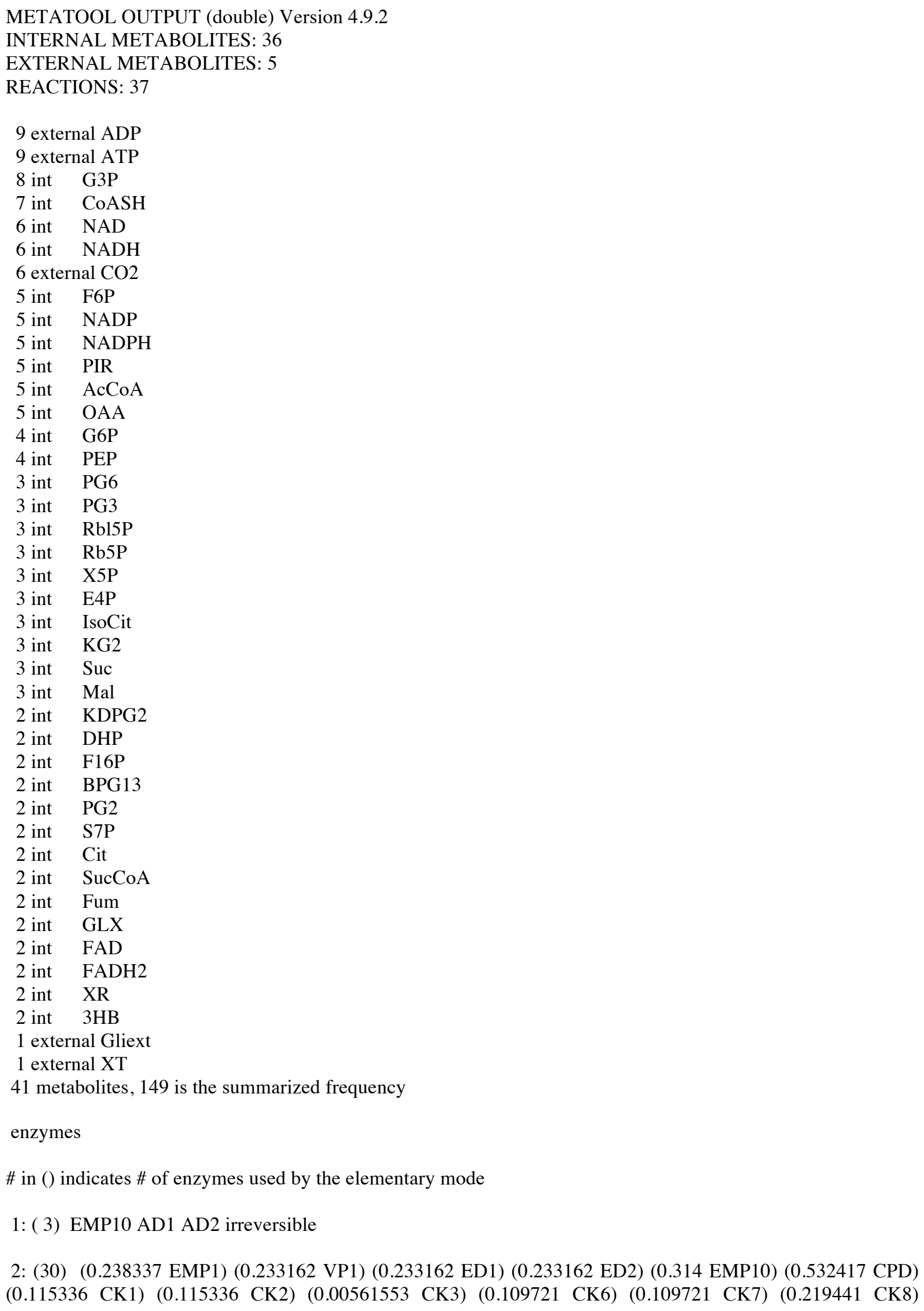


(0.109721 CGLX1) (0.109721 CGLX2) (0.0948048 AD2) (5.20438e-006 BIOMASSA) (0.109721 OXFAD) OXNAD (0.143927 P3HB) (5.20438e-006 BIOTOT) (0.00410799 EMP2) (0.229682 EMP6) (0.229682 EMP7) (0.221896 EMP8) (0.221896 EMP9) (0.00373848 VP6) (-0.00373848 VP7) $(-0.00092985$ VP8) (-0.00092985 VP9) (-0.00280863 VP10) irreversible

3: (30) (0.318105 EMP1) (0.309946 VP1) (0.309946 ED1) (0.309946 ED2) (0.287926 EMP10) (0.55111 CPD) (0.0665165 CK1) (0.0665165 CK2) (0.0665165 CK3) (0.0576629 CK4) (0.0576629 CK5) (0.0576629 CK6) (0.0576629 CK7) (0.0576629 CK8) (0.0235166 AD1) (8.20538e-006 BIOMASSA) (0.0576629 OXFAD) OXNAD (0.22692 P3HB) (8.20538e-006 BIOTOT) (0.00647678 EMP2) (0.30446 EMP6) (0.30446 EMP7) (0.292185 EMP8) (0.292185 EMP9) (0.0058942 VP6) (-0.0058942 VP7) (-0.00146603 VP8) (-0.00146603 VP9) (-0.00442817 VP10) irreversible

4: (31) (0.302251 EMP1) (0.294685 VP1) (0.294685 ED1) (0.294685 ED2) (0.274266 EMP10) (0.547395 CPD) (0.0762195 CK1) (0.0762195 CK2) (0.0544123 CK3) (0.0462023 CK4) (0.0462023 CK5) (0.0680094 CK6) $\quad(0.0680094$ CK7) $\quad(0.0898166$ CK8) $\quad(0.0218072$ CGLX1) $(0.0218072 \quad$ CGLX2) $\quad$ (7.60893e-006 BIOMASSA) (0.0680094 OXFAD) OXNAD (0.210425 P3HB) (7.60893e-006 BIOTOT) (0.00600598 EMP2) (0.289597 EMP6) (0.289597 EMP7) (0.278215 EMP8) (0.278215 EMP9) (0.00546575 VP6) (-0.00546575 VP7) (-0.00135946 VP8) (-0.00135946 VP9) (-0.00410628 VP10) irreversible

5: (25) (0.368637 EMP1) (0.397535 VP1) (0.339004 ED1) (0.339004 ED2) (0.331195 EMP10) (0.0585313 VP5) (0.612185 CPD) (0.010984 CK1) (0.010984 CK2) (0.010984 CK3) (0.0291754 AD1) (1.01798e-005 BIOMASSA) OXNAD (0.281523 P3HB) (1.01798e-005 BIOTOT) (-0.0309856 EMP2) (0.351708 EMP6) (0.351708 EMP7) (0.336479 EMP8) (0.336479 EMP9) (0.0268229 VP6) (0.0317083 VP7) (0.0176916 VP8) (0.0176916 VP9) (0.0140167 VP10) irreversible

6: (30) (0.337974 EMP1) (0.358854 VP1) (0.314097 ED1) (0.314097 ED2) (0.304839 EMP10) (0.0447575 VP5) (0.593413 CPD) (0.0355405 CK1) (0.0355405 CK2) (0.0097207 CK3) (0.0258198 CK6) (0.0258198 CK7) (0.0516396 CK8) (0.0258198 CGLX1) (0.0258198 CGLX2) (9.00899e-006 BIOMASSA) (0.0258198 OXFAD) OXNAD (0.249144 P3HB) (9.00899e-006 BIOTOT) (-0.0227272 EMP2) (0.322992 EMP6) (0.322992 EMP7) (0.309515 EMP8) (0.309515 EMP9) (0.0213906 VP6) (0.0233669 VP7) (0.0133096 VP8) (0.0133096 VP9) (0.0100573 VP10) irreversible

7: (30) (206.628 EMP1) (205.661 VP1) (200.079 ED1) (200.079 ED2) (254.709 EMP10) (5.58276 VP5) (441.429 CPD) (84.0243 CK1) (84.0243 CK2) (5.08767 CK3) (78.9366 CK6) (78.9366 CK7) (157.873 CK8) (78.9366 CGLX1) (78.9366 CGLX2) (65.423 AD2) (0.00471517 BIOMASSA) (78.9366 OXFAD) (814.814 OXNAD) (130.398 P3HB) (0.00471517 BIOTOT) (198.787 EMP6) (198.787 EMP7) (191.733 EMP8) (191.733 EMP9) (5.24798 VP6) (0.334777 VP7) (1.01848 VP8) (1.01848 VP9) (-0.683699 VP10) irreversible

8: (30) (183.134 EMP1) (181.986 VP1) (177.501 ED1) (177.501 ED2) (227.202 EMP10) (4.48476 VP5) (392.911 CPD) (75.7956 CK1) (75.7956 CK2) (4.49101 CK3) (71.3046 CK6) (71.3046 CK7) (142.609 CK8) (71.3046 CGLX1) (71.3046 CGLX2) (59.3758 AD2) (0.00416219 BIOMASSA) (71.3046 OXFAD) (726.496 OXNAD) (115.105 P3HB) (0.00416219 BIOTOT) (0.295516 EMP2) (176.213 EMP6) (176.213 EMP7) (169.986 EMP8) (169.986 EMP9) (4.48476 VP6) (0.751276 VP8) (0.751276 VP9) (-0.751276 VP10) irreversible

9: (29) (375.699 EMP1) (370.37 VP1) (365.885 ED1) (365.885 ED2) (480.899 EMP10) (4.48476 VP5) (823.08 CPD) (168.982 CK1) (168.982 CK2) (9.0281 CK3) (159.954 CK6) (159.954 CK7) (319.908 CK8) (159.954 CGLX1) (159.954 CGLX2) (135.974 AD2) (0.0083671 BIOMASSA) (159.954 OXFAD) (1534.45 OXNAD) (231.392 P3HB) (0.0083671 BIOTOT) (3.61459 EMP2) (361.785 EMP6) (361.785 EMP7) (349.268 EMP8) (349.268 EMP9) (7.50529 VP6) (-3.02052 VP7) (-3.02052 VP10) irreversible

10: (30) (118.463 EMP1) (118.697 VP1) (114.247 ED1) (114.247 ED2) (142.108 EMP10) (4.45024 VP5) (248.568 CPD) (44.5986 CK1) (44.5986 CK2) (2.96591 CK3) (41.6327 CK6) (41.6327 CK7) (83.2655 CK8) (41.6327 CGLX1) (41.6327 CGLX2) (33.7548 AD2) (0.00274876 BIOMASSA) (41.6327 OXFAD) (455.475 OXNAD) (76.017 P3HB) (0.00274876 BIOTOT) (-0.797141 EMP2) (113.892 EMP6) (113.892 EMP7) (109.78 EMP8) (109.78 EMP9) (3.45794 VP6) (0.992303 VP7) (0.992303 VP8) (0.992303 VP9) irreversible

11: (30) (180.316 EMP1) (179.349 VP1) (173.767 ED1) (173.767 ED2) (162.973 EMP10) (5.58276 VP5) (309.868 CPD) (31.3999 CK1) (31.3999 CK2) (31.3999 CK3) (26.3122 CK4) (26.3122 CK5) (26.3122 CK6) (26.3122 CK7) (26.3122 CK8) (13.5137 AD1) (0.00471517 BIOMASSA) (26.3122 OXFAD) $(551.692$ 
OXNAD) (130.398 P3HB) (0.00471517 BIOTOT) (172.475 EMP6) (172.475 EMP7) (165.421 EMP8) (165.421 EMP9) (5.24798 VP6) (0.334777 VP7) (1.01848 VP8) (1.01848 VP9) (-0.683699 VP10) irreversible

12: (30) (159.366 EMP1) (158.217 VP1) (153.733 ED1) (153.733 ED2) (144.058 EMP10) (4.48476 VP5) (274.07 CPD) (28.2592 CK1) (28.2592 CK2) (28.2592 CK3) (23.7682 CK4) (23.7682 CK5) (23.7682 CK6) (23.7682 CK7) (23.7682 CK8) (11.9288 AD1) (0.00416219 BIOMASSA) (23.7682 OXFAD) (488.814 OXNAD) (115.105 P3HB) (0.00416219 BIOTOT) (0.295516 EMP2) (152.445 EMP6) (152.445 EMP7) (146.218 EMP8) (146.218 EMP9) (4.48476 VP6) (0.751276 VP8) (0.751276 VP9) (-0.751276 VP10) irreversible

13: (29) (322.381 EMP1) (317.052 VP1) (312.567 ED1) (312.567 ED2) (291.607 EMP10) (4.48476 VP5) (556.49 CPD) (62.346 CK1) (62.346 CK2) (62.346 CK3) (53.3179 CK4) (53.3179 CK5) (53.3179 CK6) (53.3179 CK7) (53.3179 CK8) (23.9801 AD1) (0.0083671 BIOMASSA) (53.3179 OXFAD) (1001.27 OXNAD) (231.392 P3HB) (0.0083671 BIOTOT) (3.61459 EMP2) (308.467 EMP6) (308.467 EMP7) (295.95 EMP8) (295.95 EMP9) (7.50529 VP6) (-3.02052 VP7) (-3.02052 VP10) irreversible

14: (30) (98.1365 EMP1) (98.3558 VP1) (94.18 ED1) (94.18 ED2) (88.65 EMP10) (4.17582 VP5) (168.131 CPD) (15.8048 CK1) (15.8048 CK2) (15.8048 CK3) (13.0218 CK4) (13.0218 CK5) (13.0218 CK6) (13.0218 CK7) (13.0218 CK8) (7.39216 AD1) (0.00257926 BIOMASSA) (13.0218 OXFAD) (297.17 OXNAD) (71.3294 P3HB) (0.00257926 BIOTOT) (-0.747985 EMP2) (93.8472 EMP6) (93.8472 EMP7) (89.9887 EMP8) (89.9887 EMP9) (3.24471 VP6) (0.931113 VP7) (0.931113 VP8) (0.931113 VP9) irreversible

15: (31) (184.82 EMP1) (183.854 VP1) (178.271 ED1) (178.271 ED2) (167.478 EMP10) (5.58276 VP5) (332.391 CPD) (40.409 CK1) (40.409 CK2) (26.8953 CK3) (21.8077 CK4) (21.8077 CK5) (35.3213 CK6) (35.3213 CK7) (48.835 CK8) (13.5137 CGLX1) (13.5137 CGLX2) (0.00471517 BIOMASSA) (35.3213 OXFAD) (596.737 OXNAD) (130.398 P3HB) (0.00471517 BIOTOT) (176.979 EMP6) (176.979 EMP7) (169.925 EMP8) (169.925 EMP9) (5.24798 VP6) (0.334777 VP7) (1.01848 VP8) (1.01848 VP9) (-0.683699 VP10) irreversible

16: (31) (163.343 EMP1) (162.194 VP1) (157.709 ED1) (157.709 ED2) (148.034 EMP10) (4.48476 VP5) (293.952 CPD) (36.2118 CK1) (36.2118 CK2) (24.2829 CK3) (19.7919 CK4) (19.7919 CK5) (31.7208 CK6) (31.7208 CK7) (43.6496 CK8) (11.9288 CGLX1) (11.9288 CGLX2) (0.00416219 BIOMASSA) (31.7208 OXFAD) (528.577 OXNAD) (115.105 P3HB) (0.00416219 BIOTOT) (0.295516 EMP2) (156.421 EMP6) (156.421 EMP7) (150.194 EMP8) (150.194 EMP9) (4.48476 VP6) (0.751276 VP8) (0.751276 VP9) (-0.751276 VP10) irreversible

17: (30) (330.375 EMP1) (325.045 VP1) (320.56 ED1) (320.56 ED2) (299.601 EMP10) (4.48476 VP5) (596.457 CPD) (78.3328 CK1) (78.3328 CK2) (54.3527 CK3) (45.3246 CK4) (45.3246 CK5) (69.3047 CK6) (69.3047 CK7) (93.2848 CK8) (23.9801 CGLX1) (23.9801 CGLX2) (0.0083671 BIOMASSA) (69.3047 OXFAD) (1081.2 OXNAD) (231.392 P3HB) (0.0083671 BIOTOT) (3.61459 EMP2) (316.46 EMP6) (316.46 EMP7) (303.943 EMP8) (303.943 EMP9) (7.50529 VP6) (-3.02052 VP7) (-3.02052 VP10) irreversible

18: (31) (107.212 EMP1) (107.445 VP1) (102.995 ED1) (102.995 ED2) (97.1018 EMP10) (4.45024 VP5) (192.31 CPD) (22.0955 CK1) (22.0955 CK2) (14.2175 CK3) (11.2516 CK4) (11.2516 CK5) (19.1295 CK6) (19.1295 CK7) (27.0075 CK8) (7.87795 CGLX1) (7.87795 CGLX2) (0.00274876 BIOMASSA) (19.1295 OXFAD) (342.959 OXNAD) (76.017 P3HB) (0.00274876 BIOTOT) (-0.797141 EMP2) (102.641 EMP6) (102.641 EMP7) (98.5284 EMP8) (98.5284 EMP9) (3.45794 VP6) (0.992303 VP7) (0.992303 VP8) (0.992303 VP9) irreversible

19: (27) (0.406463 EMP1) (0.516533 VP1) (0.516533 ED1) (0.516533 ED2) (0.121534 GLN1) (0.121534 GLN2) (0.121534 GLN3) (0.242523 EMP10) (0.69335 CPD) (0.0124403 CK1) (0.0124403 CK2) (0.0124403 CK3) (0.0330436 AD1) (1.15295e-005 BIOMASSA) OXNAD (0.318848 P3HB) (1.15295e-005 BIOTOT) (0.112434 EMP2) (0.265755 EMP6) (0.265755 EMP7) (0.248507 EMP8) (0.248507 EMP9) (0.00828203 VP6) $(-0.00828203$ VP7) (-0.00205994 VP8) (-0.00205994 VP9) (-0.00622209 VP10) irreversible

20: (32) (0.363009 EMP1) (0.443293 VP1) (0.443293 ED1) (0.443293 ED2) (0.0901228 GLN1) (0.0901228 GLN2) (0.0901228 GLN3) (0.236494 EMP10) (0.651755 CPD) (0.0390347 CK1) (0.0390347 CK2) (0.0106764 CK3) (0.0283583 CK6) (0.0283583 CK7) (0.0567165 CK8) (0.0283583 CGLX1) (0.0283583 CGLX2) (9.89472e-006 BIOMASSA) (0.0283583 OXFAD) OXNAD (0.273638 P3HB) (9.89472e-006 BIOTOT) (- 
0.0823125 EMP2) (0.256432 EMP6) (0.256432 EMP7) (0.241629 EMP8) (0.241629 EMP9) (0.00710771 VP6) $(-0.00710771$ VP7) (-0.00176786 VP8) (-0.00176786 VP9) (-0.00533985 VP10) irreversible

21: (32) (62.4279 EMP1) (62.1435 VP1) (62.1435 ED1) (62.1435 ED2) (1.09489 GLN1) (1.09489 GLN2) (1.09489 GLN3) (79.3094 EMP10) (137.523 CPD) (28.5502 CK1) (28.5502 CK2) (1.49668 CK3) (27.0536 CK6) (27.0536 CK7) (54.1071 CK8) (27.0536 CGLX1) (27.0536 CGLX2) (23.0781 AD2) (0.0013871 BIOMASSA) (27.0536 OXFAD) (255.577 OXNAD) (38.3603 P3HB) (0.0013871 BIOTOT) (59.0262 EMP6) (59.0262 EMP7) (56.9511 EMP8) (56.9511 EMP9) (0.996401 VP6) (-0.996401 VP7) (-0.247829 VP8) (0.247829 VP9) (-0.748572 VP10) irreversible

22: (32) (52.7299 EMP1) (52.4491 VP1) (52.4491 ED1) (52.4491 ED2) (1.08094 GLN1) (1.08094 GLN2) (1.08094 GLN3) (46.6121 EMP10) (91.2568 CPD) (10.3806 CK1) (10.3806 CK2) (10.3806 CK3) (8.90301 CK4) (8.90301 CK5) (8.90301 CK6) (8.90301 CK7) (8.90301 CK8) (3.92481 AD1) (0.00136944 BIOMASSA) (8.90301 OXFAD) (163.292 OXNAD) (37.8718 P3HB) (0.00136944 BIOTOT) (49.3715 EMP6) (49.3715 EMP7) (47.3229 EMP8) (47.3229 EMP9) (0.983712 VP6) (-0.983712 VP7) (-0.244673 VP8) (-0.244673 VP9) $(-0.739039$ VP10) irreversible

23: (33) (54.7352 EMP1) (54.4508 VP1) (54.4508 ED1) (54.4508 ED2) (1.09489 GLN1) (1.09489 GLN2) (1.09489 GLN3) (48.5385 EMP10) (99.0597 CPD) (13.1648 CK1) (13.1648 CK2) (9.18939 CK3) (7.69271 CK4) (7.69271 CK5) (11.6681 CK6) (11.6681 CK7) (15.6436 CK8) (3.97543 CGLX1) (3.97543 CGLX2) (0.0013871 BIOMASSA) (11.6681 OXFAD) (178.65 OXNAD) (38.3603 P3HB) (0.0013871 BIOTOT) (51.3335 EMP6) (51.3335 EMP7) (49.2584 EMP8) (49.2584 EMP9) (0.996401 VP6) (-0.996401 VP7) (0.247829 VP8) (-0.247829 VP9) (-0.748572 VP10) irreversible

24: (27) (147.482 EMP1) (181.986 VP1) (177.501 ED1) (177.501 ED2) (35.6523 GLN1) (35.6523 GLN2) (35.6523 GLN3) (96.5213 EMP10) (4.48476 VP5) (250.302 CPD) (4.49101 CK1) (4.49101 CK2) (4.49101 CK3) (11.9288 AD1) (0.00416219 BIOMASSA) (369.973 OXNAD) (115.105 P3HB) (0.00416219 BIOTOT) (35.3568 EMP2) (104.908 EMP6) (104.908 EMP7) (98.6815 EMP8) (98.6815 EMP9) (4.48476 VP6) (0.751276 VP8) (0.751276 VP9) (-0.751276 VP10) irreversible

25: (26) (295.723 EMP1) (370.37 VP1) (365.885 ED1) (365.885 ED2) (79.9769 GLN1) (79.9769 GLN2) (79.9769 GLN3) (184.971 EMP10) (4.48476 VP5) (503.172 CPD) (9.0281 CK1) (9.0281 CK2) (9.0281 CK3) (23.9801 AD1) (0.0083671 BIOMASSA) (734.681 OXNAD) (231.392 P3HB) (0.0083671 BIOTOT) (-76.3623 EMP2) (201.831 EMP6) (201.831 EMP7) (189.314 EMP8) (189.314 EMP9) (7.50529 VP6) (-3.02052 VP7) (3.02052 VP10) irreversible

26: (27) (91.6256 EMP1) (111.378 VP1) (107.202 ED1) (107.202 ED2) (19.5327 GLN1) (19.5327 GLN2) (19.5327 GLN3) (62.6064 EMP10) (4.17582 VP5) (155.109 CPD) (2.78302 CK1) (2.78302 CK2) (2.78302 CK3) (7.39216 AD1) (0.00257926 BIOMASSA) (232.061 OXNAD) (71.3294 P3HB) (0.00257926 BIOTOT) (20.2807 EMP2) (67.8036 EMP6) (67.8036 EMP7) (63.945 EMP8) (63.945 EMP9) (3.24471 VP6) (0.931113 VP7) (0.931113 VP8) (0.931113 VP9) irreversible

27: (32) (153.447 EMP1) (181.986 VP1) (177.501 ED1) (177.501 ED2) (29.6879 GLN1) (29.6879 GLN2) (29.6879 GLN3) (108.45 EMP10) (4.48476 VP5) (274.16 CPD) (16.4199 CK1) (16.4199 CK2) (4.49101 CK3) (11.9288 CK6) (11.9288 CK7) (23.8577 CK8) (11.9288 CGLX1) (11.9288 CGLX2) (0.00416219 BIOMASSA) (11.9288 OXFAD) (429.618 OXNAD) (115.105 P3HB) (0.00416219 BIOTOT) (-29.3924 EMP2) (116.837 EMP6) (116.837 EMP7) (110.61 EMP8) (110.61 EMP9) (4.48476 VP6) (0.751276 VP8) (0.751276 VP9) (0.751276 VP10) irreversible

28: (31) (307.713 EMP1) (370.37 VP1) (365.885 ED1) (365.885 ED2) (67.9869 GLN1) (67.9869 GLN2) (67.9869 GLN3) (208.952 EMP10) (4.48476 VP5) (551.132 CPD) (33.0082 CK1) (33.0082 CK2) (9.0281 CK3) (23.9801 CK6) (23.9801 CK7) (47.9602 CK8) (23.9801 CGLX1) (23.9801 CGLX2) (0.0083671 BIOMASSA) (23.9801 OXFAD) (854.582 OXNAD) (231.392 P3HB) (0.0083671 BIOTOT) (-64.3723 EMP2) (225.811 EMP6) (225.811 EMP7) (213.294 EMP8) (213.294 EMP9) (7.50529 VP6) (-3.02052 VP7) (-3.02052 VP10) irreversible

29: (32) (101.586 EMP1) (118.697 VP1) (114.247 ED1) (114.247 ED2) (16.8774 GLN1) (16.8774 GLN2) (16.8774 GLN3) (74.5986 EMP10) (4.45024 VP5) (181.058 CPD) (10.8439 CK1) (10.8439 CK2) (2.96591 CK3) (7.87795 CK6) (7.87795 CK7) (15.7559 CK8) (7.87795 CGLX1) (7.87795 CGLX2) (0.00274876 BIOMASSA) (7.87795 OXFAD) (286.701 OXNAD) (76.017 P3HB) (0.00274876 BIOTOT) (-17.6745 EMP2) 
(80.1374 EMP6) (80.1374 EMP7) (76.0252 EMP8) (76.0252 EMP9) (3.45794 VP6) (0.992303 VP7) (0.992303 VP8) (0.992303 VP9) irreversible

30: (32) (624.932 EMP1) (622.016 VP1) (606.687 ED1) (606.687 ED2) (1.01005 GLN1) (1.01005 GLN2) (1.01005 GLN3) (772.521 EMP10) (15.3286 VP5) (1338.91 CPD) (257.045 CK1) (257.045 CK2) (15.35 CK3) (241.695 CK6) (241.695 CK7) (483.389 CK8) (241.695 CGLX1) (241.695 CGLX2) (200.923 AD2) (0.0142261 BIOMASSA) (241.695 OXFAD) (2473.02 OXNAD) (393.423 P3HB) (0.0142261 BIOTOT) (600.264 EMP6) (600.264 EMP7) (578.982 EMP8) (578.982 EMP9) (15.3286 VP6) (2.56781 VP8) (2.56781 VP9) (-2.56781 VP10) irreversible

31: (31) (108.72 EMP1) (108.219 VP1) (106.908 ED1) (106.908 ED2) (1.05615 GLN1) (1.05615 GLN2) (1.05615 GLN3) (136.29 EMP10) (1.31041 VP5) (236.272 CPD) (47.2628 CK1) (47.2628 CK2) (2.63793 CK3) (44.6248 CK6) (44.6248 CK7) (89.2497 CK8) (44.6248 CGLX1) (44.6248 CGLX2) (37.6181 AD2) (0.00244479 BIOMASSA) (44.6248 OXFAD) (437.792 OXNAD) (67.6108 P3HB) (0.00244479 BIOTOT) (103.598 EMP6) (103.598 EMP7) (99.9408 EMP8) (99.9408 EMP9) (2.19298 VP6) (-0.882571 VP7) (0.882571 VP10) irreversible

32: (32) (543.453 EMP1) (540.541 VP1) (525.239 ED1) (525.239 ED2) (1.00836 GLN1) (1.00836 GLN2) (1.00836 GLN3) (490.209 EMP10) (15.3029 VP5) (934.509 CPD) (95.7538 CK1) (95.7538 CK2) (95.7538 CK3) (80.4296 CK4) (80.4296 CK5) (80.4296 CK6) (80.4296 CK7) (80.4296 CK8) (40.7036 AD1) (0.0142022 BIOMASSA) (80.4296 OXFAD) (1664.57 OXNAD) (392.763 P3HB) (0.0142022 BIOTOT) (518.826 EMP6) (518.826 EMP7) (497.58 EMP8) (497.58 EMP9) (15.3029 VP6) (2.5635 VP8) (2.5635 VP9) (-2.5635 VP10) irreversible

33: (31) (93.0617 EMP1) (92.5647 VP1) (91.2652 ED1) (91.2652 ED2) (1.04733 GLN1) (1.04733 GLN2) (1.04733 GLN3) (83.0974 EMP10) (1.29947 VP5) (160.546 CPD) (17.3667 CK1) (17.3667 CK2) (17.3667 CK3) (14.7508 CK4) (14.7508 CK5) (14.7508 CK6) (14.7508 CK7) (14.7508 CK8) (6.94829 AD1) (0.00242439 BIOMASSA) (14.7508 OXFAD) (286.629 OXNAD) (67.0464 P3HB) (0.00242439 BIOTOT) (87.9826 EMP6) (87.9826 EMP7) (84.3557 EMP8) (84.3557 EMP9) (2.17467 VP6) (-0.875203 VP7) (0.875203 VP10) irreversible

34: (33) (557.958 EMP1) (555.041 VP1) (539.713 ED1) (539.713 ED2) (1.01005 GLN1) (1.01005 GLN2) (1.01005 GLN3) (504.624 EMP10) (15.3286 VP5) (1004.03 CPD) (123.096 CK1) (123.096 CK2) (82.3242 CK3) (66.9742 CK4) (66.9742 CK5) (107.746 CK6) (107.746 CK7) (148.518 CK8) (40.772 CGLX1) (40.772 CGLX2) (0.0142261 BIOMASSA) (107.746 OXFAD) (1803.28 OXNAD) (393.423 P3HB) (0.0142261 BIOTOT) (533.29 EMP6) (533.29 EMP7) (512.007 EMP8) (512.007 EMP9) (15.3286 VP6) (2.56781 VP8) (2.56781 VP9) (-2.56781 VP10) irreversible

35: (32) (96.1807 EMP1) (95.6795 VP1) (94.3691 ED1) (94.3691 ED2) (1.05615 GLN1) (1.05615 GLN2) (1.05615 GLN3) (86.1326 EMP10) (1.31041 VP5) (173.576 CPD) (22.1841 CK1) (22.1841 CK2) (15.1773 CK3) (12.5394 CK4) (12.5394 CK5) (19.5461 CK6) (19.5461 CK7) (26.5529 CK8) (7.00678 CGLX1) (7.00678 CGLX2) (0.00244479 BIOMASSA) (19.5461 OXFAD) (312.398 OXNAD) (67.6108 P3HB) (0.00244479 BIOTOT) (91.0588 EMP6) (91.0588 EMP7) (87.4014 EMP8) (87.4014 EMP9) (2.19298 VP6) (-0.882571 VP7) (-0.882571 VP10) irreversible

overall reaction

$$
\begin{array}{ll}
\text { 1: } & \text { ATP }=\text { ADP } \\
\text { 2: } & 45795.3 \text { Gliext }+640571 \mathrm{ADP}=640571 \mathrm{ATP}+121597 \mathrm{CO} 2+\mathrm{XT} \\
\text { 3: } & 38767.9 \mathrm{Gliext}+398772 \mathrm{ADP}=398772 \mathrm{ATP}+79432.3 \mathrm{CO} 2+\mathrm{XT} \\
\text { 4: } & 39723.2 \mathrm{Gliext}+434119 \mathrm{ADP}=434119 \mathrm{ATP}+85164.3 \mathrm{CO} 2+\mathrm{XT} \\
\text { 5: } & 36212.5 \mathrm{Gliext}+304221 \mathrm{ADP}=304221 \mathrm{ATP}+64099.7 \mathrm{CO} 2+\mathrm{XT} \\
\text { 6: } & 37515.2 \mathrm{Gliext}+352422 \mathrm{ADP}=352422 \mathrm{ATP}+71916.1 \mathrm{CO} 2+\mathrm{XT} \\
\text { 7: } & 43822 \mathrm{Gliext}+571899 \mathrm{ADP}=571899 \mathrm{ATP}+109757 \mathrm{CO} 2+\mathrm{XT}
\end{array}
$$


8: $\quad 43999.5$ Gliext $+578076 \mathrm{ADP}=578076 \mathrm{ATP}+110822 \mathrm{CO} 2+\mathrm{XT}$

9: $\quad 44902$ Gliext $+609483 \mathrm{ADP}=609483 \mathrm{ATP}+116237 \mathrm{CO} 2+\mathrm{XT}$

10: 43097 Gliext $+546669 \mathrm{ADP}=546669 \mathrm{ATP}+105407 \mathrm{CO} 2+\mathrm{XT}$

11: $\quad 38241.7$ Gliext $+379302 \mathrm{ADP}=379302 \mathrm{ATP}+76275 \mathrm{CO} 2+\mathrm{XT}$

12: $\quad 38289$ Gliext $+381053 \mathrm{ADP}=381053 \mathrm{ATP}+76559 \mathrm{CO} 2+\mathrm{XT}$

13: $\quad 38529.7$ Gliext $+389958 \mathrm{ADP}=389958 \mathrm{ATP}+78003 \mathrm{CO} 2+\mathrm{XT}$

14: $\quad 38048.3$ Gliext +372148 ADP $=372148 \mathrm{ATP}+75115 \mathrm{CO} 2+\mathrm{XT}$

15: 39197 Gliext $+414649 \mathrm{ADP}=414649 \mathrm{ATP}+82007 \mathrm{CO} 2+\mathrm{XT}$

16: $\quad 39244.3$ Gliext $+416400 \mathrm{ADP}=416400 \mathrm{ATP}+82291 \mathrm{CO} 2+\mathrm{XT}$

17: 39485 Gliext $+425305 \mathrm{ADP}=425305 \mathrm{ATP}+83735 \mathrm{CO} 2+\mathrm{XT}$

18: $\quad 39003.7$ Gliext $+407496 \mathrm{ADP}=407496 \mathrm{ATP}+80847 \mathrm{CO} 2+\mathrm{XT}$

19: $\quad 35254.2$ Gliext $+247682 \mathrm{ADP}=247682 \mathrm{ATP}+58350 \mathrm{CO} 2+\mathrm{XT}$

20: $\quad 36687.2$ Gliext $+303569 \mathrm{ADP}=303569 \mathrm{ATP}+66948 \mathrm{CO} 2+\mathrm{XT}$

21: 45006 Gliext $+611366 \mathrm{ADP}=611366 \mathrm{ATP}+116861 \mathrm{CO} 2+\mathrm{XT}$

22: $\quad 38504.8$ Gliext $+387458 \mathrm{ADP}=387458 \mathrm{ATP}+77853.7 \mathrm{CO} 2+\mathrm{XT}$

23: $\quad 39460.1$ Gliext $+422805 \mathrm{ADP}=422805 \mathrm{ATP}+83585.7 \mathrm{CO} 2+\mathrm{XT}$

24: $\quad 35433.8$ Gliext $+258277 \mathrm{ADP}=258277 \mathrm{ATP}+59427.5 \mathrm{CO} 2+\mathrm{XT}$

25: $\quad 35343.5$ Gliext $+252953 \mathrm{ADP}=252953 \mathrm{ATP}+58886 \mathrm{CO} 2+\mathrm{XT}$

26: $\quad 35524$ Gliext $+263602 \mathrm{ADP}=263602 \mathrm{ATP}+59969 \mathrm{CO} 2+\mathrm{XT}$

27: $\quad 36866.8$ Gliext $+314164 \mathrm{ADP}=314164 \mathrm{ATP}+68025.5 \mathrm{CO} 2+\mathrm{XT}$

28: $\quad 36776.5$ Gliext $+308840 \mathrm{ADP}=308840 \mathrm{ATP}+67484 \mathrm{CO} 2+\mathrm{XT}$

29: $\quad 36957$ Gliext $+319489 \mathrm{ADP}=319489 \mathrm{ATP}+68567 \mathrm{CO} 2+\mathrm{XT}$

30: $\quad 43928.5$ Gliext +575449 ADP $=575449 \mathrm{ATP}+110396 \mathrm{CO} 2+\mathrm{XT}$

31: 44470 Gliext +593499 ADP $=593499 \mathrm{ATP}+113645 \mathrm{CO} 2+\mathrm{XT}$

32: $\quad 38265.3$ Gliext $+380035 \mathrm{ADP}=380035 \mathrm{ATP}+76417 \mathrm{CO} 2+\mathrm{XT}$

33: $\quad 38385.7$ Gliext $+383766 \mathrm{ADP}=383766 \mathrm{ATP}+77139 \mathrm{CO} 2+\mathrm{XT}$

34: $\quad 39220.7$ Gliext $+415383 \mathrm{ADP}=415383 \mathrm{ATP}+82149 \mathrm{CO} 2+\mathrm{XT}$

35: 39341 Gliext $+419113 \mathrm{ADP}=419113 \mathrm{ATP}+82871 \mathrm{CO} 2+$ 
APÊNDICE G- Tabela de dados do cultivo de B. sacchari realizado em biorreator com glicose como fontede carbono. Gráfico contendo curva de LnXr (biomassa residual) - EB3

\begin{tabular}{|c|c|c|c|c|c|c|c|c|c|}
\hline $\begin{array}{l}\text { Tempo } \\
\text { (h) }\end{array}$ & pH & $\begin{array}{l}\text { Nitrogênio } \\
(\mathrm{g} / \mathrm{l})\end{array}$ & $\begin{array}{l}\text { OD } \\
(\%)\end{array}$ & $\begin{array}{c}\text { Volume } \\
\text { (ml) }\end{array}$ & $\begin{array}{c}\text { PHB } \\
(\%)\end{array}$ & $\begin{array}{c}\mathrm{Xt} \\
(\mathrm{g} / \mathrm{l})\end{array}$ & $\begin{array}{c}\mathrm{Xr} \\
(\mathrm{g} / \mathrm{l})\end{array}$ & $\begin{array}{c}\text { PHB } \\
\text { (g/l) }\end{array}$ & $\begin{array}{c}\text { Glicose } \\
(\mathrm{g} / \mathrm{l})\end{array}$ \\
\hline 0,0 & 6,68 & 0,76 & 114,30 & 1994,72 & 31,93 & 0,17 & 0,12 & 0,05 & 0,00 \\
\hline 1,0 & 6,69 & 0,66 & 89,90 & 1971,90 & 27,41 & 0,34 & 0,24 & 0,09 & 0,00 \\
\hline 2,0 & 6,71 & 0,86 & 79,20 & 1945,88 & 19,99 & 0,45 & 0,36 & 0,09 & 1,96 \\
\hline 3,0 & 6,67 & 0,84 & 57,60 & 1920,35 & 17,58 & 0,50 & 0,41 & 0,09 & 1,96 \\
\hline 4,0 & 6,62 & 0,80 & 66,70 & 1904,88 & 16,98 & 0,62 & 0,51 & 0,10 & 1,96 \\
\hline 5,0 & 6,62 & 0,80 & 44,40 & 1880,71 & 17,25 & 0,90 & 0,74 & 0,16 & 4,50 \\
\hline 6,0 & 6,63 & 0,80 & 58,10 & 1862,24 & 13,21 & 1,23 & 1,07 & 0,16 & 4,50 \\
\hline 7,0 & 6,64 & 0,73 & 55,20 & 1840,42 & 14,28 & 1,58 & 1,35 & 0,23 & 4,97 \\
\hline 8,0 & 6,65 & 0,71 & 57,80 & 1812,46 & 14,07 & 2,12 & 1,82 & 0,30 & 6,43 \\
\hline 9,0 & 6,68 & 0,50 & 61,60 & 1878,24 & 15,95 & 3,01 & 2,53 & 0,48 & 7,47 \\
\hline 10,0 & 6,68 & 0,37 & 62,50 & 1856,77 & 17,50 & 4,01 & 3,31 & 0,70 & 9,85 \\
\hline 11,0 & 6,71 & 0,16 & 59,00 & 1839,15 & 24,84 & 5,59 & 4,20 & 1,39 & 10,59 \\
\hline 12,0 & 6,70 & 0,01 & 59,70 & 1821,69 & 34,41 & 6,93 & 4,54 & 2,38 & 14,33 \\
\hline 13,0 & 6,71 & 0,00 & 66,70 & 1803,22 & 41,91 & 8,13 & 4,72 & 3,40 & 18,61 \\
\hline 14,0 & 6,69 & 0,00 & 67,30 & 1785,25 & 44,61 & 8,91 & 4,93 & 3,97 & 22,51 \\
\hline 15,0 & 6,61 & 0,00 & 67,00 & 1765,78 & 49,74 & 9,75 & 4,90 & 4,85 & 25,87 \\
\hline 16,0 & 6,63 & 0,00 & 69,10 & 1748,17 & 46,92 & 10,19 & 5,41 & 4,78 & 29,16 \\
\hline 17,0 & 6,64 & 0,00 & 72,30 & 1731,55 & 48,03 & 10,77 & 5,59 & 5,17 & 31,66 \\
\hline 18,0 & 6,63 & 0,00 & 72,20 & 1748,95 & 54,55 & 10,67 & 4,85 & 5,82 & 33,29 \\
\hline 20,0 & 6,68 & 0,00 & 76,60 & 1736,90 & 58,90 & 10,51 & 4,32 & 6,19 & 37,86 \\
\hline 22,0 & 7,05 & 0,00 & 79,70 & 1727,34 & 59,13 & 9,61 & 3,93 & 5,68 & 41,23 \\
\hline 24,0 & 6,84 & 0,00 & 76,90 & 1734,59 & 57,56 & 9,62 & 4,08 & 5,54 & 43,15 \\
\hline 26,0 & 6,95 & 0,00 & 79,80 & 1720,33 & 56,67 & 9,00 & 3,90 & 5,10 & 46,13 \\
\hline
\end{tabular}

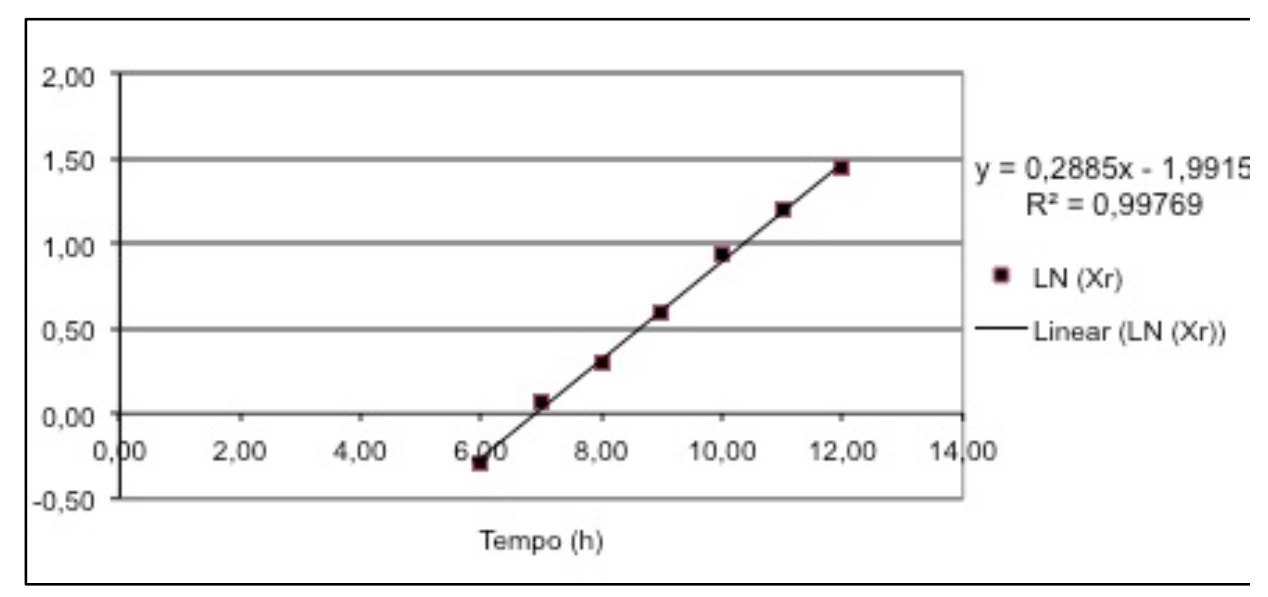




\begin{tabular}{cccccccccc}
28,0 & 7,03 & 0,00 & 81,90 & 1703,92 & 56,80 & 8,71 & 3,76 & 4,94 & 48,77 \\
30,0 & 7,08 & 0,00 & 80,00 & 1685,80 & 60,01 & 8,10 & 3,24 & 4,86 & 49,93 \\
32,0 & 7,08 & 0,00 & 81,90 & 1714,94 & 57,39 & 8,02 & 3,41 & 4,60 & 51,03 \\
41,0 & 7,13 & 0,00 & 83,90 & 1722,40 & nd & 7,69 & 7,69 & nd & nd \\
\hline
\end{tabular}


APÊNDICE H - Tabela contendo dados do cultivo de B. sacchari realizado em biorreator com sacarose. Gráfico contendo LnXr.- EB4

\begin{tabular}{|c|c|c|c|c|c|c|c|c|c|}
\hline $\begin{array}{l}\text { Tempo } \\
\text { (h) }\end{array}$ & pH & $\begin{array}{c}\text { Nitrogênio } \\
(\mathrm{g} / \mathrm{l})\end{array}$ & $\begin{array}{l}\text { OD } \\
(\%)\end{array}$ & $\begin{array}{c}\text { Volume } \\
\text { (ml) }\end{array}$ & $\begin{array}{c}\text { PHB } \\
(\%)\end{array}$ & $\begin{array}{l}\mathrm{Xt} \\
(\mathrm{g} / \mathrm{l})\end{array}$ & $\begin{array}{l}\mathrm{Xr} \\
(\mathrm{g} / \mathrm{l})\end{array}$ & $\begin{array}{l}\text { PHB } \\
(\mathrm{g} / \mathrm{l})\end{array}$ & $\begin{array}{c}\text { Glicose } \\
(\mathrm{g} / \mathrm{l})\end{array}$ \\
\hline 0,0 & 6,96 & 0,69 & 92,80 & 1972,14 & 52,30 & 0,18 & 0,01 & 0,17 & 0,00 \\
\hline 1,0 & 6,97 & 0,66 & 88,30 & 1945,70 & 38,12 & 0,27 & 0,10 & 0,17 & 0,00 \\
\hline 2,0 & 6,96 & 0,64 & 79,30 & 1926,27 & 26,52 & 0,30 & 0,18 & 0,11 & 0,04 \\
\hline 3,0 & 6,95 & 0,69 & 62,20 & 1900,83 & 24,82 & 0,44 & 0,29 & 0,16 & 0,12 \\
\hline 4,0 & 6,95 & 0,71 & 64,30 & 1878,38 & 23,92 & 0,55 & 0,38 & 0,17 & 0,38 \\
\hline 5,0 & 6,95 & 0,69 & 60,50 & 1856,43 & 22,45 & 0,86 & 0,65 & 0,21 & 0,34 \\
\hline 6,0 & 7,05 & 0,64 & 67,80 & 1835,46 & 24,95 & 1,17 & 0,79 & 0,38 & 2,03 \\
\hline 7,0 & 7,06 & 0,56 & 60,20 & 1813,48 & 26,91 & 2,27 & 1,64 & 0,62 & 3,57 \\
\hline 8,0 & 7,00 & 0,38 & 59,50 & 1795,47 & 27,28 & 3,55 & 2,55 & 0,99 & 6,57 \\
\hline 9,0 & 7,01 & 0,36 & 63,70 & 1769,97 & 26,40 & 4,77 & 3,58 & 1,18 & 9,87 \\
\hline 10,0 & 7,02 & 0,03 & 61,90 & 1765,82 & 34,57 & 6,96 & 4,52 & 2,43 & 9,61 \\
\hline 11,0 & 7,17 & 0,00 & 73,90 & 1748,06 & 43,29 & 8,53 & 4,83 & 3,70 & 20,61 \\
\hline 12,0 & 7,15 & 0,00 & 78,80 & 1730,83 & 46,19 & 9,50 & 5,12 & 4,38 & 23,00 \\
\hline 13,0 & 7,05 & 0,00 & 73,20 & 1747,46 & 55,83 & 10,64 & 4,64 & 6,00 & 26,94 \\
\hline 14,0 & 7,05 & 0,00 & 74,30 & 1724,52 & 52,09 & 11,54 & 5,54 & 6,00 & 29,68 \\
\hline 15,0 & 7,04 & 0,00 & 75,70 & 1702,57 & 57,76 & 12,49 & 5,19 & 7,30 & 30,84 \\
\hline 16,0 & 7,05 & 0,00 & 77,20 & 1682,11 & 58,73 & 13,05 & 5,36 & 7,69 & 34,30 \\
\hline 17,0 & 7,04 & 0,00 & 78,20 & 1660,67 & 64,72 & 13,85 & 4,94 & 8,91 & 35,97 \\
\hline 18,0 & 7,06 & 0,00 & 78,70 & 1672,40 & 62,88 & 13,82 & 5,07 & 8,74 & 40,28 \\
\hline 19,0 & 7,03 & 0,00 & 77,40 & 1640,43 & 58,18 & 13,85 & 5,78 & 8,07 & 44,35 \\
\hline 20,0 & 7,04 & 0,00 & 78,30 & 1610,47 & 61,92 & 13,89 & 5,41 & 8,48 & 47,53 \\
\hline 22,0 & 7,03 & 0,00 & 77,40 & 1593,55 & 65,14 & 13,73 & 4,71 & 9,02 & 47,47 \\
\hline 24,0 & 7,03 & 0,00 & 78,20 & 1572,13 & 64,66 & 13,28 & 4,75 & 8,53 & 50,02 \\
\hline 26,0 & 7,07 & 0,00 & 80,10 & 1583,86 & 61,60 & 12,64 & 4,67 & 7,97 & 56,30 \\
\hline 28,0 & 7,03 & 0,00 & 79,50 & 1567,44 & 61,04 & 12,04 & 4,61 & 7,43 & 57,48 \\
\hline 30,0 & 7,08 & 0,00 & 80,70 & 1550,03 & 61,30 & 12,03 & 4,57 & 7,45 & 59,69 \\
\hline 41,0 & 7,15 & 0,00 & 85,30 & 1536,33 & 45,25 & 9,22 & 4,57 & 4,65 & 64,19 \\
\hline
\end{tabular}

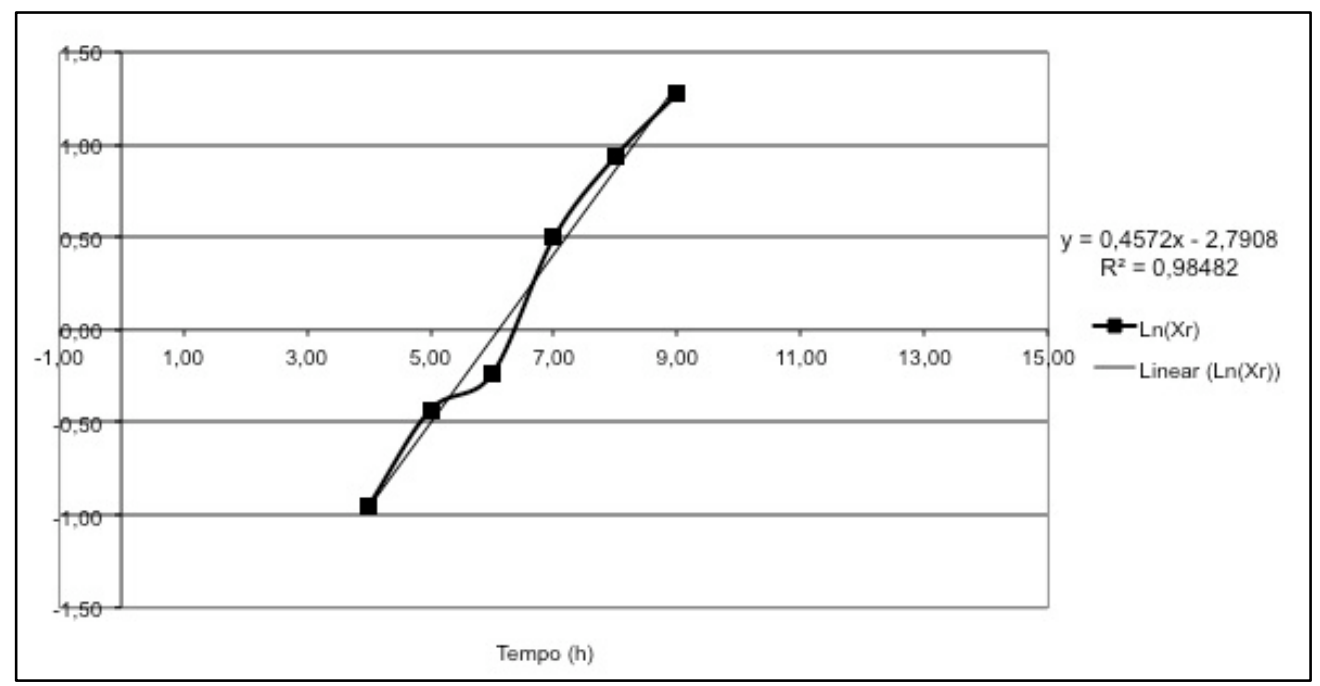

